\title{
LILIAN CORDEIRO
}

\section{Estudo comparativo de diferentes soluções osmóticas em diálise peritoneal na hipertrofia ventricular esquerda}

Tese apresentada à Faculdade de Medicina da Universidade de São Paulo para obtenção do título de Doutor em Ciências

Programa de Nefrologia

Orientadora: Prof. Dra. Rosilene Motta Elias

São Paulo

2021 


\title{
LILIAN CORDEIRO
}

\section{Estudo comparativo de diferentes soluções osmóticas em diálise peritoneal na hipertrofia ventricular esquerda}

\author{
Tese apresentada à Faculdade de Medicina da \\ Universidade de São Paulo para obtenção do \\ título de Doutor em Ciências \\ Programa de Nefrologia \\ Orientadora: Prof. Dra. Rosilene Motta Elias
}

São Paulo 
Dados Internacionais de Catalogaçäo na Publicação (CIP)

Preparada pela Biblioteca da

Faculdade de Medicina da Universidade de São Paulo

అreprodução autorizada pelo autor

Cordeiro, Lilian

Batudo comparativo de diferentes soluçōes

osm6ticas em dislise peritoneal na hipertrofia ventricular esquerda / Lilian Cordeiro. -- Săo Paulo, 2021.

Tese (doutorado) --Faculdade de Medicina da

Univeraidade de säo paulo.

Programa de Nefrologia.

orientadora: Rosilene Motta Elias.

Descritores: 1.Dislise peritoneal 2.Hipertrofia

ventricular esquerda 3. Icodextrina

$\mathrm{USP} / \mathrm{FM} / \mathrm{DBD}-347 / 21$

Responsável: Erinalva da Conceiçäo Batista, CRB-8 6755 


\section{DEDICATÓRIA}

À minha filha, desejo que você tenha as mesmas oportunidades que eu tive, que você tenha alegria e o prazer de conhecer pessoas especiais que façam sua vida mais completa. 


\section{AGRADECIMENTOS}

Agradeço a minha família por ter me apoiado e por ser meu porto seguro em todas as escolhas que fiz até hoje. Meu pai por proporcionar o sonho de me tornar médica, a mamãe por cuidar da gente com amor incondicional e a minha irmã por ser um dos meus exemplos de mulher forte. Ao meu marido, que apesar de termos nos conhecido quando essa tese já estava quase toda finalizada, não ter me deixado desistir quando a Pandemia da COVID-19 pareceu devastar meu desfecho, por ter sido meu companheiro durante essa fase com carinho e amor.

À minha orientadora Profa. Dra. Rosilene Motta Elias, ou carinhosamente chamada por mim de "Doc" ou de "chefa": a mais competente orientadora que um pósgraduando pode ter. Além de ter compartilhado comigo durante esses anos seu conhecimento técnico-científico com toda paciência que uma mãe ensina a um filho, compartilhou também momentos pessoais, profissionais, dias bons e ruins!

Aos pacientes que aceitaram participar do protocolo e as enfermeiras, médicos e funcionários do Programa de Diálise Peritoneal do Serviço de Nefrologia do HC-FMUSP e da UNIFESP. Em especial agradeço à enfermeira Érica Adelina Guimarães, sem ela eu não teria como concretizar o projeto.

Aos funcionários do LIM-16, Ivone, Wagner e Claudia que me recebiam sempre com disposição e paciência! À Profa. Dra. Vanda por torcer e compartilhar a alegria que era incluir um novo paciente ou somente ouvir um desabafo quando algo não saía conforme o planejado e à Profa. Dra. Rosa por me incentivar a continuar me aprimorando; ambas sempre dispostas e presentes durante a elaboração da tese. À Luciene por me receber com carinho e um sorriso no rosto todas as vezes que nos vimos.

A toda equipe da Gestão de Projetos Científicos da Radiologia do INCOR que foram muito gentis e respeitosos no agendamento da RNM dos pacientes incluídos. Ao Dr. Walther por ter aceitado realizar o projeto em conjunto.

Por fim, aos colegas da pós-graduação por compartilharem das mesmas angústias e desafios! 
"No final, não são os anos da sua vida que contam mas a vida que aconteceu naqueles anos",

Abraham Lincoln 


\section{NORMALIZAÇÃO ADOTADA}

Esta tese está de acordo com as seguintes normas, em vigor no momento desta publicação:

Universidade de São Paulo. Faculdade de Medicina. Divisão de Biblioteca e Documentação. Guia de apresentação de dissertações, teses e monografias. Elaborado por Anneliese Carneiro da Cunha, Maria Julia de A. L. Freddi, Maria F. Crestana, Marinalva de Souza Aragão, Suely Campos Cardoso, Valéria Vilhena. 3a ed. São Paulo: Divisão de Biblioteca e Documentação; 2011.

Abreviaturas dos títulos dos periódicos de acordo com List of Journals Indexed in Index Medicus.

Referências: Para a elaboração das referências foi utilizado a ferramenta EndNote Web no estilo Vancouver-NIH Reference 


\section{RESUMO}

Cordeiro, L. Estudo comparativo de diferentes soluções osmóticas em diálise peritoneal na hipertrofia ventricular esquerda [tese]. São Paulo: Faculdade de Medicina, Universidade de São Paulo; 2021.

Introdução: A alta taxa de mortalidade cardiovascular continua sendo um desafio para todos os nefrologistas que lidam com pacientes em diálise. A hipertrofia de ventrículo esquerdo (HVE) é um dos fatores de risco para mortalidade cardiovascular na população dialítica e ocorre com muita frequência. Além da hipertensão arterial, que sabidamente leva à HVE, outros fatores são associados na fisiopatologia da HVE da doença renal crônica (DRC): os não reversíveis como idade, diabetes, enrijecimento de grandes artérias e os reversíveis, tais como hipervolemia, distúrbio mineral e ósseo da doença renal crônica e anemia. Em diálise peritoneal (DP), o uso de diferentes concentrações de glicose ou de icodextrina são opções terapêuticas para controle de volemia, sendo a icodextrina com maior poder de ultrafiltração e, portanto, maior potencial de controle de volemia. Objetivo: Avaliar alterações no índice de massa do ventrículo esquerdo (IMVE) por meio de ressonância nuclear magnética (RNM) de coração em pacientes em DP, comparando solução de icodextrina vs. solução de glicose; correlacionar os achados com a extração de fósforo pelo dialisato e com o fator de crescimento de fibroblasto 23 (FGF-23). Métodos: Estudo randomizado, tipo coorte, prospectivo, de caráter intervencionista com grupo controle. Pacientes em Diálise Peritoneal Ambulatorial Contínua ou em Diálise Peritoneal Cíclica Contínua foram recrutados dos Programas de Diálise Peritoneal do Serviço de Nefrologia do Hospital das Clínicas da Faculdade de Medicina da Universidade de São Paulo e da Universidade Federal do Estado de São Paulo. Dados clínicos, demográficos, bioquímicos, bioimpedância (relação água extracelular/água corporal total - AEC/ACT) e RNM cardíaca foram avaliados no momento basal e após 6 meses de acompanhamento. Resultados: Foram incluídos 38 pacientes, com idade $48 \pm$ 18 anos, 77,2\% mulheres, 22,7\% com diabetes melitus, que estavam em diálise há 11 (628) meses. Hemoglobina estava no alvo preconizado $11,3 \pm 2,1 \mathrm{~g} / \mathrm{dl}$, PTH era 300 (189 604) $\mathrm{pg} / \mathrm{ml}$ e FGF-23 era de $877 \mathrm{pg} / \mathrm{ml}$ (154-4522). Vinte pacientes foram alocados no grupo controle (GC) com 12 tendo concluído o estudo e 18 pacientes no grupo icodextrina (GI), com 10 tendo concluído. Pacientes dos dois grupos não diferiram em idade, sexo, 
doença de base e tempo em diálise ( $p>0,05$ para todas as comparações). Pacientes do GI apresentaram cálcio mais baixo $(\mathrm{p}=0,036)$ e pacientes do $\mathrm{GC}$ tinham maior relação AEC/ACT ( $\mathrm{p}=0,002)$. HVE foi encontrada em 17 pacientes $(77,3 \%)$, sem diferença entre os grupos ( $\mathrm{p}=0,748)$. O IMVE se correlacionou com a pressão arterial diastólica ( $\mathrm{r}=0,726$, $\mathrm{p}=0,027)$. O IMVE se correlacionou $(\mathrm{p}<0,05)$ com o hematócrito $(\mathrm{r}=-0,495)$, com a creatinina $(\mathrm{r}=0,823)$, com a pressão arterial diastólica $(\mathrm{r}=0,832)$ e sistólica $(\mathrm{r}=0,754)$, com tendência a se correlacionar com o peptídeo natriurético cerebral $(\mathrm{r}=0,755)$. Durante o acompanhamento, observamos por ANOVA multifatorial uma redução da diurese e do $\mathrm{Kt} / \mathrm{V}$ renal em ambos os grupos assim como uma melhora da $25(\mathrm{OH})$-vitamina D. A relação AEC/ACT ficou estável no GC e aumentou no GI. A pressão arterial sistólica reduziu no GC e aumentou no GI. O cálcio sérico teve aumento mais acentuado no GC. Interação entre fatores tempo (basal vs. 6 meses) e intervenção (GC vs. GI) foi identificada no comportamento da proteína $\mathrm{C}$ reativa (reduziu no $\mathrm{GC}$ e aumentou no GI) e na albumina (aumentou no GC e reduziu no GI), sendo também observado aumento da pressão arterial sistólica neste grupo. O IMVE variou de $66,2 \pm 13,5 \mathrm{~g} / \mathrm{m}^{2}$ para $62,2 \pm$ $14,9 \mathrm{~g} / \mathrm{m}^{2}$ no GC e de $89,1 \pm 28,9 \mathrm{~g} / \mathrm{m}^{2}$ para $88,1 \pm 28,9 \mathrm{~g} / \mathrm{m}^{2}$ no GI, diferindo entre os grupos $(\mathrm{p}=0,020)$. Outros parâmetros da RNM incluindo a fração de ejeção mostraram melhora no GC. O delta de variação do IMVE (valor em 6 meses subtraído do valor basal) se correlacionou com dados do momento basal tais como a pressão arterial diastólica $(\mathrm{r}=0,482, \mathrm{p}=0,027)$, creatinina $(\mathrm{r}=0,534, \mathrm{p}=0,013)$, proteína $\mathrm{C}$ reativa $(\mathrm{r}=-0,589$, $\mathrm{p}=0,010)$ e hematócrito $(\mathrm{r}=0,459, \mathrm{p}=0,036)$ e com o delta do peptídeo natriurético cerebral $(\mathrm{r}=0,566, \mathrm{p}=0,044)$, com tendência de correlação com o delta da relação AEC/ACT $(\mathrm{r}=0,419, \mathrm{p}=0,074)$ e com o delta de remoção semanal de $\mathrm{P}(\mathrm{r}=-0,426, \mathrm{p}=0,054)$. O delta do BNP se confirmou como variável independente associada ao delta do $\operatorname{IMVE}(\mathrm{p}=0,012)$ em análise de regressão linear múltipla com múltiplos ajustes. Conclusão: O uso de icodextrina não foi superior à glicose para controlar a HVE em pacientes em DP. No entanto, o controle de fatores de risco clássicos como a volemia parece ser o fator responsável por reduzir a HVE, mesmo com uso de solução padrão de glicose, devendo ser sempre almejado nesta população. O papel da extração de fósforo pelo dialisato e do FGF-23 na HVE nesta população precisa ser mais bem avaliado em estudos futuros.

Descritores: Diálise peritoneal; Hipertrofia de ventrículo esquerdo, Icodextrina 


\section{Summary}

Cordeiro, L. Comparative study of different osmotic solutions in peritoneal dialysis on the left ventricular hypertrophy [thesis]. São Paulo: Faculdade de Medicina, Universidade de São Paulo; 2021.

Introduction: High cardiovascular mortality remains a challenge for all nephrologists treating patients on dialysis. Left ventricular hypertrophy $(\mathrm{LVH})$ is one of the risk factors for cardiovascular mortality in the dialysis population and occurs very often. In addition to high blood pressure, which is known to lead to LVH, other factors are listed as possibly associated with the pathophysiology of LVH in chronic kidney disease (CKD): nonreversible factors such as age, diabetes, atherosclerosis of large arteries, and reversible factors such as hypervolemia, mineral and bone disorder of chronic kidney disease, and anemia. In peritoneal dialysis (PD) the use of different concentrations of glucose or icodextrin is a therapeutic option for blood volume control, with icodextrin with greater ultrafiltration power and, therefore, greater potential for volume control. Objective: To evaluate changes in the left ventricular mass index (LVMI), measured by nuclear magnetic resonance (MRI) of the heart in patients on $\mathrm{PD}$, comparing icodextrin solution vs. glucose solution; correlate the findings with the dialysate phosphate extraction and with fibroblast growth factor 23 (FGF-23). Method: This is a randomized prospective cohort with intervention with a control group. Patients on Continuous Ambulatory Peritoneal Dialysis or Continuous Cyclic Peritoneal Dialysis were recruited from the Peritoneal Dialysis Program of the Nephrology Service, Hospital das Clínicas, Faculty of Medicine, University of São Paulo, and the Program of Peritoneal Dialysis at the Federal University of the State of São Paulo. Clinical, demographic, biochemical, bioimpedance (extracellular water/total body water ratio - AEC/ACT) data, and cardiac MRI were evaluated at baseline and after 6 months of follow-up. Results: 38 patients were included, aging $48 \pm 18$ years, $77.2 \%$ women, $22.7 \%$ with diabetes mellitus, who had been on dialysis for 11 (6-28) months. Hemoglobin was within recommended target $11.3 \pm 2.1$ g/dl, PTH was 300 (189 - 604) pg/ml and FGF-23 was 877 pg/ml (154-4522). Twenty patients were allocated to the control group (CG) with 12 having completed the study and 18 patients in the icodextrin group (IG), with 10 having completed the study. Patients from CG and IG did not differ regarding age, sex, underlying disease, and time on dialysis ( $p>0.05$ for all comparisons). Patients from IG had lower serum calcium $(p=0.036)$ and 
from $\mathrm{CG}$ exhibited a higher AEC/ACT ratio $(\mathrm{p}=0.002)$. $\mathrm{LVH}$ was found in 17 patients $(77.3 \%)$, with no difference between groups $(p=0.748)$. LVMI was significantly correlated $(\mathrm{p}<0.05)$ with hematocrit $(\mathrm{r}=-0.495)$, creatinine $(\mathrm{r}=0.823)$, diastolic $(\mathrm{r}=0.832)$ and systolic $(\mathrm{r}=0.754)$ blood pressure, with a trend to correlate with brain natriuretic peptide $(\mathrm{r}=0.755)$. During follow-up, we observed by multifactorial ANOVA, a reduction in diuresis and renal $\mathrm{Kt} / \mathrm{V}$ in both groups as well as an improvement in $25(\mathrm{OH})$-vitamin D. The AEC/ACT ratio was stable in the CG and had increased in the IG. Systolic blood pressure decreased in CG and increased in IG. Serum calcium had a more pronounced increase in CG. Interaction between factors time (baseline vs. 6 months) and intervention (CG vs. IG) was identified in the behavior of C-reactive protein (reduced in CG and increased in IG) and in serum albumin (increased in CG and reduced in IG). An increase in systolic blood pressure was also observed in the IG. The LVMI ranged from $66.2 \pm$ $13.5 \mathrm{~g} / \mathrm{m}^{2}$ to $62.2 \pm 14.9 \mathrm{~g} / \mathrm{m}^{2}$ in the CG and from $89.1 \pm 28.9 \mathrm{~g} / \mathrm{m}^{2}$ to $88.1 \pm 28.9 \mathrm{~g} / \mathrm{m}^{2}$ in the $\mathrm{IG}$, differing between groups $(\mathrm{p}=0.020)$. Other MRI parameters including ejection fraction showed an improvement in the CG. The LVMI delta variation (value at 6 months subtracted from baseline) correlated with baseline data such as diastolic blood pressure $(\mathrm{r}=0.482, \mathrm{p}=0.027)$, creatinine $(\mathrm{r}=0.534, \mathrm{p}=0.013)$, protein $\mathrm{C}$ reactive $(\mathrm{r}=-0.589$, $\mathrm{p}=0.010)$, hematocrit $(\mathrm{r}=0.459, \mathrm{p}=0.036)$, and with the delta of the brain natriuretic peptide $(\mathrm{r}=0.566, \mathrm{p}=0.044)$, with a tendency to correlate with the delta of the relationship AEC/ACT $(r=0.419, p=0.074)$ and the delta of weekly P removal $(r=-0.426, p=0.054)$. BNP delta was confirmed as an independent variable associated with LVMI delta $(p=0.012)$ in a fully adjusted multiple linear regression analysis. Conclusion: The use of icodextrin was not superior to glucose to control LVH in PD patients. The control of classical risk factors such as blood volume seems to be the main factor responsible to reduce $\mathrm{LVH}$, even with the use of a standard glucose solution, and should always be aimed at in this population. The role of dialysate phosphate extraction and FGF-23 on the $\mathrm{LVH}$ in this population deserves further evaluation.

Keywords: Peritoneal dialysis; Left ventricular hypertrophy, Icodextrin 


\section{Sumário}

Lista de figuras

Lista de tabelas

Lista de abreviaturas, símbolos e siglas

1. INTRODUÇÃO.

1.1 Hipertrofia de ventrículo esquerdo e fatores do metabolismo mineral e ósseo da doença renal crônica.

1.1.2 Diagnóstico de hipertrofia de ventrículo esquerdo.

1.2 Diálise peritoneal.

1.2.1 Icodextrina

1.3 Estudos dos efeitos da icodextrina na massa de ventrículo esquerdo.

1.4 Justificativa e interesse científico

2. OBJETIVO.

2.1 Objetivos específicos

3. CASUÍSTICA E MÉTODOS

3.1 Delineamento e população de estudo

3.2 Amostragem e cálculo do poder

3.3 Critérios de inclusão.

3.4 Critérios de exclusão

3.5 Randomização

3.6 Protocolo de pesquisa.

3.6.1 Coleta de dados clínicos basais e 6 meses após inclusão no estudo

3.6.2 Avaliação laboratorial

3.6.3 Realização de bioimpedância segmentar

3.6.4 Ressonância nuclear magnética cardíaca.

3.6.5 Solução de diálise de icodextrina.

3.7 Estatística.

3.8 Aspectos técnicos.

3.8.1 Ética.

3.8.2 Fonte financiadora.

4. RESULTADOS.

4.1 Resultados basais.
Página 1

Página 4

Página 6

Página 6

Página 7

Página 12

Página 15

Página 16

Página 17

Página 19

Página 19

Página 19

Página 19

Página 19

Página 20

Página 20

Página 21

Página 22

Página 22

Página 23

Página 23

Página 23

Página 24

Página 24

Página 24

Página 25

Página 26 
4.2 Resultados de acompanhamento

Página 34

5. DISCUSSÃO

Página 42

6. CONCLUSÕES.

Página 48

7. REFERÊNCIAS.

Página 50

ANEXOS 


\section{LISTAS}

\section{FIGURAS}

Figura 1 - "Quebra-cabeça urêmico"................................................... Página 3

Figura 2 - Resumo da Fisiopatologia do DMO-DRC............................ Página 5

Figura 3 - Molécula de Icodextrina.................................................. Página 8

Figura 4 - Desenho esquemático da metabolização da icodextrina......... Página 9

Figura 5 - Estratégias para reduzir efeitos colaterais da icodextrina....... Página 12

Figura 6 - Desenho esquemático do estudo.......................................... Página 21

Figura 7 - Fluxograma do estudo..................................................... Página 26

Figura 8 - Foto de paciente com Rash palmar após uso de icodextrina... Página 27

Figura 9 - Histograma da relação AEC/AIC no grupo controle (GC) e grupo icodextrina (GI).................................................................. Página 32

Figura 10 - Correlação entre índice de massa de ventrículo esquerdo

(IMVE) e variáveis independentes no momento basal............................ Página 34

Figura 11 - Fluxograma da evolução dos pacientes em relação à hipertrofia do ventrículo esquerdo (HVE)............................................ Página 35

Figura 12 - Comportamento em 6 meses das variáveis relacionadas à ressonância nuclear magnética do coração de acordo com o grupo

Página 39 de estudo

Figura 13 -Correlações entre o delta do índice de massa de ventrículo esquerdo (IMVE) e variáveis independentes durante o seguimento. 


\section{TABELAS}

Tabela 1- Características das soluções................................................ Página 10

Tabela 2 - Comparação dos estudos dos efeitos da icodextrina na massa

de ventrículo esquerdo.......................................................................... Página 14

Tabela 3 - Características basais dos pacientes incluídos que

concluíram o estudo........................................................................ Página 28

Tabela 4 - Dados clínicos relacionados à diálise e à volemia................. Página 30

Tabela 5 - Dados basais da RNM........................................................ Página 33

Tabela 6 - Análise obtida com ANOVA multifatorial de medidas

repetidas

Página 36

Tabela 7 - Análise comparativa basal e após 6 meses de seguimento da RNM, por grupo de estudo entre os grupos.

Página 38 


\section{ABREVIATURAS, SÍMBOLOS E SIGLAS}

\begin{tabular}{|c|c|}
\hline Alb & Albumina \\
\hline BNP & Peptídeo natriurético tipo $\mathrm{B}$, do inglês brain natriuretic peptide \\
\hline BRA & Bloqueador de receptor de angiotensina \\
\hline $\mathrm{Ca}$ & Cálcio \\
\hline CAPD & Diálise peritoneal ambulatorial contínua \\
\hline CCPD & Diálise peritoneal cíclica contínua \\
\hline Col & Colesterol total \\
\hline $\mathrm{Cr}$ & Creatinina \\
\hline DMO-DRC & Distúrbio mineral e ósseo da doença renal crônica \\
\hline DP & Diálise peritoneal \\
\hline DP2 & Maltose \\
\hline DP3 & Maltotriose \\
\hline DP4 & Maltotetraose \\
\hline DPA & Diálise peritoneal automatizada \\
\hline DRC & Doença Renal Crônica \\
\hline FA & Fosfatase alcalina \\
\hline FAPESP & Fundação de Amparo à Pesquisa do Estado de São Paulo \\
\hline FE & Fração de ejeção \\
\hline Fer & Ferritina \\
\hline FGF-23 & Fator de crescimento de fibroblastos \\
\hline FRR & Função renal residual \\
\hline $\mathrm{GC}$ & Grupo Controle \\
\hline GI & Grupo Icodextrina \\
\hline Glic & Glicemia \\
\hline $\mathrm{Hb}$ & Hemoglobina \\
\hline $\mathrm{HbAl} 1$ & Hemoglobina glicosilada \\
\hline
\end{tabular}




\begin{tabular}{|c|c|}
\hline HC-FMUSP & $\begin{array}{l}\text { Hospital das Clínicas da Faculdade de Medicina da Universidade } \\
\text { de São Paulo }\end{array}$ \\
\hline HD & Hemodiálise \\
\hline $\mathrm{Ht}$ & Hematócrito \\
\hline HVE & Hipertrofia de ventrículo esquerdo \\
\hline $\mathrm{ICO}$ & Icodextrina \\
\hline IECA & Inibidor da enzima conversora da angiotensina \\
\hline IMC & Índice de massa corpórea \\
\hline IMVE & Índice de massa de ventrículo esquerdo \\
\hline INCOR & Instituto do Coração do Hospital da Clínicas \\
\hline IVDFVE & $\begin{array}{l}\text { Volume diastólico final de ventrículo esquerdo indexado pela } \\
\text { superfície corpórea }\end{array}$ \\
\hline IVSFVE & $\begin{array}{l}\text { Volume sistólico final de ventrículo esquerdo indexado pela } \\
\text { superfície corpórea }\end{array}$ \\
\hline LIM-16 & Laboratório de investigação médica 16 \\
\hline $\mathrm{P}$ & Fósforo \\
\hline PCR & Proteína $\mathrm{C}$ reativa \\
\hline $\mathrm{Pd}$ & Fósforo dialisato \\
\hline PET & $\begin{array}{l}\text { Teste de equilíbrio peritoneal, do inglês peritoneal equilibration } \\
\text { test }\end{array}$ \\
\hline PTH & Paratormônio \\
\hline RNM & Ressonância magnética cardíaca \\
\hline satT & Índice de saturação de transferrina \\
\hline SUS & Sistema Único de Saúde \\
\hline TCLE & Termo de consentimento livre e esclarecido \\
\hline TFG & Taxa de filtração glomerular \\
\hline $\operatorname{Tg}$ & Triglicerídeos \\
\hline TSR & Terapia de Substituição Renal \\
\hline
\end{tabular}


$\mathrm{U}$

UF

UNIFESP

Vit.D
Ureia

Ultrafiltração

Universidade Federal do Estado de São Paulo

25OH-Hidroxivitamina D 


\section{INTRODUÇÃO}




\section{INTRODUÇÃO}

A doença renal crônica (DRC) atinge milhares de pessoas em todo mundo com prevalência crescente em decorrência do número de indivíduos acometidos com diabetes e hipertensão arterial, duas das principais patologias que levam à disfunção renal (1-4). DRC é definida como queda da taxa de filtração glomerular (TFG) abaixo de $60 \mathrm{ml} / \mathrm{min} / 1,73 \mathrm{~m}^{2}$ ou presença de marcadores de lesão renal, ou ambos, por pelo menos três meses, sendo atualmente classificada em cinco estádios (5). O estádio 5 da DRC é definido como taxa de filtração glomerular $<15 \mathrm{ml} / \mathrm{min} / 1,73 \mathrm{~m}^{2}$ e reflete um estádio de insuficiência renal no qual a maioria dos pacientes necessitará de terapia de substituição renal (TSR), como diálise peritoneal (DP), hemodiálise (HD) ou transplante renal.

No Brasil, segundo dados do Censo 2019 de Diálise realizado pela Sociedade Brasileira de Nefrologia, existiam 139.691 pacientes em terapia dialítica. Deste total de pacientes apenas $6,8 \%$ estavam em diálise peritoneal (DP) (6).

Na literatura há diversos estudos que compararam DP x HD, seus resultados são conflitantes, ora favorecendo a sobrevida com um método, ora favorecendo o outro (718). De qualquer forma, sabe-se que a DP é uma excelente alternativa dialítica principalmente para pacientes jovens, crianças e aqueles iniciando diálise que ainda possuem função renal residual (FRR).

Apesar de todos os avanços na terapia dialítica ao longo dos últimos anos, a taxa de mortalidade destes pacientes permanece inaceitavelmente alta (19-21). A principal causa de mortalidade de pacientes com DRC em diálise é cardiovascular (21-23).

A cardiomiopatia urêmica, ou seja, alterações na função e estrutura cardíaca em pacientes DRC, termo utilizado desde 1980 (24), composto por um complexo "quebracabeça urêmico" com estrita correlação entre si, representa um resumo com todos os fatores que contribuem de maneira expressiva para alta mortalidade cardiovascular dos pacientes com DRC (25).

Este "quebra cabeça urêmico" é formado por fatores de risco tradicionais, marcadores inflamatórios, disfunção endotelial, calcificação vascular, estresse oxidativo, toxinas urêmicas (adipocinas), hipervolemia, gasto proteico energético e ativação simpática exacerbada (25), conforme representado na Figura 1. 
Figura 1 - "Quebra cabeça urêmico".

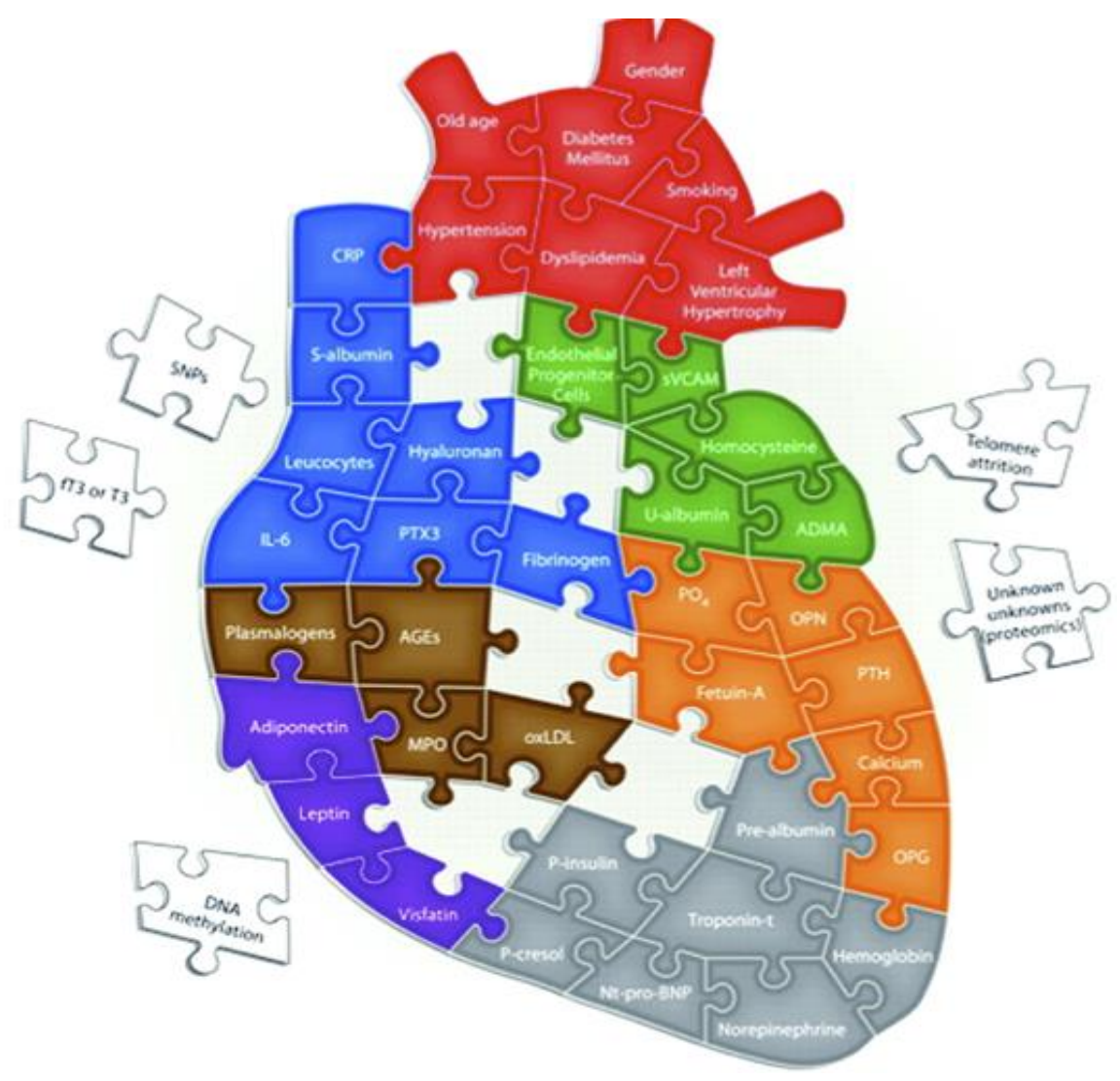

Peças vermelhas representam os fatores de risco tradicionais; azuis são biomarcadores inflamatórios e têmse associada com desfecho ruim em DRC; Verdes são marcadores de disfunção endotelial; Laranjas são marcadores de ossificação vascular; marrons são marcadores de estresse oxidativo; roxas são adipocinas urêmicas; Cinzas são marcadores de hipervolemia, gasto energético proteico e de hiperativação do simpático; brancas são marcadores novos associados a cardiomiopatia urêmica.

Fonte: adaptado de Clin J Am Soc Nephrol, Emerging Biomarkers for Evaluating Cardiovascular Risk in the Chronic Kidney Disease Patient: How Do New Pieces Fit into the Uremic Puzzle? Peter Stenvinkel et al. pag 507, março, 2008.

Dentre estas peças, neste estudo destacaremos a hipertrofia do ventrículo esquerdo (HVE), hipervolemia e distúrbio no metabolismo ósseo ligados à DRC (DMODRC).

A HVE é um dos fatores de risco para mortalidade cardiovascular na população dialítica (26-30). Além da hipertensão arterial, que sabidamente leva a uma maior HVE, outros fatores tem sido listados como possivelmente associados na fisiopatologia da HVE da DRC: os não reversíveis, como idade, diabetes, enrijecimento de grandes artérias e os reversíveis tais como hipervolemia, DMO-DRC, anemia, presença de fístula arteriovenosa (nos pacientes que realizam hemodiálise) e uremia (27).

A hipervolemia se constitui em uma das variáveis clínicas com grande dificuldade de manejo em pacientes dialíticos. O controle volêmico dos pacientes portadores de DRC 
dialítica é dependente da ultrafiltração (UF) da diálise, principalmente naqueles que não possuem função renal residual. A dieta e a restrição hídrica nesta fase devem ser orientadas para se obter o controle volêmico almejado. Quando não se consegue este controle, hipertensão arterial, edema maleolar e sintomas de excesso de volume tais como dispneia aos esforços e dispneia paroxística noturna podem ser observados. Como já citado, o DMO-DRC também contribui para a mortalidade de pacientes com DRC e será descrita a seguir.

\subsection{Hipertrofia de ventrículo esquerdo e fatores do distúrbio do metabolismo mineral e ósseo da doença renal crônica}

O termo DMO-DRC define uma síndrome e foi criado em 2006 pelo grupo de estudos do KDIGO (Kidney Disease Improving Global Outcomes) (31) em reconhecimento da associação frequente destas alterações com maior risco de mortalidade e fraturas na DRC.

O DMO-DRC contribui para a HVE de maneira significativa. Os fatores que se destacam são o fósforo sérico, o fator de crescimento de fibroblastos (FGF-23) (32-35) e o Klotho (36).

As alterações no metabolismo ósseo se iniciam precocemente, quando a depuração glomerular atinge $45 \mathrm{ml} / \mathrm{min} / 1,73 \mathrm{~m}^{2}$, portanto a partir do estádio 3 da DRC com a redução progressiva da proteína Klotho, aumento progressivo do FGF-23, que por sua vez deixa de exercer efeitos Klotho - dependente, culminam em hiperfosfatemia, redução de calcitriol e aumento do paratormônio (PTH) (37).

Com a piora da função renal e consequente enfraquecimento deste mecanismo compensatório, associada a uma dieta rica em fósforo (P), na DRC estádio 5 tem-se um balanço positivo de $\mathrm{P}$ e hiperfosfatemia. Uma das complicações mais comuns nos pacientes com DRC que estão em diálise e seu manejo baseia-se na restrição de fósforo na dieta, uso de quelantes e sua remoção na diálise.

A descoberta do FGF-23 contribuiu para uma melhor compreensão do DMODRC. O FGF-23 é um hormônio secretado pelos osteócitos, principalmente em resposta ao aumento da ingestão de fosfato e concentrações de $1,25(\mathrm{OH})^{2} \mathrm{D}^{3}$ (forma ativa da vitamina D). Para exercer suas funções, é necessária a presença da proteína Klotho, uma proteína de membrana tipo I, que se expressa principalmente nos túbulos proximais renais, glândula paratireoide e no cérebro. O FGF-23 age por meio de seu receptor, o 
complexo Klotho-FGRFR1, leva à diminuição da expressão e atividade do cotransportador $\mathrm{Na}-\mathrm{P}$ (NaPi2a e $\mathrm{NaPi} 2 \mathrm{c})$ no túbulo renal, exercendo assim sua ação fosfatúrica. Age também nos genes da síntese e degradação do calcitriol, inibindo a CYP27 relacionada à sua síntese e na CYP24 aumentando sua degradação $(38,39)$.

A correlação entre FGF-23 e HVE abordada numa coorte na qual altas concentrações de FGF-23 foram independentemente associadas com HVE. Além disso, na mesma publicação experimentos comprovaram: FGF-23 causa hipertrofia patológica de cardiomiócitos de ratos independente do Klotho; injeção intra-miocárdica ou intravenosa de FGF-23 em camundongos do tipo selvagem resultou em HVE; em animais deficientes em Klotho observou-se níveis elevados de FGF-23 e HVE; em modelos animais de DRC o tratamento com um bloqueador do receptor de FGF atenuou a HVE, sem nenhuma alteração na pressão arterial. Portanto, esses resultados revelam um papel causal independente do FGF-23 na patogênese da HVE (36).

Em resumo, altas concentrações de FGF-23 estão associadas a aumento do risco cardiovascular em pacientes portadores ou não de DRC, conforme esquematizado na Figura 2.

Figura 2 - Resumo da Fisiopatologia do DMO-DRC.

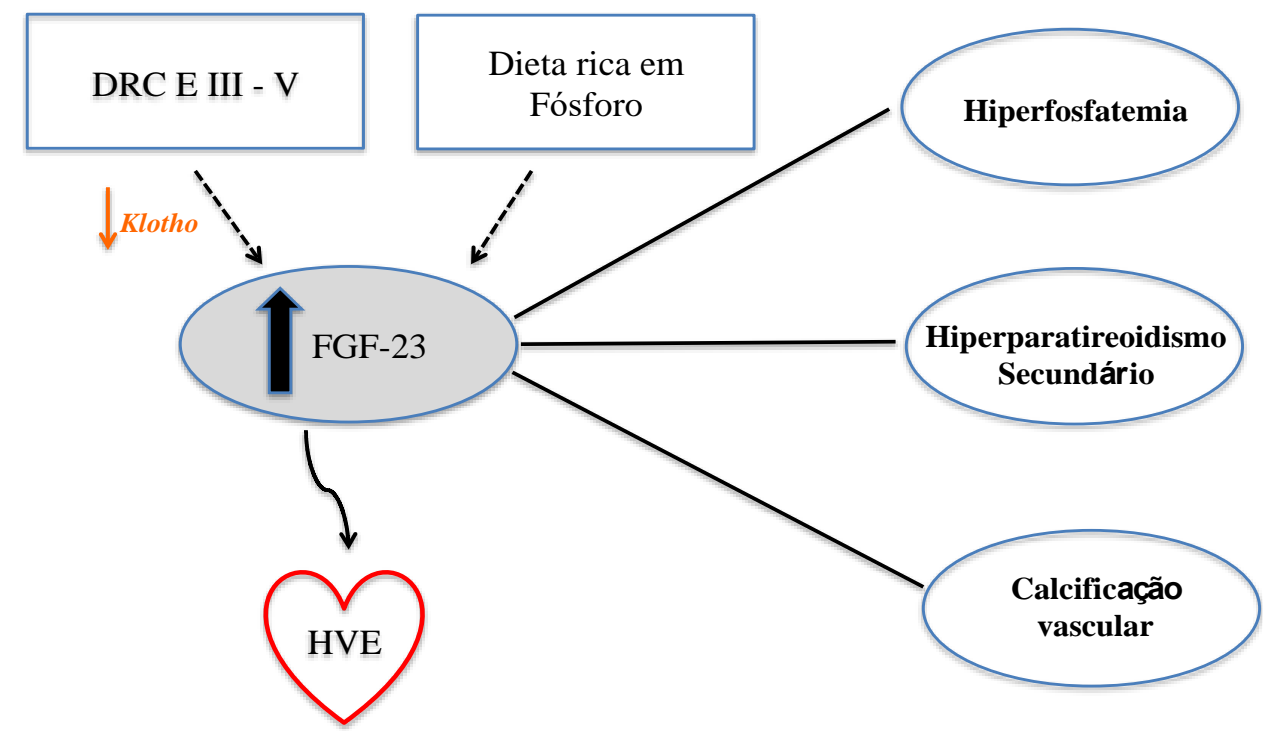

DRC: doença renal crônica; HVE: hipertrofia de ventrículo esquerdo. 


\subsubsection{Diagnóstico de hipertrofia de ventrículo esquerdo}

Apesar do ecocardiograma ser o método de imagem mais empregado e de menor custo para o diagnóstico de HVE, a ressonância nuclear magnética (RNM) é atualmente considerada padrão ouro para tal (40). A RNM possui custo mais elevado e não pode ser realizada em pacientes com alguns tipos de próteses metálicas, porém sua melhor resolução espacial permite uma avaliação mais precisa do ventrículo esquerdo, além de ser um exame não invasivo, sem uso de contraste para avaliação cardíaca $(41,42)$.

Num estudo comparativo entre os dois exames, foi evidenciado que a HVE é superestimada no ecocardiograma devido a anormalidades frequentes na geometria miocárdica, mesmo quando há um bom controle volêmico e que, para esse grupo de pacientes, a RNM fornece uma medida mais confiável da massa do ventrículo esquerdo. Além disso, concluiu-se que na RNM há uma menor variabilidade inter-observador, uma das falhas na interpretação do ecocardiograma (43).

Um outro estudo que comparou ecocardiograma e RNM cardíaca na avaliação de massa de ventrículo esquerdo em pacientes com e sem doença renal (44). Os resultados deste estudo mostraram que:

- O diagnóstico de HVE é superestimado através do ecocardiograma entre pacientes em diálise comparados aos pacientes com função renal normal;

- A concordância entre ecocardiograma e RNM foi inferior entre pacientes em diálise comparados aos pacientes com função renal normal;

Não encontramos dados de comparação entre ecocardiograma e RNM suficientes nos pacientes em DP e, embora o ecocardiograma continue sendo usado de rotina na avaliação de HVE, a RNM cardíaca se constitui em uma alternativa que permite uma avaliação mais precisa.

\subsection{Diálise peritoneal}

A DP é um método utilizado no mundo todo há mais de 30 anos, considerado simples, conveniente e de custo relativamente baixo. Consiste numa modalidade de TSR na qual a membrana peritoneal é responsável pelo transporte de solutos e de água. Através de sua rede de capilares, o sangue entra em contato com a solução de diálise na cavidade, que contém eletrólitos, tampão (bicarbonato ou lactato) e agente osmótico, geralmente glicose. Desta forma, os mecanismos responsáveis pela diálise ocorrem através de difusão, 
resultando na retirada dos solutos; convecção, controlando o excesso de líquido e por arraste removendo os solutos juntamente com a UF.

Dispomos de três métodos de DP: diálise peritoneal ambulatorial contínua (CAPD), na qual as trocas (infusão e drenagem de líquido peritoneal) são feitas manualmente de 3 a 4 trocas de solução de diálise por dia; diálise peritoneal automatizada (DPA), na qual a terapia é realizada por 8 a $9 \mathrm{~h}$ e as trocas são realizadas por uma máquina apropriada e a diálise peritoneal cíclica contínua (CCPD), na qual além da terapia ser feita pela máquina como a DPA mantém-se a cavidade úmida durante o dia.

Para adequação em DP, sua eficiência depende do volume da solução de diálise infundida, do número de trocas realizadas por dia, do tempo de permanência no peritônio e também do agente osmótico da solução (45). Estudos evidenciaram que em relação à depuração de fósforo peritoneal, esta se correlaciona com a depuração de creatinina peritoneal. Além disso, CAPD é o método que melhor remove $\mathrm{P}$ e que aumento no volume de infusão, mas não da ultrafiltração, pode aumentar a remoção semanal de $\mathrm{P}(46,47)$.

Em relação ao controle da volemia, para aumentar a taxa de UF são prescritas soluções de diálise com maior conteúdo de glicose, que em longo prazo resultam na piora do controle glicêmico, do perfil lipídico e na falência da membrana peritoneal. As soluções de glicose são caracterizadas por serem soluções de baixo peso molecular, disponíveis em 3 concentrações diferentes: 1,5\%, 2,5\% e 4,25\%. Apesar de seu poder osmótico e boa depuração de solutos, a solução de dextrose pode levar a complicações metabólicas como hiperglicemia, hiperlipidemia, hiperinsulinemia e obesidade (48).

No Brasil, pacientes cuja fonte pagadora é o Sistema Único de Saúde (SUS), não possuem disponibilidade para uso de bolsas de icodextrina (ICO), solução de DP constituída por um polímero da glicose, que devido ao seu alto poder osmótico (49) é indicada para pacientes com difícil controle de volemia, pela sua reconhecida maior eficiência e poder de UF (49-53). Por ser o foco deste estudo comparar ICO x glicose, descreveremos a ICO mais detalhadamente.

\subsubsection{Icodextrina}

Desde a década de 1980 havia um reconhecimento de que um agente osmótico diferente da dextrose era necessário para que se minimizasse as complicações metabólicas e aumentasse a UF nas trocas de longa permanência. Uma série de diferentes macromoléculas foram avaliadas a partir do conceito de que agentes de alto peso 
molecular seriam menos absorvidos pelo peritônio e provavelmente produziriam UF sustentada e reduziriam as complicações metabólicas (54).

Após aproximadamente 10 anos de estudos, mais precisamente em 1993, a solução "dextrina 20", posteriormente nomeada "Icodextrina", do grego icosa, que significa vinte e faz correlação com seu peso molecular de aproximadamente 19.000 Daltons (52), foi liberada para uso no Reino Unido. Na Europa seu uso foi liberado em 1994 e nos Estados Unidos somente em 2002. Portanto, a ICO está em uso clínico há mais de 15 anos e tem sido um passo importante na história da DP. Estima-se que seja usada por aproximadamente 30.000 pacientes em mais de 55 países, sendo que nos países mais ricos seu uso ultrapassa 50\% (55).

A ICO é uma solução de alto peso molecular formada por um polímero de glicose hidrossolúvel derivado do amido de milho hidrolisado. Sua estrutura é similar à do glicogênio, consistindo em um polissacarídeo de polímeros de D-glucopiranose ligados em cadeias alfa (1-4) e alfa (1-6) em menor número (56). Sua fórmula representativa está abaixo:

Figura 3 - Molécula de Icodextrina.

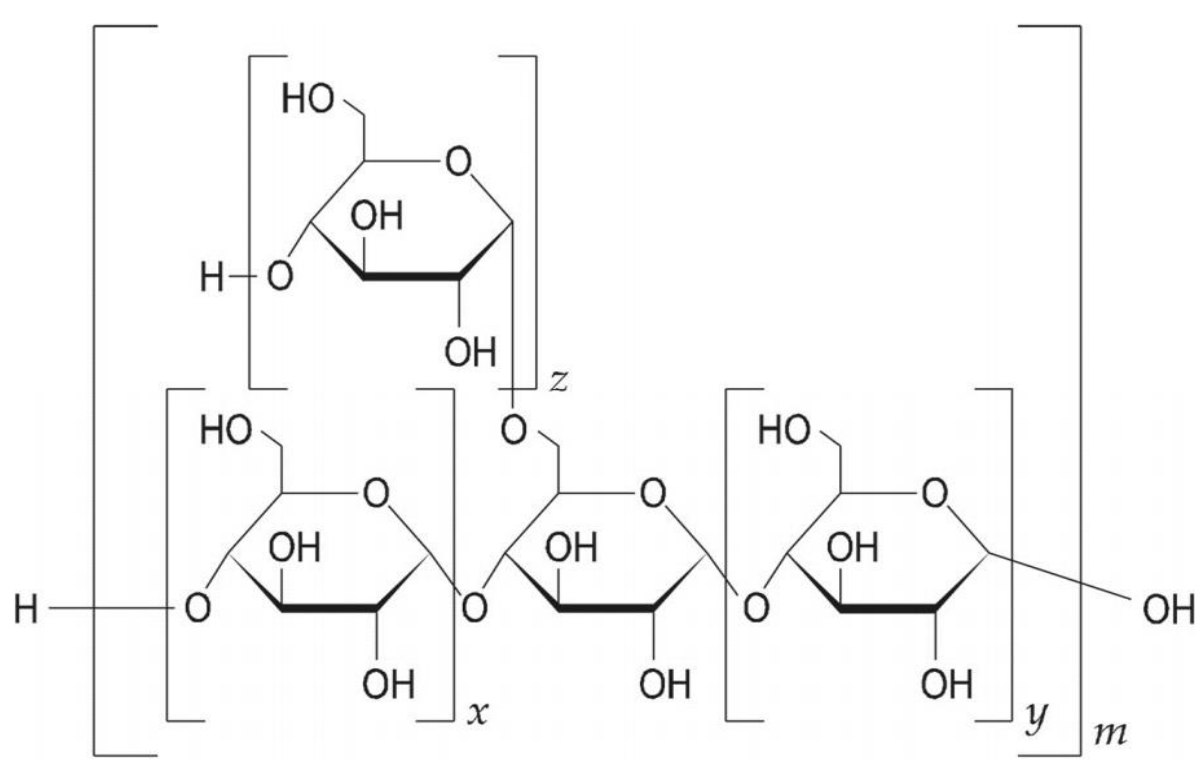

Fonte: $\underline{\text { https://www.baxterpi.com/pi-pdf/Extraneal_PI.pdf }}$

Diferentemente da glicose e de outros solutos pequenos que são absorvidos por difusão pelos capilares endoteliais, a ICO tem uma capacidade de difusão limitada e sua 
absorção se caracteriza por convecção através dos vasos linfáticos. Como resultado, obtemos uma pressão osmótica constante, o que lhe confere a característica de permanecer ultrafiltrando por tempo de permanência maior $(52,57,58)$. A ICO absorvida é hidrolisada por alfa amilases, resultando em oligossacarídeos, como maltose (DP2), maltotriose (DP3) e maltotetraose (DP4). A DP2, um dissacarídeo, sofre ação da amilase somente no intracelular, portanto, temos como resultado da metabolização da ICO altas concentrações de amilase no sangue (Figura 4).

Figura 4 - Desenho esquemático da metabolização da Icodextrina.

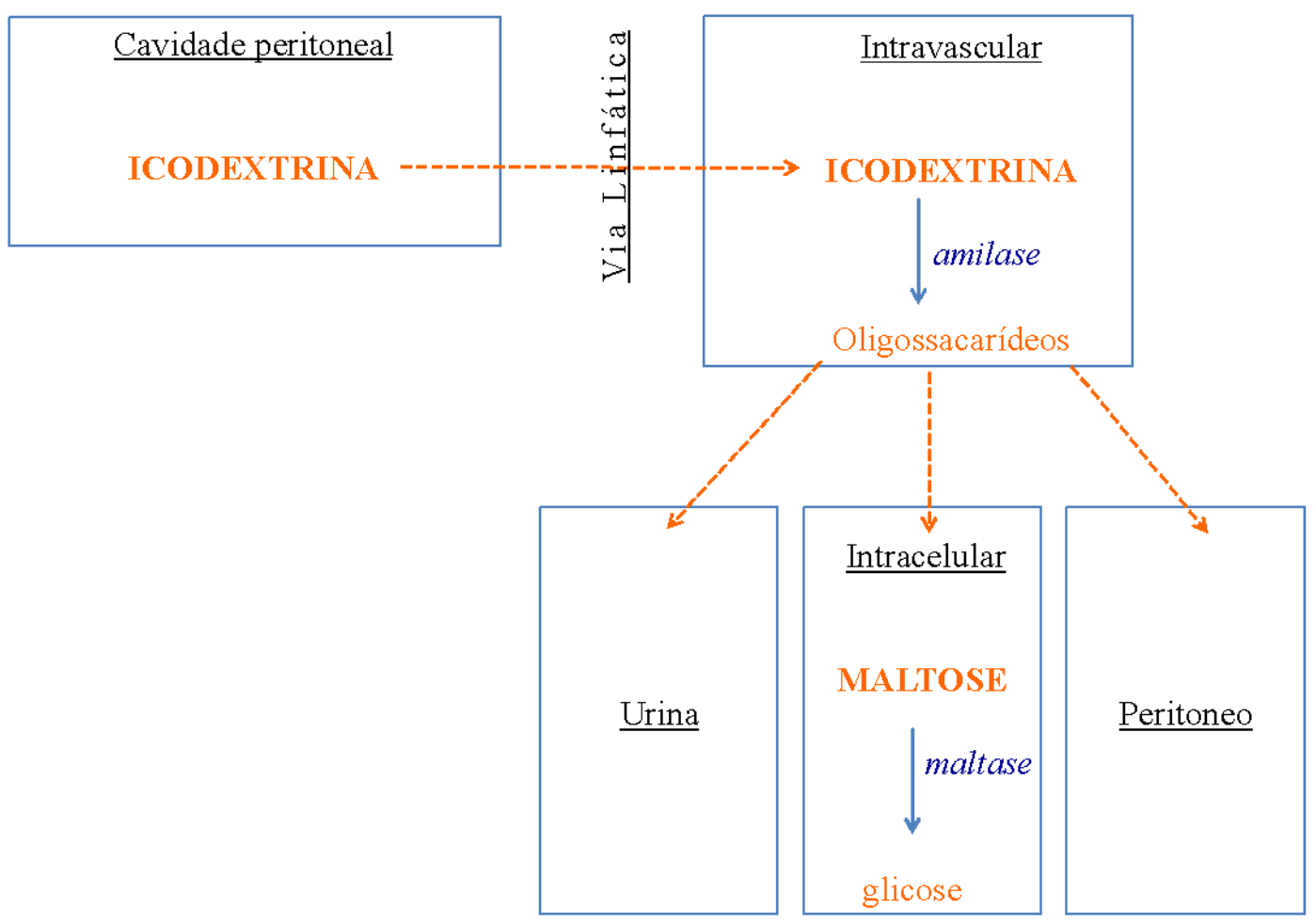

Essas altas concentrações são temidas por dois motivos: podem levar a testes falsos positivos de hiperglicemia em glicosímetros que utilizam o método da glicose desidrogenase com pirrolquinolinoquinona (GDH-PQQ) (59) e pelo risco de acúmulo de DP2 com consequente doença de depósito, fato esse que não foi demonstrado nos estudos. Há um pico em sua concentração em 15 dias após início do uso e depois deste período se mantém estável. Essa concentração também cai 15 dias após se cessar o seu uso (52). 
Os oligossacarídeos resultantes são transformados em glicose por maltases teciduais, excretadas pela urina ou eliminadas pela diálise peritoneal. A ICO possui a vantagem de não causar hiperglicemia ou hiperinsulinemia pois seus metabólitos são transformados em glicose via intracelular $(56,60)$. Com isso, não acarreta dislipidemia e ganho de peso quando comparada ao uso de glicose (61).

Em relação à sua farmacocinética, sabemos que após $12 \mathrm{~h}$ uma média de $60,24 \mathrm{~g}$ (40\%) de ICO é absorvida, possui meia-vida mediana de 14,73h, uma depuração mediana de $1,09 \mathrm{~L} / \mathrm{h}$, sendo que tanto a sua meia-vida, quanto sua depuração média assim como sua excreção urinaria são diretamente proporcionais à FRR (56).

As bolsas para DP que contém ICO são caracterizadas por uma solução estéril contendo ICO em uma concentração de 7,5\% ( 1 bolsa de $2 \mathrm{~L}$ contém $150 \mathrm{~g}$ de ICO) e eletrólitos. A composição da bolsa de ICO no mercado (Extraneal ${ }^{\mathrm{TM}}$; Baxter Hospitalar Ltda), comparativa com as soluções de glicose estão resumidas na Tabela 1.

Tabela 1 - Características das soluções.

\begin{tabular}{|c|c|c|}
\hline SOLUÇÃo & DEXTROSE & ICODEXTRINA \\
\hline Concentração (g/dL) & $1,5 \% / 2,5 \% / 4,25 \%$ & $7,5 \%$ \\
\hline $\mathbf{p H}$ & $4,0-6,5$ & $5,0-6,0$ \\
\hline Osmolaridade (mOsm/kg) & $346-485$ & $282-286$ \\
\hline Sódio (mEq/L) & 132 & 132 \\
\hline Cálcio (mEq/L) & $2,5 / 3,5$ & 3,5 \\
\hline Lactato (mEq/L) & 40 & 40 \\
\hline Magnésio (mEq/L) & 0,5 & 0,5 \\
\hline Cloreto $(\mathbf{m E q} / \mathbf{L})$ & 96 & 96 \\
\hline
\end{tabular}

Dentre os benefícios clínicos da ICO, além do aumento da UF, principalmente em pacientes com rápido transporte de membrana, podemos destacar: melhora do controle glicêmico em diabéticos, do perfil lipídico, da HVE e aumento da remoção de fósforo $(49,62-65)$.

Em relação aos efeitos adversos podemos encontrar:

1. Efeitos hemodinâmicos: hipotensão devido a maior UF (50) e perda da FRR, clinicamente sem significância (66); 
2. Efeitos metabólicos: hipoglicemia devido falso positivo em glicosímetros que reconhecem a maltose como glicose. Portanto, é necessário verificar o aparelho de dextro que o paciente faz uso; hiponatremia por mecanismo similar ao da hipertrigliceridemia, por provável aumento da pressão coloide isosmolar; acúmulo de maltose, pois sua metabolização é incompleta devido a ausência de maltase na nossa circulação; redução da atividade da amilase (pode dificultar diagnóstico de pancreatite) e aumento discreto da fosfatase alcalina (FA) devido provável inibição parcial de sua metabolização por competitividade pelos receptores nos hepatócitos;

3. Efeitos idiopáticos: rash cutâneo com uma prevalência de até $15 \%$ dos casos e que pode ser moderado a severo, de caráter macular e psoriariforme que inclui descamação da pele das palmas das mãos e plantas dos pés. Já foram descritos também casos generalizados e pustulares. Geralmente ocorre nos primeiros 15 dias de uso e melhora após sua descontinuação; peritonite estéril, caracterizada por quadro de desconforto abdominal, líquido de diálise turvo, aumento da celularidade do líquido

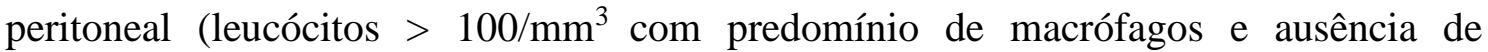
neutrófilos), cultura do líquido peritoneal negativa. Pode ocorrer até os primeiros 8 meses de uso e melhora após 48h, não requer tratamento específico e a depender da sua gravidade é definido se seu uso necessita ser suspenso (67). Algumas estratégias podem ser adotadas para reduzir a ocorrência destes efeitos adversos, conforme ilustrado na Figura 5. 
Figura 5 - Estratégias para reduzir efeitos colaterais da Icodextrina.

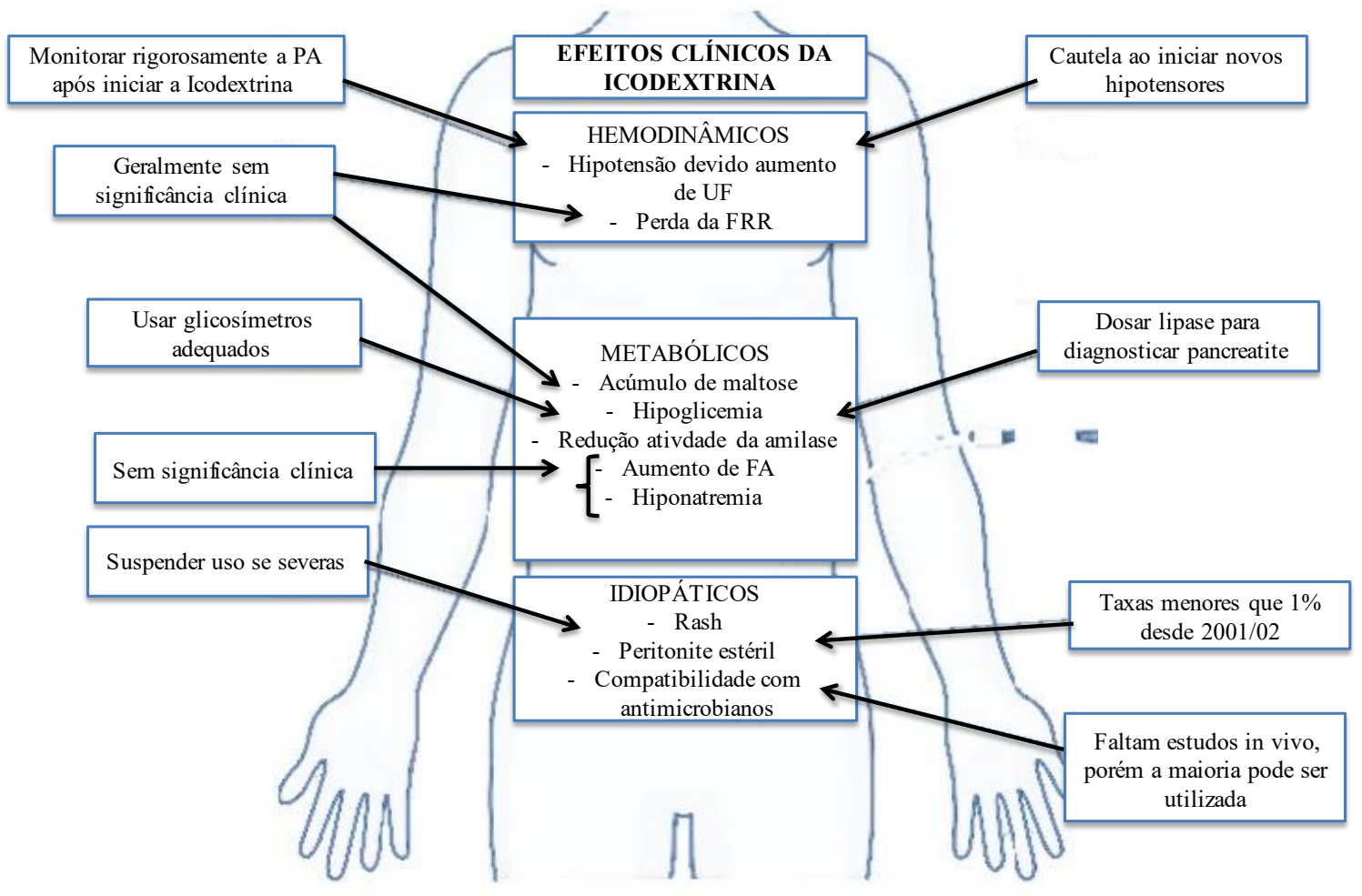

Fonte: Adaptado de Am J Nephrol, Practical Considerations When Prescribing Icodextrin: A Narrative Review, Silver et al pág 525, Junho, 2014,(67)

\subsection{Estudos dos efeitos da icodextrina na massa de ventrículo esquerdo}

Em pesquisa bibliográfica encontramos seis publicações que abordaram o impacto do uso de ICO na redução da HVE, descrita conforme resumo abaixo e tabela 2:

I. Estudo de Hiramatsu e colaboradores (62) publicado em 2013 teve como objetivo identificar fatores de inibição da arteriosclerose e avaliar doença valvular em pacientes diabéticos com DRC estádio 5. Neste estudo retrospectivo, 20 pacientes em DP com glicose foram comparados a 20 pacientes com icodextrina. Os resultados mostraram que a icodextrina foi capaz de diminuir a HVE e a calcificação aórtica além de aumentar a eliminação de fósforo. Nenhum dado de volemia foi mencionado neste estudo.

II. Konings e colaboradores (63) em publicação de 2003 avaliaram o efeito da icodextrina na volemia, na pressão arterial e nos dados de ecocardiograma. Um total de 40 pacientes foram incluídos ( 22 com ICO e 18 controles, sendo que somente 19 tratados e 13 controles completaram o estudo). Os resultados mostraram que a ICO levou a maior 
taxa de UF e diminuição de HVE.

III. Paniagua e colaboradores (64) avaliaram o uso de ICO em um estudo multicêntrico e randomizado. Foram avaliados aspectos ecocardiográficos e pressão arterial em um grupo de pacientes diabéticos em DP. Os resultados mostraram melhora do controle pressórico em seis meses e do volume diastólico final, que parecem ter influenciado no melhor controle volêmico. Nenhum aspecto do DMO-DRC foi abordado.

IV. Oba e colaboradores (68) determinaram o efeito da ICO na massa ventricular de pacientes em DP que apresentavam volume de diurese residual. Este foi um estudo retrospectivo que incluiu 18 pacientes divididos em dois grupos: ICO e controle. Os autores demonstraram uma redução da massa de ventrículo e um aumento da UF. Pressão arterial, volume urinário e peptídeo natriurético tipo $\mathrm{B}$, do inglês brain natriuretic peptide (BNP) não se modificaram com o uso de ICO.

V. Chen e colaboradores (65) publicaram em 2018 estudo que não encontrou alterações significativas na estrutura e função cardíaca entre diferentes soluções de DP. Trata-se de um estudo prospectivo, randomizado, com objetivo de comparar o impacto da ICO e das soluções de glicose na estrutura e na função cardíaca por um período de 2 anos. Foram incluídos 43 pacientes randomizados em dois grupos. Ecocardiograma foi realizado em três momentos, na inclusão, 1 e 2 anos após.

VI. O IMPENDIA and EDEN Study (69) foi um estudo multicêntrico, prospectivo, randomizado e controlado, com objetivo de comparar as diferentes soluções de DP e seus efeitos metabólicos após 6 meses de uso. Incluiu no total de 251 pacientes, porém apenas 82 realizaram RNM. Apesar de não ter avaliado especificamente o impacto da ICO sobre a HVE, foram realizadas RNM cardíaca no momento basal e 6 meses após. Não foi observada diferença significativa na massa ventricular esquerda e nem na fração de ejeção entre os grupos. 
Tabela 2 - Comparação dos estudos quantos aos efeitos da icodextrina na massa de ventrículo esquerdo.

\begin{tabular}{|c|c|c|c|c|c|c|}
\hline & $\begin{array}{c}\text { Hiramatsu et al. } \\
2013\end{array}$ & $\begin{array}{l}\text { Konings etal. } \\
2003\end{array}$ & $\begin{array}{c}\text { Paniagua et al. } \\
2008\end{array}$ & $\begin{array}{c}\text { Oba et al. } \\
2013\end{array}$ & $\begin{array}{c}\text { Chen et al. } \\
2018\end{array}$ & $\begin{array}{l}\text { Li et al. } \\
2013\end{array}$ \\
\hline $\begin{array}{l}\text { Tipo de } \\
\text { estudo }\end{array}$ & Retrospectivo & $\begin{array}{l}\text { Multicêntrico, } \\
\text { randomizado }\end{array}$ & $\begin{array}{l}\text { Multicêntrico, } \\
\text { randomizado }\end{array}$ & Retrospectivo & $\begin{array}{l}\text { Prospectivo, } \\
\text { randomizado }\end{array}$ & $\begin{array}{l}\text { Multicêntrico, } \\
\text { randomizado }\end{array}$ \\
\hline $\mathbf{N}$ & 40 & 32 & 59 & 18 & 43 & 251 \\
\hline Tempo & 2 anos & 4 meses & 12 meses & 12 meses & 2 anos & 6 meses \\
\hline Modalidade & CAPD & CAPD e CCPD & CAPD & - & CCPD & CAPD e CCPD \\
\hline Grupo & $\begin{array}{c}\text { Apenas } \\
\text { pacientes } \\
\text { diabéticos; } \\
\text { ICO X Glicose }\end{array}$ & $\begin{array}{l}\text { Glicose } 1,5 \% \\
\text { x ICO }\end{array}$ & $\begin{array}{c}\text { Apenaspacientes } \\
\text { diabéticos; } \\
\text { ICO X Glicose }\end{array}$ & $\begin{array}{c}\text { Débito } \\
\text { urinário> } \\
800 \mathrm{ml}\end{array}$ & ICO X Glicose & $\begin{array}{c}\text { ICO x Glicose } x \\
\text { AA }\end{array}$ \\
\hline $\begin{array}{l}\text { Avaliação } \\
\text { HVE }\end{array}$ & ECO & ECO & ECO & ECO & ECO & RNM \\
\hline Desfecho & $\begin{array}{c}\text { Melhorada } \\
\text { HVE } \\
\text { e da } \\
\text { calcificação } \\
\text { valvular } \\
\text { no grupo ICO }\end{array}$ & $\begin{array}{c}\text { Redução AEC } \\
\text { e da MVE no } \\
\text { grupo ICO }\end{array}$ & $\begin{array}{l}\text { Redução PA,no } \\
\text { diâmentodo VE, } \\
\text { diâmetro } \\
\text { diastólico } \\
\text { no grupo ICO }\end{array}$ & $\begin{array}{l}\text { ICO melhora } \\
\text { ou } \\
\text { manutenção } \\
\text { IMVE, sem } \\
\text { alterar FRR }\end{array}$ & $\begin{array}{c}\text { Ausência de } \\
\text { alterações } \\
\text { significativas } \\
\text { na estrutura e } \\
\text { função } \\
\text { cardíaca }\end{array}$ & $\begin{array}{c}\text { Ausência de } \\
\text { diferença } \\
\text { significativa na } \\
\text { MVE e na FE }\end{array}$ \\
\hline
\end{tabular}

$\mathrm{N}$ : número de pacientes do estudo; CAPD: diálise peritoneal ambulatorial contínua; CCPD: diálise peritoneal cíclica contínua; ICO: icodextrina; AA: aminoácidos; ECO: ecocardiograma; RNM: ressonância magnética; HVE: hipertrofia de ventrículo esquerdo; AEC: água extracelular; MVE: massa de ventrículo esquerdo; PA: pressão arterial; VE: ventrículo esquerdo; IMVE: índice de massa de ventrículo esquerdo; FE: fração de ejeção 


\subsection{Justificativa e interesse científico}

A alta taxa de mortalidade de etiologia cardiovascular continua sendo um desafio para todos os nefrologistas que lidam com pacientes em DP. Pressão arterial, diabetes mellitus, manejo de volume, controle do DMO-DRC são as variáveis que sabidamente influenciam no desenvolvimento progressivo de hipertrofia miocárdica e consequentemente, em um desastroso desfecho cardiovascular.

O uso de diferentes concentrações de glicose ou de icodextrina são opções terapêuticas para controle de volemia e ainda evidenciou impacto no DMO-DRC. Apenas um estudo avaliou a ação da ICO na HVE utilizando-se de uma metodologia mais confiável, a ressonância magnética de coração. Devido à sua alta acurácia e à sua reprodutibilidade para a avaliação da massa e dos volumes ventriculares, este exame é particularmente interessante no acompanhamento do remodelamento ventricular ao longo do tempo, sendo considerado o método padrão-ouro nesta avaliação (70).

Este estudo tenta elucidar de forma objetiva as alterações de HVE através de ressonância cardíaca, tentando correlacionar a HVE com marcadores do DMO-DRC. 
2. OBJETIVOS 


\section{OBJETIVOS}

Avaliar alterações no índice de massa do ventrículo esquerdo (IMVE) por meio de ressonância nuclear magnética de coração de pacientes em DP, comparando solução de ICO vs. solução de glicose.

\subsection{OBJETIVOS ESPECÍFICOS}

1. Correlacionar as variações da massa de ventrículo esquerdo com marcadores do DMO-DRC, tais como FGF-23.

2. Correlacionar as variações da massa de ventrículo esquerdo com a extração de fósforo pelo dialisato;

3. Identificar o papel de diferentes soluções de DP com fator independente associado à redução da massa de ventrículo esquerdo, ajustando para possíveis variáveis de confusão tais como controle de volemia, hemoglobina e pressão arterial. 
3. CASUíSTICA E MÉTODOS 


\section{CASUÍSTICA E MÉTODOS}

\subsection{Delineamento e população de estudo}

Trata-se de um estudo randomizado, tipo coorte, prospectivo, de caráter intervencionista, com grupo controle e duração de seis meses.

O estudo foi aprovado pelo Comitê de Ética em Pesquisa do Hospital das Clínicas da Faculdade de Medicina da Universidade de São Paulo, sob número (57602516.6.1001.0068, parecer 1.739.787) e pelo Comitê de Ética em Pesquisa da Universidade Federal de São Paulo (57602516.6.3001.5505, parecer \#3.138.877)

Os pacientes foram recrutados do Programa de Diálise Peritoneal do Serviço de Nefrologia do Hospital das Clínicas da Faculdade de Medicina da Universidade de São Paulo (HC-FMUSP) e do Programa de Diálise Peritoneal da Universidade Federal do Estado de São Paulo (UNIFESP) pelo próprio pesquisador.

Todos os pacientes foram orientados quanto aos objetivos da pesquisa antes de assinar o termo de consentimento livre e esclarecido (TCLE). Os pacientes recebiam as explicações sobre o processo de alocação e só eram incluídos se aceitassem e assinassem o TCLE.

\subsection{Amostragem e cálculo do poder}

Baseado em achado anterior de redução significativa de massa de ventrículo esquerdo (de $241 \pm 53$ gramas vs. $228 \pm 42$ gramas) com uso de ICO, mas não no grupo controle (63), a amostra calculada com erro alfa de $5 \%$ e poder de $90 \%$ foi de 9 pacientes em cada grupo.

\subsection{Critérios de inclusão}

Foram incluídos pacientes adultos dos Programas de Diálise Peritoneal HCFMUSP e da UNIFESP que realizavam os seguintes métodos dialíticos: CAPD ou CCPD, de novembro 2016 até agosto de 2020 com aceitação manifesta ao assinarem o TCLE.

\subsection{Critérios de exclusão}

Pacientes que não conseguiram compreender ou que se recusaram a assinar o TCLE; pacientes com insuficiência cardíaca congestiva descompensada (sintomática); 
presença de elemento metálico ou marcapasso que contraindique a realização de RNM; claustrofobia que impossibilite a realização da RNM.

\subsection{Randomização}

Após incluídos no estudo, os pacientes foram alocados nos grupos controle (GC) ou grupo icodextrina (GI) de formas distintas em cada centro participante: alocação controlada no HC-FMUSP e através de randomização por sorteio na UNIFESP. Isso ocorreu pois o sistema de conexão das bolsas de ICO são incompatíveis com o sistema de conexão da empresa Fresenius, pois a solução de ICO é fabricada exclusivamente pela empresa Baxter. Portanto somente os pacientes que realizam DP pelo equipamento da empresa Baxter conseguem fazer uso da ICO.

Como no HC-FMUSP há pacientes em DP por ambas as empresas, alocamos os pacientes do HC-FMUSP da seguinte forma:

- Pacientes que faziam DP com material fornecido pela empresa Baxter foram alocados no GI

- Pacientes que faziam DP com material fornecido pela empresa Fresenius foram alocados no GC

Os pacientes da UNIFESP por fazerem diálise peritoneal exclusivamente através de insumos da empresa Baxter, a randomização foi feita por sorteio após assinatura do TCLE.

Depois de alocados em cada grupo, dados clínicos, demográficos e bioquímicos foram obtidos e o agendamento do exame da RNM cardíaca solicitado à Gestão de Projetos Científicos da Radiologia do Instituto do Coração do Hospital das Clínicas (INCOR).

\subsection{Protocolo de pesquisa}

Os pacientes foram acompanhados durante os 6 meses com o médico nefrologista do próprio paciente, com consultas de rotina mensais, sendo que a prescrição da diálise em relação às concentrações de glicose das bolsas era livre, de acordo com o médico prescritor.

As bolsas de ICO foram prescritas no tempo de maior permanência na cavidade, ou seja, se o paciente estava em CAPD, a ICO foi utilizada na última troca da noite e se o paciente estava em CCPD, a ICO foi utilizada durante o dia (infusão e drenagem pela 
máquina). No grupo controle aqueles que estavam em CAPD realizaram o número e trocas de acordo com a prescrição médica, somente com glicose, e nos que estavam em CCPD permaneceram com a cavidade úmida durante o dia também conforme o que o nefrologista em acompanhamento prescrevia. Após 6 meses de estudo completos, os mesmos dados coletados na inclusão inicial foram obtidos conforme demonstrado no desenho esquemático do estudo (Figura 6).

Figura 6 - Desenho esquemático do estudo.

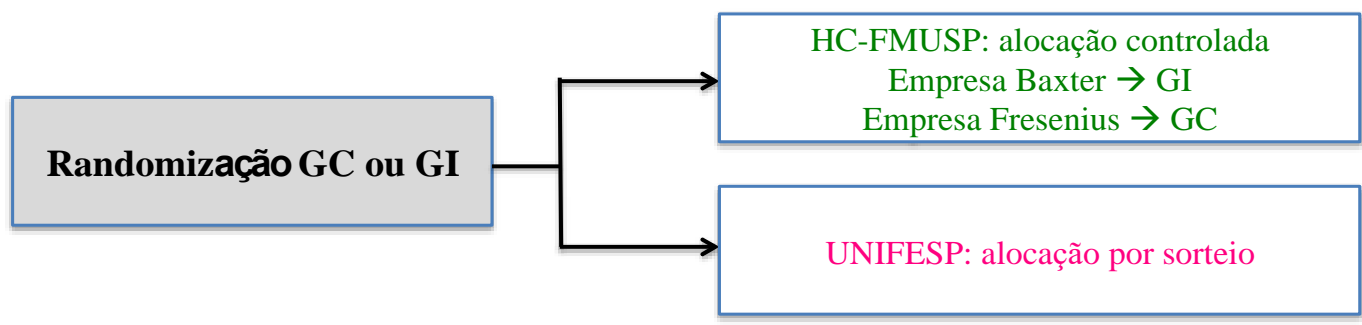

*Concentração das bolsas de glicose à critério do médico prescritor

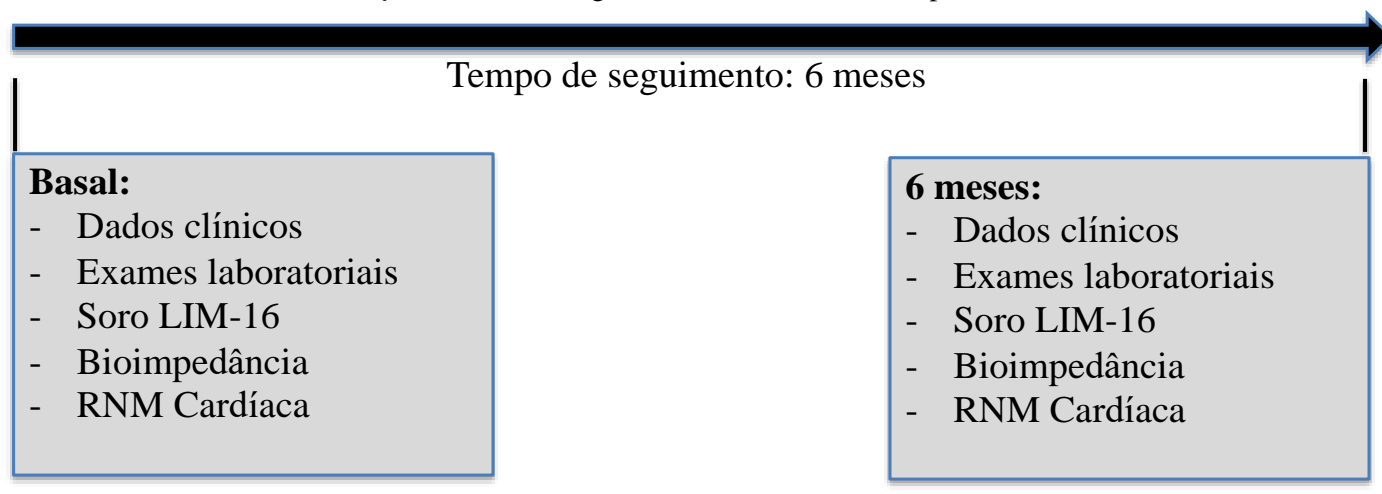

GC: grupo controle; GI: grupo icodextrina; Dados clínicos: sexo, idade, altura, peso, doença de base, tabagismo, comorbidades, método dialítico, tempo em DP, diurese residual, Kt/v, teste de equilíbrio peritoneal, PET, do inglês peritoneal equilibration test, pressão arterial, medicações em uso; Exames laboratoriais: hemograma, perfil de ferro, função renal, bioquímica, perfil hormonal, albumina, proteína $\mathrm{C}$ reativa (PCR) e peptídeo natriurético cerebral, do inglês brain natriuretic peptide (BNP).

\subsubsection{Coleta de dados clínicos basais e 6 meses após inclusão no estudo}

Os dados clínicos dos pacientes foram obtidos a partir do prontuário da Instituição, anotados e arquivados com todas as precauções necessárias para manter o sigilo das informações do paciente. São eles: etiologia da doença renal, idade, história de tabagismo, presença de comorbidades como hipertensão e diabetes mellitus, história de doença cardiovascular (doença coronariana e cerebrovascular) e medicações prescritas. Os pacientes foram questionados sobre tempo, método de diálise realizada e taxa de UF 
média. Consideramos anúria quando débito urinário $\leq 300 \mathrm{ml}$. Dados antropométricos foram coletados quando o paciente assinou o TCLE, calculamos o índice de massa corpórea de acordo com a fórmula padronizada pela Organização Mundial de Saúde, calculado dividindo-se o peso do paciente pela sua altura elevada ao quadrado. A aferição de pressão arterial foi realizada pela enfermeira de cada centro no dia da consulta de enfermagem com aparelho oscilométrico digital com o paciente sentado, após 5 minutos de repouso e de bexiga vazia.

\subsubsection{Avaliação laboratorial}

No momento da inclusão nos grupos e 6 meses após foram anotados os resultados de: hemoglobina $(\mathrm{Hb})$, hematócrito $(\mathrm{Ht})$, índice de saturação de transferrina (satT), ferritina, ureia, creatinina, cálcio (Ca), P, PTH, FA, 25OH-hidroxivitamina D (25-vitD), albumina (Alb), glicemia, Hemoglobina glicosilada (HbA1), colesterol, triglicerídeos, proteína $\mathrm{C}$ reativa $(\mathrm{PCR})$ e $\mathrm{BNP}$.

Também foram realizadas coletas de material biológico (soro), armazenado em freezer a $-80^{\circ} \mathrm{C}$, utilizado para análise de FGF-23 pela equipe especializada no laboratório de investigação médica (LIM-16) da Faculdade de Medicina. E no mesmo momento solicitado para o paciente coleta de líquido peritoneal para dosar fósforo do dialisato (Pd).

\subsubsection{Realização de bioimpedância segmentar}

A bioimpedância feita através do aparelho de bioimpedância segmentar tetrapolar InBody ${ }^{\mathrm{TM}} \mathrm{S} 10$ (Biospace Co.,Ltd., Korea), realizada no mesmo momento da inclusão do paciente (basal) e após 6 meses do estudo (seguimento) nos dois grupos de estudo controle e ICO. Com os pacientes deitados e as pernas esticadas, foi avaliada a quantidade de fluido em membro inferior através de uma corrente entre eletrodos colocados no tornozelo e nos dedos polegar e indicador bilateralmente. Esta técnica foi previamente validada (acurácia de $0,5 \%$ e repetibilidade $0,3 \%$ ) para medidas de fluidos corpóreos (71).

Os parâmetros avaliados por bioimpedância foram: água corporal total (ACT), água extracelular (AEC), água intracelular (AIC) e relação AEC/ACT. A relação AEC/ACT é considerada normal, ou seja, indica normovolemia quando resulta entre 0,36 e 0,39 . Valores maiores ou iguais a 0,40 indicam hipervolemia. 


\subsubsection{Ressonância nuclear magnética (RNM) cardíaca}

Os exames de RNM foram realizados no INCOR, sob coordenação do Dr. Walther Ishikawa, nos momentos basal e seguimento nos dois grupos de pacientes. Todos os pacientes foram orientados a respeito das datas e horários do exame, após agendamento feito pela Gestão de Projetos Científicos da Radiologia do INCOR.

A RNM foi realizada em aparelhos de 1.5 Tesla (Achieva, Philips Healthcare, Holanda; e Titan, Toshiba Medical Systems, Japão), com aquisições multiplanares em Gradiente-ECO rápido, aquisições em estado de equilíbrio (SSFP) com sincronização eletrocardiográfica, sem a administração do meio de contraste venoso.

As análises dos exames foram realizadas através da estação de trabalho CVi42 (Circle Cardiovascular Imaging, Canadá). Os resultados foram expressos como dimensões cavitárias cardíacas (diâmetros e volumes, ao final de sístole e diástole) e massa miocárdica ventricular esquerda (todos estes valores absolutos e indexados para área de superfície corpórea), além da fração de ejeção do ventrículo direito e esquerdo.

Consideramos HVE de acordo com Petersen e colaboradores (72) paciente com IMVE quando possuíam os seguintes valores:

- Mulheres, independente da idade, considera-se HVE quando o IMVE é $\geq$ $55 \mathrm{~g} / \mathrm{m}^{2}$

- Homens até 64 anos, considera-se HVE quando o IMVE é $\geq 72 \mathrm{~g} / \mathrm{m}^{2}$

- Homens > 65 anos, considera-se HVE quando o IMVE é $\geq 70 \mathrm{~g} / \mathrm{m}^{2}$

\subsubsection{Solução de diálise de icodextrina}

Esta solução é produzida somente pela empresa Baxter, no Brasil e no mundo. $\mathrm{O}$ material foi entregue no endereço domiciliar do paciente, com um pedido realizado pelo pesquisador e custeado pela Fundação de Amparo à Pesquisa do Estado de São Paulo (FAPESP).

\subsection{Estatística}

Os resultados estão apresentados como média e desvio padrão ou mediana e interquartis 25,75 quando paramétricos ou não paramétricos, respectivamente, após aplicação de teste te D'Agostino Pearson. A comparação entre os grupos controle e ICO foi feita através de qui-quadrado ou Fisher quando apropriado, para as variáveis categóricas e através de teste $\mathrm{t}$ ou Mann Whitney para as variáveis contínuas. A 
comparação de efeitos pré e pós-intervenção foi feita através de teste t pareado em cada grupo de tratamento (controle e icodextrina). A alteração da massa de ventrículo esquerdo foi a variável dependente em análise multivariada ajustada para pressão arterial, hemoglobina e grupo de tratamento. Para obtenção dos gráficos e análise estatística foram utilizados os softwares SPSS ${ }^{\text {TM }}$ versão 22 (SPSS Inc., Chicago, IL, Estados Unidos) e Graphpad Prism ${ }^{\mathrm{TM}}$ versão 8 (GraphPad Software, La Jolla, CA, Estados Unidos). Nos testes o nível de rejeição foi fixado em 5\%, ou seja, $p<0,05$.

\subsection{Aspectos técnicos}

\subsection{1 Ética}

O presente estudo está sendo desenvolvido e aplicado em conformidade com os requerimentos do Comitê de Ética em Pesquisa da Universidade de São Paulo e da Universidade Federal de São Paulo. Também está de acordo com os fundamentos estabelecidos na Declaração de Helsinki (1964), ementa de Tóquio (1975), Veneza (1983) e Hong Kong (1989).

O protocolo se encontra aprovado e publicado na Plataforma Brasil sob o número 57602516.6.1001.0068 desde o dia 22 de setembro de 2016.

\subsubsection{Fonte Financiadora}

O projeto recebeu auxílio financeiro da FAPESP (\#2016/18798-7), para a compra das bolsas de icodextrina e de material de laboratório. 
4. RESULTADOS 


\section{RESULTADOS}

\subsection{Resultados basais}

Entre outubro de 2016 e agosto de 2020, 42 pacientes foram identificados como elegíveis e abordados para participarem do estudo. Destes, três se negaram a participar, sendo um por claustrofobia, o que o impediria de realizar a RNM cardíaca e dois por motivos pessoais. Tivemos uma perda de paciente que teve diagnóstico de câncer de bexiga uma semana após assinar o TCLE e foi a óbito.

Na alocação entre os grupos, obtivemos 20 no GI e 18 no GC. As saídas durante o estudo $(\mathrm{n}=16)$ foram similares nos dois grupos, conforme ilustra o fluxograma abaixo (Figura 7).

Figura 7 - Fluxograma do estudo.

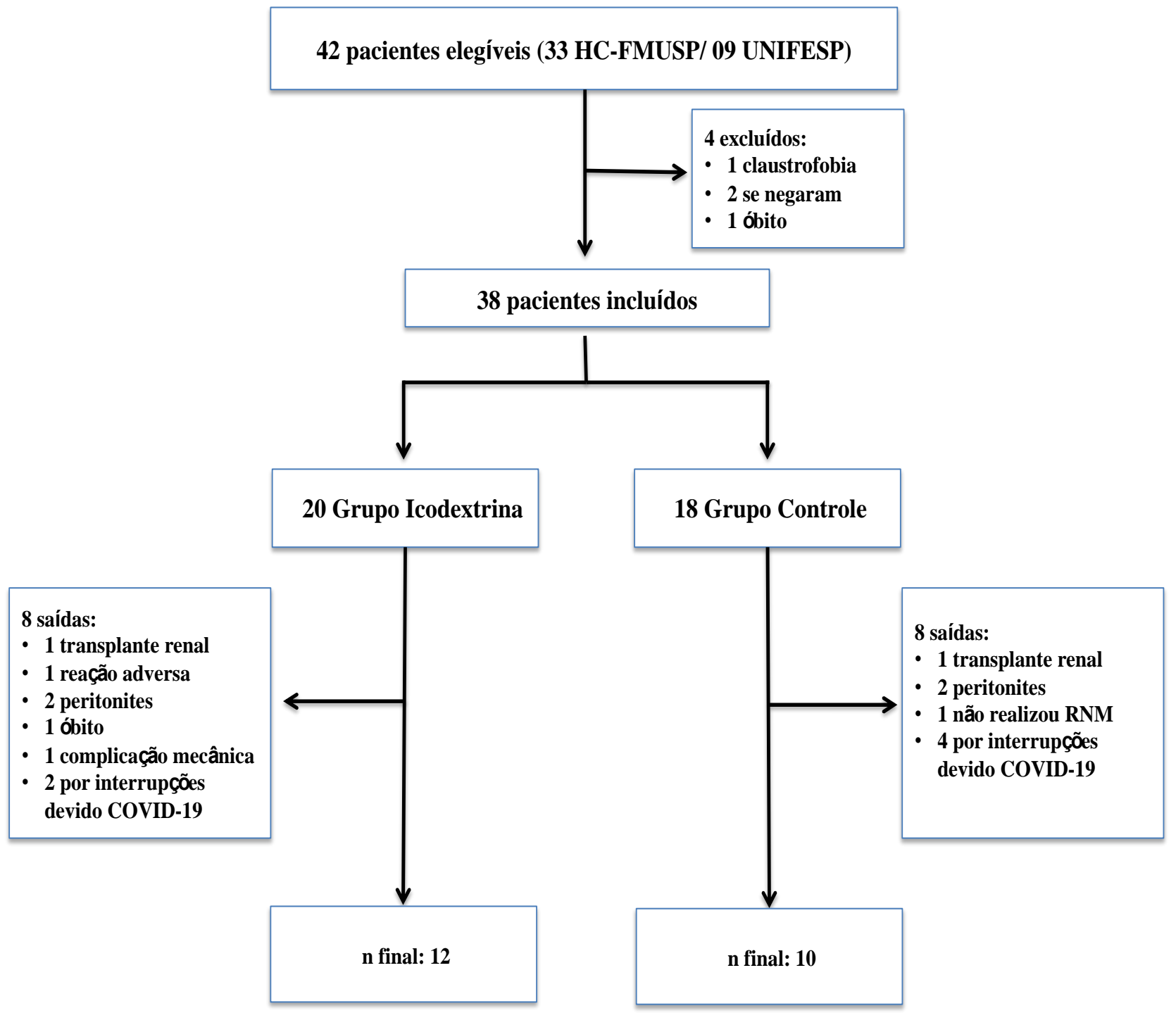


No GI um paciente transplantou, um apresentou como reação adversa um rash cutâneo palmo-plantar (Figura 8), dois pacientes tiveram peritonite com necessidade de conversão do método ( 1 bacteriana e 1 fúngica), um paciente foi a óbito devido fratura de fêmur e um apresentou complicação mecânica (edema genital, com necessidade de converter de CAPD para DPA). No GC dois pacientes interromperam o estudo por peritonite com necessidade de conversão do método, um paciente transplantou e um paciente não realizou a RNM cardíaca inicial. Devido a pandemia da COVID-19, seis pacientes não completaram o estudo por interrupção da realização de exames de imagem (2 do GI e 4 do GC).

Figura 8 - Foto de paciente com Rash palmar após uso de Icodextrina.

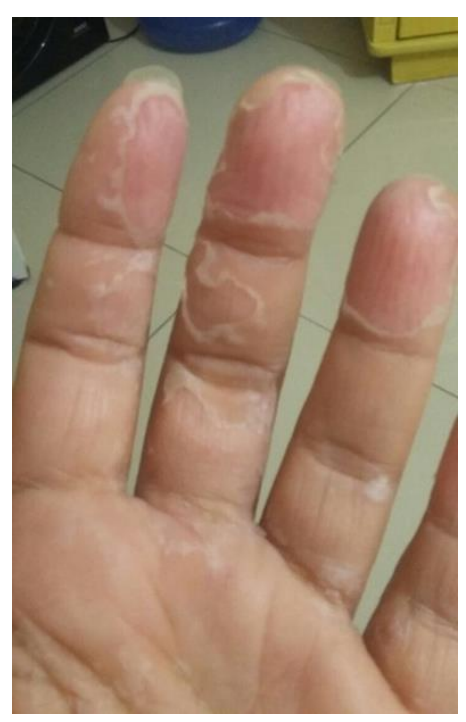

Não observamos nenhuma diferença quanto à idade, sexo, doença de base e variáveis bioquímicas ( $\mathrm{p}>0,05$ para todas as comparações) entre pacientes que não completaram e aqueles que completaram o estudo.

Na tabela 3 estão sumarizadas as características iniciais dos pacientes incluídos na análise final do estudo, de acordo com o grupo alocado. 
Tabela 3 - Características basais dos pacientes incluídos que concluíram o estudo.

\begin{tabular}{|c|c|c|c|c|}
\hline & $\begin{array}{l}\text { Total } \\
\mathrm{n}=\mathbf{2 2}\end{array}$ & $\begin{array}{c}\text { Grupo Controle } \\
\qquad \mathbf{n}=\mathbf{1 0}\end{array}$ & $\begin{array}{c}\text { Grupo Icodextrina } \\
\qquad \mathbf{n}=12\end{array}$ & $\mathbf{p}$ \\
\hline \multicolumn{5}{|l|}{ Dados Demográficos } \\
\hline Idade (anos) & $48 \pm 18$ & $51 \pm 18$ & $46 \pm 18$ & 0,533 \\
\hline Mulheres, n (\%) & $17(77,2)$ & $9(90)$ & $8(66,7)$ & 0,212 \\
\hline Tabagismo atual, n (\%) & $4(18,2)$ & $2(20)$ & $2(16,7)$ & 0,840 \\
\hline Etiologia da DRC, n (\%) & & & & 0,827 \\
\hline Hipertensão, n (\%) & $5(22,7)$ & $3(30)$ & $2(16,7)$ & \\
\hline Diabetes, n (\%) & $5(22,7)$ & $2(20)$ & $3(25)$ & \\
\hline Glomerulopatia, n (\%) & $6(27,3)$ & $3(30)$ & $3(25)$ & \\
\hline Outra, n (\%) & $4(18,2)$ & $1(10)$ & $3(25)$ & \\
\hline Desconhecida, n (\%) & $2(9,1)$ & $1(10)$ & $1(8,3)$ & \\
\hline \multicolumn{5}{|l|}{ Dados Clínicos } \\
\hline Peso (kg) & $66,6 \pm 12,2$ & $68,0 \pm 15,6$ & $65,5 \pm 9,2$ & 0,639 \\
\hline $\operatorname{IMC}\left(\mathrm{kg} / \mathrm{m}^{2}\right)$ & $25,7 \pm 5,7$ & $27,2 \pm 7,5$ & $24,5 \pm 7,5$ & 0,288 \\
\hline PA sistólica (mmHg) & $142 \pm 28$ & $144 \pm 26$ & $140 \pm 30$ & 0,753 \\
\hline PA diastólica $(\mathrm{mmHg})$ & $87 \pm 18$ & $87 \pm 18$ & $87 \pm 19$ & 0,960 \\
\hline \multicolumn{5}{|l|}{ Exames laboratoriais } \\
\hline Hemoglobina (g/dl) & $11,3 \pm 2,1$ & $11,2 \pm 1,9$ & $11,3 \pm 2,3$ & 0,933 \\
\hline Ferritina (ng/ml) & $196(109-422)$ & $347(153-431)$ & $170(62-388)$ & 0,283 \\
\hline Ureia (mg/dl) & $116 \pm 26$ & $117 \pm 33$ & $115 \pm 19$ & 0,902 \\
\hline Creatinina (mg/dl) & $10,6 \pm 4,4$ & $8,5 \pm 3,4$ & $12,4 \pm 4,6$ & $\mathbf{0 , 0 3 8}$ \\
\hline Cálcio iônico (mg/dl) & $4,79 \pm 0,37$ & $4,82 \pm 0,16$ & $4,78 \pm 0,42$ & 0,868 \\
\hline Cálcio total (mg/dl) & $9,1 \pm 0,7$ & $9,1 \pm 0,7$ & $8,8 \pm 0,6$ & $\mathbf{0 , 0 3 6}$ \\
\hline Cálcio corrigido (mg/dl) & $9,3 \pm 0,8$ & $9,8 \pm 0,7$ & $8,9 \pm 0,6$ & 0,009 \\
\hline Fósforo (mg/dl) & $5,4 \pm 1,2$ & $5,4 \pm 1,1$ & $5,4 \pm 1,4$ & 0,973 \\
\hline PTH (pg/ml) & $300(189-604)$ & $230(129,697)$ & $327(228-559)$ & 0,314 \\
\hline Vit.D (ng/ml) & $19,8 \pm 6,2$ & $19,8 \pm 6,4$ & $19,7 \pm 6,2$ & 0,995 \\
\hline FGF-23* (pg/ml) & $877(154-4522)$ & $344(104-3834)$ & $1032(175-4761)$ & 0,602 \\
\hline $\mathrm{FA}(\mathrm{U} / \mathrm{L})$ & $89(56-113)$ & $76(54,120)$ & $94(59-113)$ & 0,647 \\
\hline Glicemia (g/dL) & $104,7 \pm 44,2$ & $110,0 \pm 26,9$ & $100,2 \pm 55,6$ & 0,618 \\
\hline Colesterol (mg/dL) & $189 \pm 55$ & $202 \pm 66$ & $178 \pm 43$ & 0,307 \\
\hline
\end{tabular}




\section{Continuação}

\begin{tabular}{lcccc} 
Triglicerídeos (mg/dL) & $121(80-209)$ & $151(122,245)$ & $86(76-155)$ & 0,093 \\
Albumina (g/dL) & $3,8 \pm 0,4$ & $3,6 \pm 0,4$ & $3,9 \pm 0,4$ & 0,114 \\
BNP* (ng/ml) & $4,9(2,1-1,8)$ & $4,9(3,5-1,6)$ & $4,9(1,2-4,5)$ & 1 \\
PCR (mg/dl) & $5,3(2,1-13,0)$ & $10,7(2,1-56,7)$ & $4,2(1,7-7,6)$ & 0,167 \\
$\quad$ Medicamentos & $2(1-3)$ & $1,5(0,8-2,2)$ & $2,0(1,0-3,7)$ & 0,456 \\
N de anti-hipertensivos & $15(68,2)$ & $6(60,0)$ & $9(75,0)$ & 0,452 \\
IECA/BRA, n (\%) & $13(59,1)$ & $4(40,0)$ & $9(75,0)$ & 0,096 \\
Diurético, n $(\%)$ & $15(68,2)$ & $6(60,0)$ & $9(75,0)$ & 0,452 \\
Sevelamer, n $(\%)$ & $6(27,3)$ & $2(20,0)$ & $4(33,3)$ & 0,484 \\
Calcitriol, n $(\%)$ & $3(29,0)$ & $1(10,0)$ & $2(16,7)$ & 0,650 \\
Cinacalcete, $\mathrm{n}(\%)$ & $15(68,2)$ & $7(70,0)$ & $8(66,7)$ & 0,867 \\
Colecalciferol, n $(\%)$ & & & & \\
\hline
\end{tabular}

DRC: doença renal crônica; IMC: índice de massa corpórea; PA: pressão arterial; PTH: paratormônio; 25Vit.D: 25(OH)Vitamina D; FA: fosfatase alcalina; BNP, do inglês brain natriuretic peptide; PCR: proteína $\mathrm{C}$ reativa; IECA: inibidor de enzima conversora de angiotensina; BRA: bloqueador do receptor de angiotensina. Valores apresentados como média \pm DP, mediana (25-75) ou número e percentual. Cálcio corrigido: Ca total medido + [(4 - albumina $) \times 0.8]$. *Valores de FGF-23 e BNP devem ser multiplicados por 100 .

Os pacientes incluídos no estudo eram relativamente jovens e em sua maioria mulheres. Glomerunefrite, nefropatia diabética e nefroesclerose foram responsáveis por $80 \%$ das etiologias da doença renal. No geral, os pacientes apresentavam-se com sobrepeso e com a PA sistólica não controlada. A maioria dos pacientes fazia uso de IECA ou BRA e diuréticos. Nenhum outro parâmetro demográfico e nenhum parâmetro clínico foi diferente entre os grupos.

Nos exames laboratoriais iniciais, em relação à anemia, observamos que a maioria dos pacientes apresentou $\mathrm{Hb}>10 \mathrm{mg} / \mathrm{dL}$, com apenas 4 casos $(18,2 \%)$ com $\mathrm{Hb}$ $<10 \mathrm{mg} / \mathrm{dL}$; ferritina < $100 \mathrm{ng} / \mathrm{dL}$ foi encontrada em 5 casos $(22,7 \%)$ e apenas $1(4,5 \%)$ apresentou ferritina $>500 \mathrm{ng} / \mathrm{dL}$. No GI a creatinina sérica era mais elevada.

No que se refere ao DMO-DRC, não encontramos diferença significativa entre os pacientes alocados em cada grupo, exceto pelo cálcio total, mais elevado no GC, o que foi verificado também na análise com o cálcio corrigido pela albumina. A maioria dos pacientes estava em tratamento de hiperparatireoidismo e em uso de quelantes de fósforo. Nenhum dos pacientes apresentou fósforo sérico < 2,5 mg/dL e 8 (36,4\%) apresentaram fósforo sérico > 5,5 mg/dL. Observamos $4(18,2 \%)$ pacientes com PTH < 
150 pg/dL e $11(50 \%)$ com PTH > 300 pg/dL, sendo 6 destes (27,3\% do total) com PTH $>500$ pg/dL. Para tratamento de hiperparatireoidismo secundário, além dos quelantes de fósforo, 6 pacientes $(27,3 \%)$ estavam usando calcitriol e 3 pacientes $(29 \%)$ usavam cinacalcete. Em relação à vitamina $\mathrm{D}, 15$ pacientes $(68,2 \%)$ faziam uso de colecalciferol, sendo que quase a totalidade $(\mathrm{n}=31,96,8 \%)$ apresentava concentração $<30 \mathrm{ng} / \mathrm{ml}$, sendo 6 destes $(27,3 \%)$ com concentração $<15 \mathrm{ng} / \mathrm{ml}$.

Dados de diálise e volemia dos pacientes estão sumarizados na Tabela 4.

Tabela 4 - Dados clínicos relacionados à diálise e à volemia.

\begin{tabular}{|c|c|c|c|c|}
\hline & $\begin{array}{l}\text { Total } \\
\mathrm{n}=\mathbf{2 2}\end{array}$ & $\begin{array}{c}\text { Grupo } \\
\text { Controle } \\
\text { n= } 10\end{array}$ & $\begin{array}{c}\text { Grupo } \\
\text { Icodextrina } \\
\mathbf{n}=12\end{array}$ & $\mathbf{p}$ \\
\hline Tempo em diálise, meses & $11(6-28)$ & $20(8-46)$ & $8(4-23)$ & 0,180 \\
\hline Método de DP & & & & 0,225 \\
\hline CAPD & $8(36,4)$ & $5(50)$ & $3(25)$ & \\
\hline CCPD & $14(63,6)$ & $5(50)$ & $9(75)$ & \\
\hline Diurese, $\mathrm{ml}$ & $500(37-1025)$ & $300(37-925)$ & $550(75-1325)$ & 0,582 \\
\hline Anúria, n (\%) & $9(40,9)$ & $5(50)$ & $4(33,3)$ & 0,429 \\
\hline PET* $^{*}$ & & & & 0,414 \\
\hline Transporte rápido, $\mathrm{n}$ & 4 & 1 & 3 & \\
\hline Transporte médio, $\mathrm{n}$ & 11 & 7 & 4 & \\
\hline Transporte lento, $\mathrm{n}$ & 2 & 1 & 1 & \\
\hline P no dialisato, $\mathrm{mg}$ & $2,5 \pm 0,8$ & $2,9 \pm 0,9$ & $2,2 \pm 0,6$ & 0,053 \\
\hline Remoção P diária, mg & $252 \pm 83$ & $256(195-359)$ & $218(173-278)$ & 0,228 \\
\hline Remoção P semanal, mg & $1760 \pm 580$ & $1790(1400-2500)$ & $1530(1200-1900)$ & 0,228 \\
\hline Ultrafiltração média, ml & $830(600-1050)$ & $775(575-1100)$ & $880(625-1150)$ & 0,771 \\
\hline $\mathrm{Kt} / \mathrm{V}$ renal & $0,36(0-0,82)$ & $0,31(0-1,07)$ & $0,36(0-0,68)$ & 0,973 \\
\hline $\mathrm{Kt} / \mathrm{V}$ peritoneal & $1,68 \pm 0,42$ & $1,65 \pm 0,33$ & $1,71 \pm 0,51$ & 0,759 \\
\hline $\mathrm{Kt} / \mathrm{V}$ total & $2,22 \pm 0,79$ & $2,33 \pm 0,78$ & $2,12 \pm 0,82$ & 0,574 \\
\hline ACT, L & $34,8 \pm 8,7$ & $31,7 \pm 5,3$ & $37,6 \pm 10,4$ & 0,122 \\
\hline $\mathrm{AEC} / \mathrm{ACT}$ & $0,43 \pm 0,05$ & $0,46 \pm 0,05$ & $0,40 \pm 0,02$ & 0,002 \\
\hline
\end{tabular}

DP: diálise peritoneal; CAPD: diálise peritoneal ambulatorial contínua; CCPD: diálise peritoneal cíclica contínua; Anúria = diurese $\leq 300 \mathrm{ml}$; PET: teste de equilíbrio peritoneal, do inglês peritoneal equilibration test; P: fósforo; ACT: água corporal total; AEC: água extracelular corporal. Valores apresentados como média \pm DP, mediana (25-75) ou número e percentual. *Dados obtidos em 17 pacientes. 
Pacientes alocados no GI estavam há menos tempo em diálise, embora sem significância estatística. Não houve diferença em relação à modalidade na comparação entre os grupos, assim como no volume de diurese, volume de ultrafiltração e percentual de pacientes anúricos.

$\mathrm{O} \mathrm{Kt} / \mathrm{V}$ de ureia foi considerado adequado em ambos os grupos, atingindo o alvo de 1,7 por semana. Houve um predomínio de padrão de transporte de membrana médio, sem diferença entre os grupos, de acordo com os resultados do PET.

A concentração de $\mathrm{P}$ no dialisato foi menor no GI, porém a retirada semanal de $\mathrm{P}$ foi similar entre os grupos.

$\mathrm{Na}$ análise de dados obtidos com a bioimpedância, observamos que pacientes do GC estavam mais hipervolêmicos, de acordo com a relação AEC/ACT, maior neste grupo (Tabela 4). Doze pacientes $(57,1 \%)$ foram considerados hipervolêmicos, sendo 4 $(36,8 \%)$ no GI e $8(80 \%)$ no GC ( $p=0,044)$. A figura 9 ilustra a distribuição dos pacientes de acordo com a relação AEC/ACT em cada grupo de estudo. 
Figura 9 - Histograma da relação AEC/AIC no grupo controle (GC) e no grupo icodextrina $(\mathrm{GI})$.
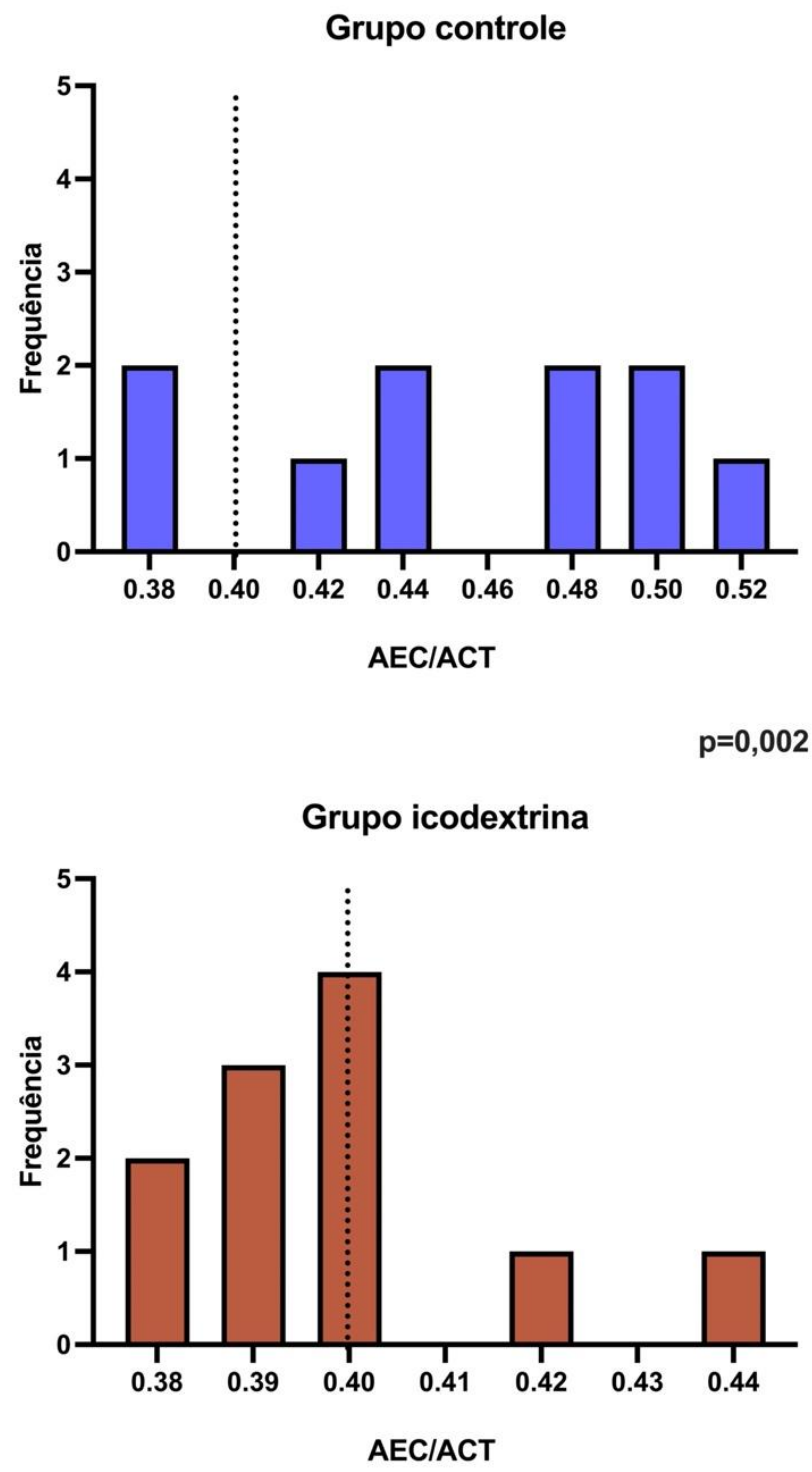

ACT: água corporal total; AEC: água extracelular corporal. Linha pontilhada indica limite da normalidade.

No momento da inclusão no estudo, conforme a tabela 5 , dados obtidos com a RNM cardíaca revelaram que o volume diastólico final de ventrículo esquerdo indexado pela superfície corpórea (IVDFVE), o volume sistólico final de ventrículo esquerdo indexado pela superfície corpórea (IVSFVE) e o IMVE foram maiores no GI e que a fração de ejeção (FE) foi menor neste grupo. No GI, 5 dos 12 pacientes apresentavam 
IVSFVE e IVDFVE acima dos valores considerados normais, o que refletiu consequentemente em menor FE. Não observamos tais diferenças no GC.

Tabela 5 - Dados basais da RNM.

\begin{tabular}{lcccccc}
\hline & $\begin{array}{c}\text { Total } \\
\mathbf{n = 2 2}\end{array}$ & $\begin{array}{c}\text { Grupo } \\
\text { Controle } \\
\mathbf{n = 1 0}\end{array}$ & $\begin{array}{c}\text { Grupo } \\
\text { Icodextrina } \\
\mathbf{n}=\mathbf{1 2}\end{array}$ & $\mathbf{p}$ & $\begin{array}{c}\text { Referência* } \\
\text { Homem Mulher }\end{array}$ \\
\hline IVAE, $\mathrm{ml} / \mathrm{m}^{2}$ & $50 \pm 21,6$ & $43,7 \pm 17,3$ & $55,1 \pm 24,2$ & 0,228 & $16-53$ & $15-53$ \\
IVDFVD, $\mathrm{ml} / \mathrm{m}^{2}$ & $76,3 \pm 21,7$ & $66,3 \pm 20,8$ & $83,8 \pm 19,7$ & 0,066 & $68-125$ & $49-10$ \\
IVSFVD, ml/m² & $26,9 \pm 9,6$ & $23,5 \pm 9,1$ & $29,5 \pm 9,4$ & 0,160 & $25-63$ & $17-46$ \\
IVDFVE, $\mathrm{ml} / \mathrm{m}^{2}$ & $86,4 \pm 33,469,8 \pm 17,0$ & $98,9 \pm 37,7$ & $\mathbf{0 , 0 4 5}$ & $60-110$ & $54-94$ \\
IVSFVE, $\mathrm{ml} / \mathrm{m}^{2}$ & $37,7 \pm 21,325,8 \pm 12,3$ & $36,7 \pm 22,6$ & $\mathbf{0 , 0 2 2}$ & $21-49$ & $19-40$ \\
IMVE, g/m & $79,3 \pm 25,866,2 \pm 13,5$ & $89,1 \pm 28,9$ & $\mathbf{0 , 0 4 1}$ & $35-70$ & $29-55$ \\
Parede lateral, mm & $8,0 \pm 1,7$ & $7,7 \pm 1,6$ & $8,1 \pm 1,4$ & 0,392 & $<12$ & $<12$ \\
Septo, mm & $10,5 \pm 2,3$ & $9,8 \pm 2,2$ & $11,0 \pm 2,2$ & 0,200 & $<12$ & $<12$ \\
FE, \% & $58,4 \pm 9,6$ & $64,2 \pm 10,8$ & $54 \pm 5,9$ & $\mathbf{0 , 0 1 2}$ & $48-69$ & $51-70$ \\
\hline
\end{tabular}

IVAE: índice de volume de átrio esquerdo máximo; IVDFVD: volume diastólico final de ventrículo direito indexado pelasuperfície corpórea; IVSFVD: volume sistólico final de ventrículo direito indexado pela superfície corpórea; IVDFVE: volume diastólico final de ventrículo esquerdo indexado pela superfície corpórea; IVSFVE: volume sistólico final de ventrículo esquerdo indexado pela superfície corpórea; IMVE: índice de massa de ventrículo esquerdo; FE: fração de ejeção. Valores apresentados como média \pm DP, mediana (25-75) ou número e percentual. *Valores de referência considerados acima do valor normal obtidos de Petersen et. al (74).

Observamos HVE em 17 pacientes (77,3\%), sendo 7 do GC e 10 do GI $(p=0,748)$. Em uma paciente do GC não foi possível medir o IMVE por dificuldade técnica (paciente se movimentou durante a realização das imagens).

O IMVE se correlacionou inversamente com o hematócrito $(r=-0,495, p=0,022)$ e diretamente com a creatinina $(r=0,823, p=0,006)$, a PA diastólica $(r=0,832, p=0,005)$ e a PA sistólica $(r=0,754, p=0,019)$, conforme ilustra a Figura 10 , com tendência a se correlacionar com o BNP $(r=0,755, \mathrm{p}=0,050)$. 
Figura 10 - Correlação entre índice de massa de ventrículo esquerdo (IMVE) e variáveis independentes no momento basal.

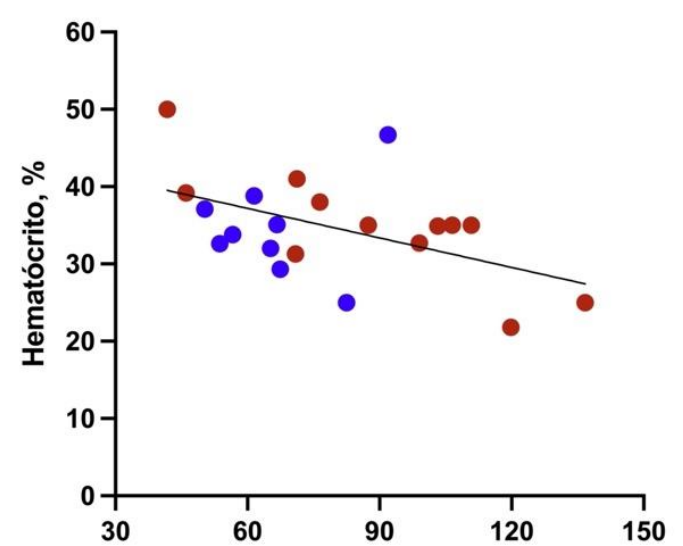

IMVE, $g / m^{2}$

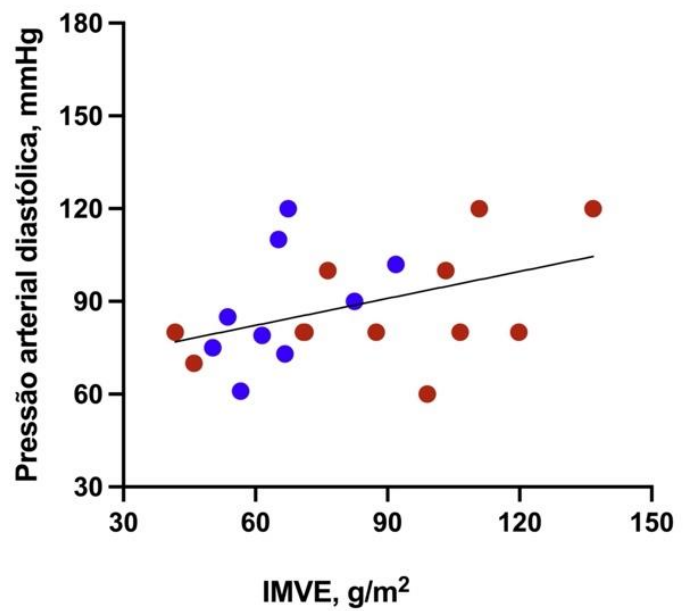

- Grupo controle

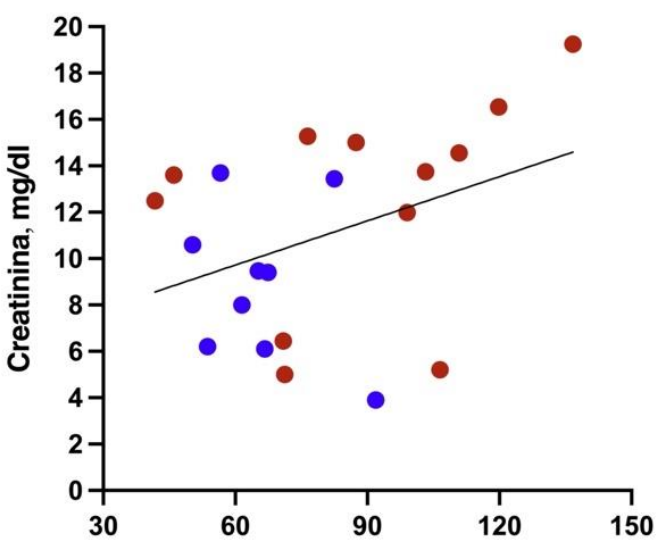

IMVE, $g / \mathrm{m}^{2}$

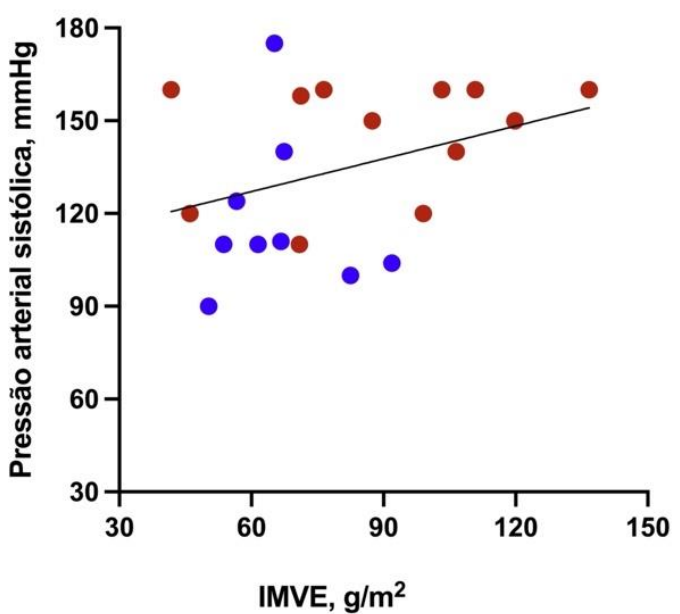

- Grupo icodextrina

IMVE: índice de massa de ventrículo esquerdo

\subsection{Resultados do período de acompanhamento}

Dos 17 pacientes que apresentavam HVE no início do estudo, 2 obtiveram melhora e 15 permaneceram com hipertrofia. Entre os pacientes sem HVE no momento da inclusão no estudo ( $\mathrm{n}=4), 2$ desenvolveram HVE e 2 mantiveram o IMVE (Figura 11). 
Figura 11 - Fluxograma da evolução dos pacientes em relação à hipertrofia do ventrículo esquerdo (HVE).
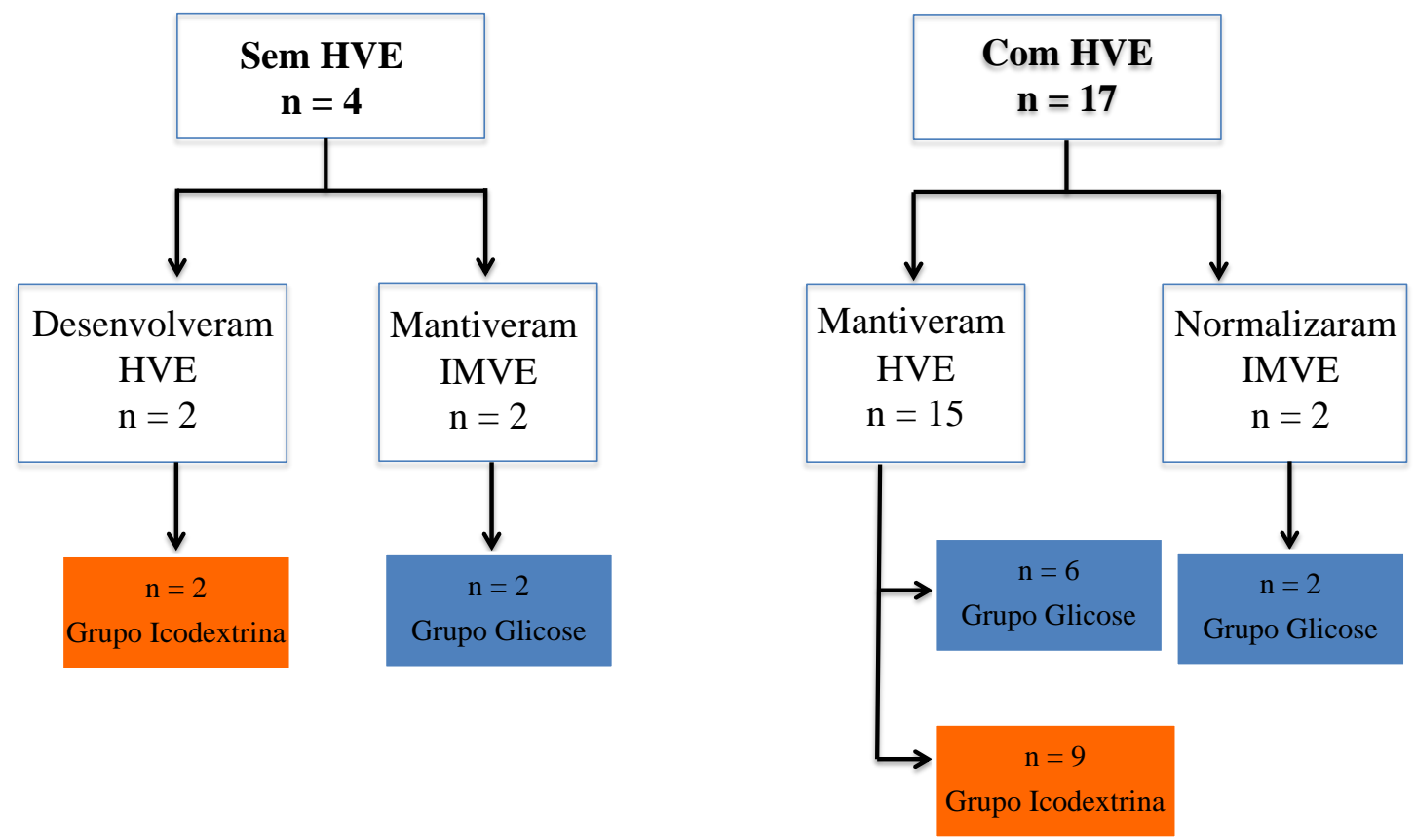

HVE: hipertrofia de ventrículo esquerdo; IMVE: índice de massa de ventrículo esquerdo

Considerando somente pacientes com hipertrofia no momento basal $(\mathrm{n}=17)$, não houve diferença estatística entre os grupos glicose e icodextrina quanto ao padrão de melhora do IMVE $v s$. manutenção ou piora da hipertrofia $(2 / 0 v s$. 6/9 nos grupos glicose/icodextrina, respectivamente, $\mathrm{p}=0,867$ ).

A Tabela 6 resume os resultados obtidos durante o período de acompanhamento do estudo, em relação à volemia, dados clínicos e exames laboratoriais. 
Tabela 6 - Análise obtida com ANOVA multifatorial de medidas repetidas.

\begin{tabular}{|c|c|c|c|c|c|c|c|}
\hline & \multicolumn{2}{|c|}{$\begin{array}{c}\text { Grupo Controle } \\
n=10\end{array}$} & \multicolumn{2}{|c|}{$\begin{array}{l}\text { Grupo Icodextrina } \\
\qquad n=12\end{array}$} & \multirow[t]{2}{*}{$\begin{array}{l}\text { Pré vs. } \\
\text { pós }\end{array}$} & \multirow[t]{2}{*}{$\begin{array}{c}\text { GC } \\
\text { vs. GI }\end{array}$} & \multirow[t]{2}{*}{ Interação } \\
\hline & Basal & Pós & Basal & Pós & & & \\
\hline \multicolumn{8}{|c|}{ Volemia, dados clínicos e da diálise } \\
\hline Peso, $\mathrm{kg}$ & $68,0 \pm 15,6$ & $69,3 \pm 13,3$ & $65,5 \pm 9,2$ & $66,2 \pm 10,0$ & 0,406 & 0,577 & 0,798 \\
\hline $\mathrm{AEC}, \mathrm{L}$ & $14,4 \pm 3,1$ & $14,5 \pm 3,3$ & $14,5 \pm 4,2$ & $14,7 \pm 3,9$ & 0,753 & 0,929 & 0,753 \\
\hline $\mathrm{AEC} / \mathrm{ACT}$ & $0,46 \pm 0,05$ & $0,46 \pm 0,05$ & $0,39 \pm 0,02$ & $0,40 \pm 0,12$ & 0,220 & 0,002 & 0,988 \\
\hline Diurese, $\mathrm{ml}$ & $500 \pm 578$ & $368 \pm 469$ & $742 \pm 756$ & $375 \pm 558$ & 0,006 & 0,619 & 0,166 \\
\hline PAS, mmHg & $144 \pm 26$ & $121 \pm 26$ & $140 \pm 30$ & $146 \pm 19$ & 0,176 & $\mathbf{0 , 0 3 0}$ & 0,277 \\
\hline $\mathrm{PAD}, \mathrm{mmHg}$ & $87 \pm 18$ & $75 \pm 16$ & $87 \pm 19$ & $86 \pm 18$ & 0,119 & 0,393 & 0,185 \\
\hline $\mathrm{UF}, \mathrm{ml}$ & $875 \pm 404$ & $903 \pm 426$ & $926 \pm 459$ & $935 \pm 287$ & 0,054 & 0,312 & 0,202 \\
\hline $\mathrm{BNP}^{*}, \mathrm{ng} / \mathrm{ml}$ & $8,9 \pm 6,9$ & $9,3 \pm 8,0$ & $17,9 \pm 2,5$ & $22,1 \pm 23,7$ & 0,773 & 0,065 & 0,804 \\
\hline P no dialisato, mg & $2,9 \pm 0,9$ & $2,5 \pm 0,6$ & $2,2 \pm 0,6$ & $2,6 \pm 0,8$ & 0,997 & 0,292 & 0,134 \\
\hline Remoção P, mg/dia & $286 \pm 100$ & $248 \pm 84$ & $213 \pm 55$ & $289 \pm 153$ & 0,569 & 0,654 & 0,095 \\
\hline Remoção P, mg/sem & $2003 \pm 703$ & $1735 \pm 589$ & $1492 \pm 388$ & $2021 \pm 1071$ & 0,569 & 0,654 & 0,095 \\
\hline $\mathrm{Kt} / \mathrm{V}$ renal & $0,68 \pm 0,94$ & $0,34 \pm 0,59$ & $0,47 \pm 0,51$ & $0,16 \pm 0,21$ & 0,012 & 0,480 & 0,898 \\
\hline $\mathrm{Kt} / \mathrm{V}$ total & $2,38 \pm 0,81$ & $2,19 \pm 0,44$ & $2,29 \pm 1,02$ & $1,71 \pm 0,56$ & 0,180 & 0,315 & 0,481 \\
\hline \multicolumn{8}{|c|}{ Função renal, marcadores inflamatórios e metabólico } \\
\hline Ureia, mg/dl & $117 \pm 33$ & $95 \pm 18$ & $115 \pm 19$ & $113 \pm 33$ & 0,054 & 0,413 & 0,113 \\
\hline Creatinina, $\mathrm{mg} / \mathrm{dl}$ & $8,5 \pm 3,4$ & $9,0 \pm 3,6$ & $12,4 \pm 4,6$ & $10,8 \pm 3,2$ & 0,273 & 0,077 & 0,056 \\
\hline $\mathrm{PCR}, \mathrm{mg} / \mathrm{dl}$ & $22 \pm 26$ & $5 \pm 5$ & $8 \pm 9$ & $13 \pm 16$ & 0,616 & 0,316 & 0,044 \\
\hline Ferritina, ng/ml & $297 \pm 184$ & $319 \pm 282$ & $221 \pm 170$ & $211 \pm 184$ & 0,889 & 0,265 & 0,705 \\
\hline Albumina, $\mathrm{g} / \mathrm{dl}$ & $3,6 \pm 0,4$ & $4,0 \pm 0,5$ & $3,9 \pm 0,4$ & $3,5 \pm 0,7$ & 0,918 & 0,602 & 0,012 \\
\hline Colesterol, mg/dL & $202 \pm 66$ & $198 \pm 70$ & $178 \pm 43$ & $156 \pm 34$ & 0,239 & 0,118 & 0,407 \\
\hline $\mathrm{TG}, \mathrm{mg} / \mathrm{dL}$ & $188 \pm 109$ & $193 \pm 106$ & $156 \pm 174$ & $115 \pm 73$ & 0,470 & 0,252 & 0,363 \\
\hline Glicemia, g/dL & $110,0 \pm 26,9$ & $100,5 \pm 27,5$ & $100,2 \pm 55,6$ & $102,7 \pm 37,0$ & 0,783 & 0,745 & 0,638 \\
\hline Hemoglobina, g/dl & $11,2 \pm 1,9$ & $11,2 \pm 1,9$ & $11,3 \pm 2,3$ & $10,9 \pm 1,4$ & 0,600 & 0,865 & 0,582 \\
\hline \multicolumn{8}{|c|}{ Metabolismo mineral e ósseo } \\
\hline Cai, mg/dl & $4,79 \pm 0,19$ & $4,84 \pm 0,23$ & $4,78 \pm 0,42$ & $4,79 \pm 0,39$ & 0,745 & 0,904 & 0,869 \\
\hline $\mathrm{CaT}, \mathrm{mg} / \mathrm{dl}$ & $9,5 \pm 0,7$ & $10,0 \pm 1,0$ & $8,8 \pm 0,6$ & $9,2 \pm 0,7$ & 0,156 & 0,005 & 0,066 \\
\hline Ca corrigido & $9,8 \pm 0,7$ & $10,1 \pm 1,0$ & $8,9 \pm 0,6$ & $8,7 \pm 0,7$ & 0,176 & 0,010 & 0,912 \\
\hline
\end{tabular}




\section{Continuação}

Fósforo, $\mathrm{mg} / \mathrm{dl}$

PTH, pg/ml

Vit.D, $\mathrm{ng} / \mathrm{ml}$

FA, U/L

$5,4 \pm 1,1$
$418 \pm 325$

$5,1 \pm 1,3$

$5,4 \pm 1,4$

$5,3 \pm 0,8$

$0,422 \quad 0,793$

0,505

FGF-23*,pg/ml

$333 \pm 207$

$472 \pm 343$

$614 \pm 504$

$0,698 \quad 0,269$

0,133

$19,8 \pm 6,4 \quad 23,2 \pm 8,9$

$19,7 \pm 6,2$

$26,2 \pm 10,7$

$\mathbf{0 , 0 1 1} 0,632$

0,392

$89,4 \pm 40,2 \quad 85,9 \pm 23,7$

$98,6 \pm 45,2$

$110,4 \pm 67,2$

$0,635 \quad 0,376$

0,385

$1,60 \pm 2,10 \quad 6,12 \pm 15,53$

$1,93 \pm 2,15 \quad 6,28 \pm 14,61$

$0,140 \quad 0,951$

0,929

AEC: água extracelular corporal; ACT: água corporal total; PAS: pressão arterial sistólica; PAD: pressão arterial diastólica; UF: ultrafiltração; P, fósforo; sem., semana; PCR: proteína C reativa; BNP, do inglês brain natriuretic peptide; TG: triglicerídeos; Cai: cálcio iônico; CaT: cálcio total; PTH: paratormônio; Vit.D: $25(\mathrm{OH})$ Vitamina D; FA: fosfatase alcalina. Valores apresentados como média \pm DP, mediana (2575) ou número e percentual. *Valores de FGF-23 e BNP devem ser multiplicados por 100. Cálcio corrigido: Ca total medido + [(4 - albumina $) \times 0.8]$.

$\mathrm{Na}$ análise de dados clínicos, de volemia e diálise, observamos uma redução da diurese e do Kt/V renal ao longo do tempo, de forma similar entre os grupos. Quanto à relação $\mathrm{AEC} / \mathrm{ACT}$, notamos um comportamento diferente entre os grupos, com estabilidade no GC (mantendo valores altos) e aumento no GI. A PA sistólica melhorou no GC e aumentou no GI. Houve uma tendência ao aumento da remoção de fósforo no GI.

Em relação aos exames laboratoriais, não observamos nenhuma mudança ao longo do tempo, exceto por uma tendência à redução da ureia. Interação significativa foi identificada no comportamento da PCR, que reduziu no GC e aumentou no GI, enquanto a albumina aumentou no GC e reduziu no GI.

$\mathrm{Na}$ análise dos exames relacionados ao DMO, observamos um aumento da vitamina D ao longo do tempo, de forma similar em ambos os grupos. Diferença significativa entre os grupos controle e icodextrina foi identificada no comportamento do cálcio total, que aumento mais no GC do que no GI. O Ca corrigido confirmou o aumento no GI.

Dados da RNM cardíaca (Tabela 7 e Figura 12) não identificaram mudança significativa comparando momento basal e 6 meses de estudo. 
Tabela 7 - Análise comparativa basal e após 6 meses de seguimento da RNM, por grupo de estudo e entre os grupos.

\begin{tabular}{|c|c|c|c|c|c|c|c|}
\hline & \multicolumn{2}{|c|}{$\begin{array}{c}\text { Grupo Controle } \\
n=10\end{array}$} & \multicolumn{2}{|c|}{$\begin{array}{c}\text { Grupo Icodextrina } \\
\qquad n=12\end{array}$} & \multicolumn{3}{|c|}{$\begin{array}{l}\text { Pré vs. GC Interação } \\
\text { pós vs. GI }\end{array}$} \\
\hline & Basal & Pós & Basal & Pós & & & \\
\hline \multicolumn{8}{|c|}{ RNM cardíaca } \\
\hline $\mathrm{FE}, \%$ & $64,2 \pm 10,8$ & $66,5 \pm 7,2$ & $54,0 \pm 5,9$ & $52,1 \pm 10,9$ & 0,924 & 0,001 & 0,384 \\
\hline IVAE, $\mathrm{ml} / \mathrm{m}^{2}$ & $43,2 \pm 18,2$ & $40,5 \pm 13,7$ & $55,1 \pm 24,2$ & $52,4 \pm 19,3$ & 0,618 & 0,099 & 0,993 \\
\hline IVDFVD, $\mathrm{ml} / \mathrm{m}^{2}$ & $66,3 \pm 20,8$ & $68,2 \pm 20,0$ & $83,7 \pm 20,0$ & $83,1 \pm 17,8$ & 0,877 & 0,046 & 0,757 \\
\hline IVSFVD, $\mathrm{ml} / \mathrm{m}^{2}$ & $23,5 \pm 9,1$ & $24,9 \pm 10,5$ & $29,5 \pm 9,4$ & $36,5 \pm 17,3$ & 0,179 & 0,068 & 0,359 \\
\hline IVDFVE, $\mathrm{ml} / \mathrm{m}^{2}$ & $69,8 \pm 17,0$ & $74,2 \pm 16,4$ & $98,9 \pm 37,4$ & $100,4 \pm 27,7$ & 0,604 & 0,018 & 0,803 \\
\hline IVSFVE, $\mathrm{ml} / \mathrm{m}^{2}$ & $25,8 \pm 12,3$ & $25,2 \pm 8,6$ & $46,7 \pm 22,6$ & $59,3 \pm 20,7$ & 0,712 & 0,003 & 0,596 \\
\hline IMVE, $\mathrm{g} / \mathrm{m}^{2}$ & $66,2 \pm 13,5$ & $62,0 \pm 14,9$ & $89,1 \pm 28,9$ & $88,1 \pm 28,9$ & 0,544 & $\mathbf{0 , 0 2 0}$ & 0,711 \\
\hline Parede, mm & $7,7 \pm 1,6$ & $8,2 \pm 1,6$ & $8,3 \pm 1,8$ & $8,6 \pm 3,6$ & 0,518 & 0,567 & 0,806 \\
\hline Septo, mm & $9,8 \pm 2,2$ & $9,8 \pm 2,6$ & $11,1 \pm 2,2$ & $11,2 \pm 3,0$ & 0,924 & 0,215 & 0,924 \\
\hline
\end{tabular}

FE: fração de ejeção; IVAE: índice de volume de átrio esquerdo indexado; IVDFVD: volume diastólico final de ventrículo direito indexado pela superfície corpórea; IVSFVD: volume sistólico final de ventrículo direito indexado pela superfície corpórea; IVDFVE: volume diastólico final de ventrículo esquerdo indexado pela superfície corpórea; IVSFVE: volume sistólico final de ventrículo esquerdo indexado pela superfície corpórea; IMVE: índice de massade ventrículo esquerdo

Figura 12 - Comportamento em 6 meses das variáveis relacionadas à ressonância nuclear magnética do coração de acordo com o grupo de estudo.

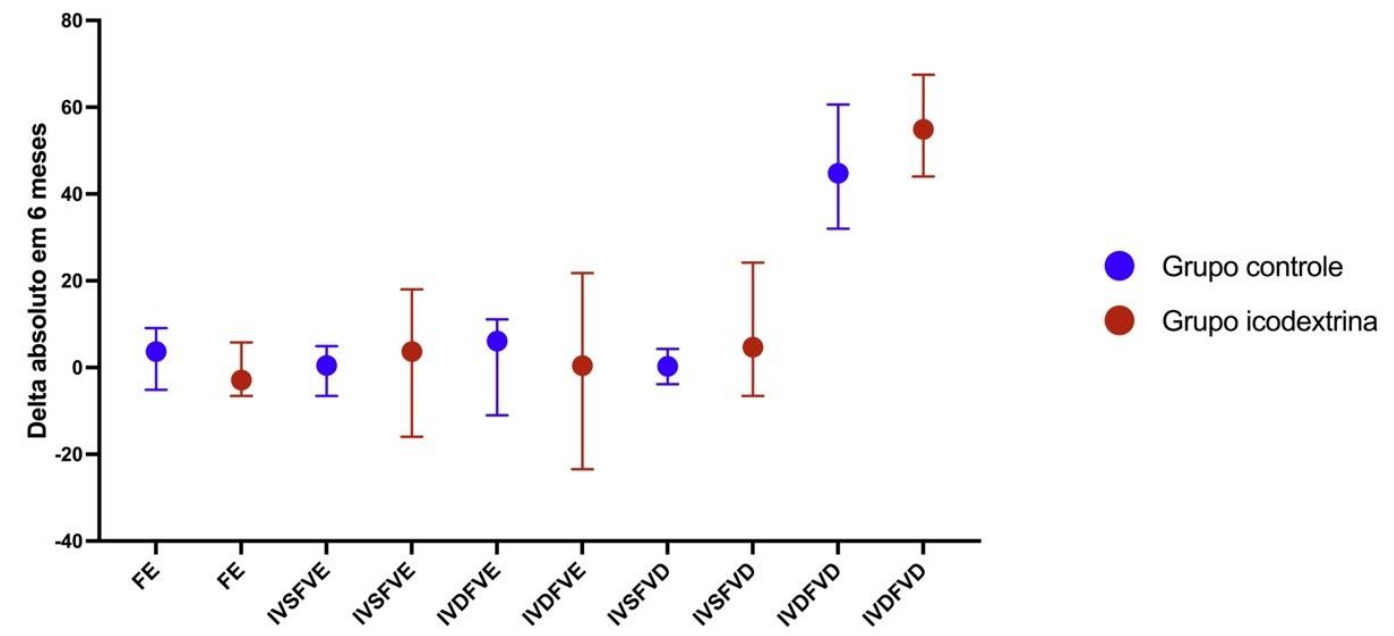

Delta: variação absoluta do parâmetro em 6 meses. FE: fração de ejeção; IVSFVE: volume sistólico final de ventrículo esquerdo indexado pela superfície corpórea; IVDFVE: volume diastólico final de ventrículo esquerdo indexado pela superfície corpórea; IVSFVD: volume sistólico final de ventrículo direito indexado pela superfície corpórea; IVDFVD: volume diastólico final de ventrículo direito indexado pela superfície corpórea. Símbolos e linhas representam mediana e percentis 25 e 75. 
Na comparação entre os grupos, observamos diferença no comportamento da FE e do IVDFVD, que aumentaram no GC e reduziram no GI. Da mesma forma, o comportamento dos índices IVDFVE, IVSFVE e IMVE também diferiram entre o GC e o GI, porém nenhuma interação foi identificada.

O delta do IMVE (valor final subtraído do valor inicial) foi de $0(-13,3 / 13,2) \mathrm{g} / \mathrm{m}^{2}$, variando de -36 a $39 \mathrm{~g} / \mathrm{m}^{2}$, analisando o grupo como um todo. Não houve diferença no delta do IMVE entre os grupos $\left[-3,9(-10,7 / 2,2)\right.$ vs. $5,2(-26,8 / 16,8) \mathrm{g} / \mathrm{m}^{2}$, nos grupos glicose e icodextrina, respectivamente, $\mathrm{p}=0,651]$.

O delta do IMVE (valor final subtraído do valor basal) se correlacionou com a PA diastólica $(\mathrm{r}=0,482, \mathrm{p}=0,027)$, com a creatinina $(\mathrm{r}=0,534, \mathrm{p}=0,013)$, com a PCR ( $\mathrm{r}=$ $0,589, \mathrm{p}=0,010)$ e com o hematócrito $(\mathrm{r}=0,459, \mathrm{p}=0,036)$ basais, assim como com o delta do BNP $(r=0,566, p=0,044)$. Houve uma tendência de correlação com o delta da relação AEC/ACT (r=0,419, p=0,074) e com o delta de remoção semanal de P ( $\mathrm{r}=-0,426$, $\mathrm{p}=0,054)$. A figura 13 ilustra estas correlações. 
Figura 13 - Correlações entre o delta do índice de massa de ventrículo esquerdo (IMVE) e variáveis independentes durante o seguimento.
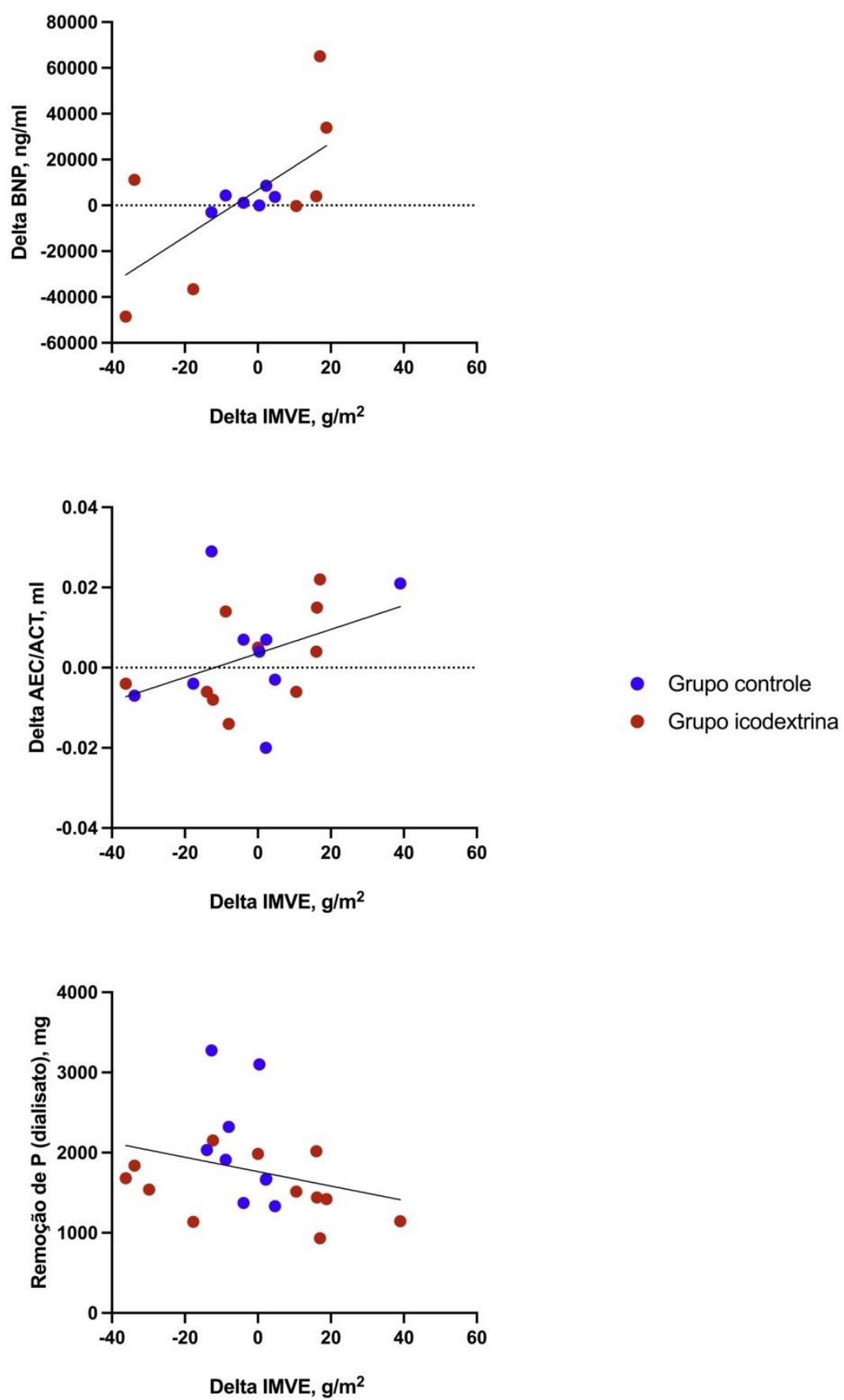

IMVE: índice de massa de ventrículo esquerdo; BNP, do inglês brain natriuretic peptide; AEC: água extracelular corporal; ACT, água corporal total; P: fósforo 
Realizamos análise de regressão linear múltipla com o delta do IMVE como variável dependente e variáveis independentes identificadas em análise univariada (PA diastólica, creatinina, PCR, hematócrito, delta de BNP, delta da relação AEC/ACT e remoção semanal de P), além do grupo de estudo. Inicialmente cada variável foi testada em modelo com o grupo de estudo e somente o delta de BNP permaneceu significante. Por serem variáveis colineares o delta de BNP e o delta da relação AEC/ACT foram testados em modelos separados. O delta do BNP se confirmou como variável independente associada ao delta do $\operatorname{IMVE}(\mathrm{p}=0,012)$, sendo o $\mathrm{R}$ do modelo 0,669 , o $\mathrm{R}^{2}$ do modelo 0,447 e o $\mathrm{R}^{2}$ ajustado do modelo 0,397 . 
5. DISCUSSÃO 


\section{DISCUSSÃO}

No presente estudo avaliamos alterações no IMVE por meio de RNM comparando solução de icodextrina vs. solução de glicose, por um período de 6 meses, em paciente em CAPD ou CCPD. Não observamos superioridade da solução de icodextrina em comparação à solução de glicose no comportamento do IMVE. Não houve correlação do IMVE com marcadores do DMO-DRC e com a extração de $\mathrm{P}$ pelo dialisato.

Havíamos calculado uma amostra de 9 pacientes em cada grupo, número que conseguimos atingir (12 no GI e 10 no GC). Apesar de ser uma amostra pequena, tivemos durante o estudo 16 saídas $(42,1 \%)$ por diversos motivos, sendo o principal deles peritonites, o que reflete a realidade dos programas de DP (73). No BRAZPD (74) 33\% de saídas do programa foram por peritonite. Além de reação adversa, peritonites, óbito, transplante renal e problemas mecânicos, devemos ressaltar que durante o período tivemos o imprevisto de saídas do estudo devido à pandemia da COVID-19. Saídas do estudo por COVID-19 corresponderam a 15,8\% do total (6 pacientes). Os estudos que compararam os efeitos da ICO na massa de ventrículo esquerdo também possuem um número limitado de pacientes, exceto um multicêntrico onde foram realizadas análises de HVE em 82 pacientes (69). No estudo citado o desfecho primário era o perfil metabólico e a massa de ventrículo esquerdo foi avaliada em um subgrupo de pacientes (82 de um total de 127). Os autores observaram um aumento não significativo na massa de ventrículo esquerdo após 6 meses de intervenção (de $128 \pm 37$ para $132 \pm 60$ g no grupo com glicose $v s .128 \pm 45$ para $124 \pm 39 \mathrm{~g}$ no grupo sem glicose, $\mathrm{p}=0,83$ ). Diferente do nosso estudo, o estudo citado não usou massa indexada e a icodextrina não foi a única solução testada. Desta forma, a comparação de resultados fica prejudicada.

Na primeira paciente incluída no estudo, nos deparamos com uma reação adversa após o uso de ICO. Apenas 14 dias após o uso da solução a paciente compareceu ao serviço de DP com rash cutâneo descamativo em palma das mãos e pés que melhoraram após cessar o uso da ICO. Essa reação é vista em até $10 \%$ dos pacientes que iniciam o uso da ICO e possui etiologia indeterminada $(75,76)$. Nenhum outro caso foi observado no decorrer do estudo.

Em relação ao perfil demográfico da amostra, obtivemos dados compatíveis com a literatura (74) como distribuição por sexo, IMC e exames laboratoriais. Incluímos uma porcentagem um pouco maior de pacientes com glomerulonefrites como etiologia da DRC ao invés de DM. Isso provavelmente ocorreu pelo fato de tanto o HC-FMUSP 
quanto a UNIFESP serem dois centros de referência no tratamento de glomerulopatias, que influenciou também na média de idade, que diferiu da literatura (74), sendo somente $5(11,9 \%)$ idosos incluídos no estudo.

Incluímos mais pacientes em CCPD e em CAPD por uma questão do desenho do estudo. $\mathrm{Na}$ atualidade, a maioria dos pacientes em DP fazem DPA (77), fator limitante para inclusão de pacientes no nosso estudo, pelo fato da icodextrina ser usada em tempo de permanência prolongado, o que dificultou a inclusão de mais pacientes na nossa amostra. O perfil da membrana de acordo com o teste de equilíbrio peritoneal da maioria dos pacientes foi o mais encontrado também na literatura, transporte médio (78-80).

A principal causa de mortalidade nos pacientes em diálise é a cardiovascular, sendo a HVE um importante fator de risco de mortalidade em pacientes em DP. Nos nossos dados iniciais, 77,3\% dos pacientes possuíam HVE. Todos os homens incluídos no estudo apresentavam HVE e entre aqueles com DM a maioria também apresentava (5 dos 6 pacientes). Dados similares foram encontrados em um estudo observacional (81) e no estudo EuroBCM (82). A alta prevalência de HVE na nossa amostra pode ser explicada pela presença de fatores de risco tradicionais como hipertensão arterial, DM, dislipidemia e tabagismo. Outros fatores de risco como HAS e tabagismo foram $22,7 \%$ e $18,2 \%$, respectivamente.

Nos dados clínicos, destaca-se o fato da PA não estar controlada adequadamente, apesar do uso de mais de duas classes de anti-hipertensivos. Dislipidemia também foi um achado frequente sendo que $59 \%$ dos pacientes apresentavam-se com colesterol alterado (colT > $170 \mathrm{mg} / \mathrm{dl}$ e TG > $100 \mathrm{mg} / \mathrm{dl})$. Apesar de termos uma amostra com mais pacientes jovens do que o esperado, o que talvez contribuiria para um percentual menor de paciente com HVE, acreditamos que os fatores de risco tradicionais citados podem ter contribuído para a alta prevalência de HVE na amostra.

Nos pacientes com DRC os fatores de risco não tradicionais como anemia, hipoalbuminemia e distúrbios do DMO-DRC acrescentam risco cardiovascular, principalmente nos pacientes em diálise. No presente estudo, no momento basal, os pacientes apresentavam-se com hemoglobina adequada, conforme recomendado pelas diretrizes do $K D I G O(83)$ e somente 4 apresentavam albumina $<3,5 \mathrm{~g} / \mathrm{dl}$.

Quanto ao DMO-DRC, nosso estudo evidenciou que 13 pacientes (59\%) eram portadores de hiperpartireoidismo, a maioria em tratamento clínico com análogo de vitamina $\mathrm{D}$ e/ou cinacalcete, ou apresentavam intratabilidade clínica devido 
hiperfosfatemia. Apesar da correlação bem estabelecida entre FGF-23 e HVE na patogenia da doença cardíaca em DRC, não confirmamos este dado. Isso pode ser pelo fato de praticamente todos os pacientes serem portadores de HVE, o que dificulta o achado de uma correlação.

Volemia é um dos parâmetros clínicos na adequação da diálise. Portanto, a análise da sobrecarga hídrica dos pacientes em DP deve ser um parâmetro clínicos revisado rotineiramente. Na prática clínica não dispomos de ferramentas eficazes para estimar a volemia de maneira precisa. Nas consultas, avaliamos a volemia indiretamente por sinais clínicos tais como edema de membros inferiores, pressão arterial, ausculta pulmonar e peso. Podemos ainda utilizar ultrassonografia de veia cava inferior, que avalia apenas volume intravascular e é influenciada por disfunção diastólica; exames laboratoriais como o BNP podem também ser utilizados, embora este marcador seja influenciado por alterações cardíacas e na presença de DRC, uma vez que sua eliminação é renal (84). Dispomos também de bioimpedância, que se demonstrou uma ferramenta útil para controle de volemia em pacientes em DP (85). A relação AEC/ACT evidenciada pela bioimpedância pode ser considerada um fator determinante na massa de ventrículo esquerdo, sendo que o controle volêmico adequado e controle da pressão arterial estão associados a melhores condições cardíacas (86).

Optamos por adicionar o uso da bioimpedância como ferramenta na avaliação de volemia no momento inicial e no fim do estudo. A maioria dos pacientes do presente estudo (59\%) apesentavam-se com relação AEC/ACT $\geq 0,4$ no momento da inclusão, sendo 8 no GC e 5 no GI, dado que se repetiu após 6 meses, com 8 pacientes no GC e 4 no GI considerados hipervolêmicos. Quando comparamos os grupos no momento inicial, houve uma maior inclusão de pacientes hipervolêmicos no GC em comparação ao GI. Essa diferença não deve ter impactado nos dados iniciais de IMVE e fração de ejeção, que eram piores no GI. Outros fatores, apesar de não terem se revelado com diferença significativa entre os grupos, podem ter contribuído para as diferenças evidenciadas pela RNM no momento basal como o FGF 23, maior no GI, e o maior número de antihipertensivos neste grupo.

Ao compararmos homens e mulheres no momento inicial, das 17 mulheres incluídas, 10 (58,8\%) estavam com a relação AEC/ACT $\geq 0,4$, o que foi encontrado em 2 dos 5 homens (40\%). Em relação à presença de DM, uma paciente era amputada e não realizou bioimpedância. Entre os outros 5 pacientes com DM que realizaram o exame, 4 
estavam com a relação $\mathrm{AEC} / \mathrm{ACT} \geq 0,4$. No geral, os pacientes apresentaram albumina adequada, com apenas 4 pacientes com albumina $<3,5 \mathrm{~g} / \mathrm{dl}$. Destes, 3 apresentaram relação $\mathrm{AEC} / \mathrm{ACT} \geq 0,4$. Estes dados estão em acordo com a literatura, que mostra maior prevalência de hipervolemia em portadores de DM e pacientes com hipoalbuminemia em DP, diferindo apenas no sexo que evidenciou que homens se apresentam frequentemente hipervolêmicos. Isso talvez tenha ocorrido pelo fato do nosso estudo termos uma proporção maior de mulheres incluídas $(81,82)$.

Durante o seguimento observamos que a HVE se desenvolveu em 2 dos 4 pacientes com IMVE normal previamente e normalizou somente em 2 dos 17 pacientes que apresentavam hipertrofia. Não houve diferença entre os grupos controle e icodextrina neste comportamento. Estes dados mostram o quanto a HVE é prevalente na população em diálise e o quanto é difícil de ser manejada, pelo menos em tempo curto.

O comportamento diferente na relação AEC/ACT e na PA sistólica no GI quando comparado ao GC pode ter tido forte influência nos resultados de melhora do IMVE e da FE no GC. No GC os pacientes eram mais hipervolêmicos, sem melhora durante o acompanhamento, mas com melhora importante do controle pressórico. No GI houve uma piora da relação AEC/ACT e uma piora do controle pressórico. Um motivo que pode ter impactado nos resultados em relação ao controle volêmico foi a ausência de aumento significativo da UF no GI, efeito esperado e evidenciado em alguns estudos após o uso da icodextrina $(87,88)$. Como o controle da volemia e da PA são essenciais no manejo na HVE, certamente o uso de GI sem o efeito desejado de maior ultrafiltração não produziu o efeito desejado e melhora do IMVE.

Como o estudo não era duplo-cego, pode ter havido efeito Hawthorne no GI, ou seja, uma mudança no comportamento de indivíduos sob vigilância em estudos. Os pacientes por terem a segurança do uso de uma solução diferente do habitual podem ter tido uma menor adesão à restrição hídrica e ao uso adequado de anti-hipertensivos do aqueles do GC.

Desnutrição está associada a hipervolemia nos pacientes em DP (89). A ICO além de alto poder de UF pode melhorar o estado nutricional e reduzir a inflamação ao melhorar a albumina e reduzir a PCR em pacientes com perfil de rápido transportadores (90). No nosso estudo a PCR e a albumina possivelmente tiveram uma interferência significativa da terapia, porém com melhora no GC e não no GI. O fato de termos incluído poucos pacientes com perfil de transporte rápido pode ter contribuído para este achado. 
Analisando somente os 4 pacientes com este perfil de transporte observamos uma redução de PCR, o que está em acordo com a literatura.

Além de contribuir para a depuração de pequenos solutos, a FRR contribui para menor risco cardiovascular (91). Observamos no presente estudo em ambos os grupos uma redução da diurese e, consequentemente, do Kt/V renal após 6 meses de acompanhamento. A redução do Kt/V e da diurese não tiveram associação com o delta do IMVE, mas sim a creatinina, indicando uma possível contribuição da perda da FRR na piora da HVE nestes pacientes.

O BNP estava alterado em quase a totalidade dos pacientes e obtivemos ao final do estudo o BNP como variável independente associada ao delta do IMVE. Estudos anteriores em pacientes em pacientes DRC conservador e em diálise confirmaram a associação BNP e HVE $(91,92)$. Essa associação se reproduz também em pacientes em DP, no qual o NT-pro-BNP se revelou um importante fator preditor de congestão, mortalidade e desfecho cardiovasculares, contribuindo para a avaliação do prognóstico cardiovascular do paciente, sendo considerado um fator adicional, além da HVE e da PA (93).

Em pacientes diabéticos em DP com perfil de transporte rápido de membrana o uso de ICO proporcionou melhora da HVE e da calcificação valvular, associada a uma maior remoção de P pelo dialisato (62), reforçando a correlação entre P e HVE, de forma independente do P sérico. Observamos, de forma similar, uma correlação negativa com o comportamento do IMVE, de tal forma que pacientes com maior remoção de $P$ pelo dialisato tiveram uma maior redução no IMVE. Não conseguimos, porém, identificar diferença entre as soluções. Embora não tenhamos confirmado a superioridade da icodextrina na remoção de $\mathrm{P}$, nossos achados sugerem que quanto mais $\mathrm{P}$ for removido pela diálise maior a chance de redução do IMVE. Além disso, expandimos o achado da literatura mostrando o efeito da remoção de $\mathrm{P}$ em pacientes com perfis de transporte variado.

Apesar de ser prospectivo e randomizado nosso estudo possui algumas limitações: nossa amostra final foi pequena em decorrência do alto índice de saídas, no momento basal os pacientes do GI possuíam um IMVE e uma FE menor e estavam mais hipervolêmicos, não obtivemos um aumento da UF e controle de hipervolemia com o uso de icodextrina, o tempo de acompanhamento foi de apenas 6 meses, embora estudos prévios tenham visto resultados neste tempo curto de seguimento ou até menor. 
Em resumo, nao identificamo superioridade entre as soluções no que diz respeito ao IMVE.O controle da volemia parece ser o principal fator que impacta na melhora do IMVE em pacientes em DP. Outro possível fator que pode participar neste desfecho é a remoção do $\mathrm{P}$ pelo dialisato, embora mais estudos precisem ser feitos para esta conclusão se fortalecer. 


\section{CONCLUSÕES}




\section{CONCLUSÕES}

Nossos achados nos permitem concluir que o controle de fatores clássicos associados à HVE são imperativos em pacientes em DP. Neste sentido, o controle da PA e da volemia são essenciais. A retirada de P pelo dialisato parece ter também um efeito no comportamento da HVE nesta população. De qualquer modo, estas medidas podem ser feitas tanto com soluções de glicose como de icodextrina.

Vigilância clínica continuada deve ser feita para garantir o controle de PA e de volemia e quem sabe, uma maior retirada de $\mathrm{P}$, em uma tentativa de redução da alta taxa de mortalidade cardiovascular nesta população. 


\section{REFERÊNCIAS}




\section{REFERÊNCIAS}

1. Leifheit-Nestler M, Grosse Siemer R, Flasbart K, Richter B, Kirchhoff F, Ziegler $\mathrm{WH}$, et al. Induction of cardiac FGF23/FGFR4 expression is associated with left ventricular hypertrophy in patients with chronic kidney disease. Nephrol Dial Transplant. 2015 Dec 17. PubMed PMID: 26681731.

2. Eknoyan G, Lameire N, Barsoum R, Eckardt KU, Levin A, Levin N, et al. The burden of kidney disease: improving global outcomes. Kidney Int. 2004 Oct;66(4):13104. PubMed PMID: 15458424.

3. Radhakrishnan J, Remuzzi G, Saran R, Williams DE, Rios-Burrows N, Powe N, et al. Taming the chronic kidney disease epidemic: a global view of surveillance efforts. Kidney Int. 2014 Aug;86(2):246-50. PubMed PMID: 24897034. Pubmed Central PMCID: 4593485.

4. Neovius M, Jacobson SH, Eriksson JK, Elinder CG, Hylander B. Mortality in chronic kidney disease and renal replacement therapy: a population-based cohort study. BMJ Open. 2014;4(2):e004251. PubMed PMID: 24549162. Pubmed Central PMCID: 3931988.

5. National Kidney F. K/DOQI clinical practice guidelines for chronic kidney disease: evaluation, classification, and stratification. Am J Kidney Dis. 2002 Feb;39(2 Suppl 1):S1-266. PubMed PMID: 11904577.

6. Neves PDMM, Sesso RC, Thomé FC, Lugon JR, Nascimento MM. Brazilian dialysis survey 201. J Bras Nefrol. 2021 Apr-Jun;43(2):217-227. PubMed PMID: 33513218. Pubmed Central PMCID: 8257289.

7. Fenton SS, Schaubel DE, Desmeules M, Morrison HI, Mao Y, Copleston P, et al. Hemodialysis versus peritoneal dialysis: a comparison of adjusted mortality rates. Am J Kidney Dis. 1997 Sep;30(3):334-42. PubMed PMID: 9292560.

8. Waldum-Grevbo B, Leivestad T, Reisaeter AV, Os I. Impact of initial dialysis modality on mortality: a propensity-matched study. BMC Nephrol. 2015;16:179. PubMed PMID: 26519164. Pubmed Central PMCID: 4628291.

9. Yeates K, Zhu N, Vonesh E, Trpeski L, Blake P, Fenton S. Hemodialysis and peritoneal dialysis are associated with similar outcomes for end-stage renal disease treatment in Canada. Nephrol Dial Transplant. 2012 Sep;27(9):3568-75. PubMed PMID: 22391139.

10. Mehrotra R, Chiu YW, Kalantar-Zadeh K, Bargman J, Vonesh E. Similar outcomes with hemodialysis and peritoneal dialysis in patients with end-stage renal disease. Arch Intern Med. 2011 Jan 24;171(2):110-8. PubMed PMID: 20876398.

11. Chang YK, Hsu CC, Hwang SJ, Chen PC, Huang CC, Li TC, et al. A comparative assessment of survival between propensity score-matched patients with peritoneal dialysis and hemodialysis in Taiwan. Medicine (Baltimore). 2012 May;91(3):144-51. PubMed PMID: 22525667.

12. Quinn RR, Hux JE, Oliver MJ, Austin PC, Tonelli M, Laupacis A. Selection bias explains apparent differential mortality between dialysis modalities. J Am Soc Nephrol. 2011 Aug;22(8):1534-42. PubMed PMID: 21784891. Pubmed Central PMCID: 3148708. 13. Vonesh EF, Snyder JJ, Foley RN, Collins AJ. Mortality studies comparing peritoneal dialysis and hemodialysis: what do they tell us? Kidney Int Suppl. 2006 Nov(103):S3-11. PubMed PMID: 17080109.

14. Held PJ, Port FK, Turenne MN, Gaylin DS, Hamburger RJ, Wolfe RA. Continuous ambulatory peritoneal dialysis and hemodialysis: comparison of patient 
mortality with adjustment for comorbid conditions. Kidney Int. 1994 Apr;45(4):1163-9. PubMed PMID: 8007587.

15. Weinhandl ED, Foley RN, Gilbertson DT, Arneson TJ, Snyder JJ, Collins AJ. Propensity-matched mortality comparison of incident hemodialysis and peritoneal dialysis patients. J Am Soc Nephrol. 2010 Mar;21(3):499-506. PubMed PMID: 20133483. Pubmed Central PMCID: 2831857.

16. Lukowsky LR, Mehrotra R, Kheifets L, Arah OA, Nissenson AR, Kalantar-Zadeh $\mathrm{K}$. Comparing mortality of peritoneal and hemodialysis patients in the first 2 years of dialysis therapy: a marginal structural model analysis. Clin J Am Soc Nephrol. 2013 Apr;8(4):619-28. PubMed PMID: 23307879. Pubmed Central PMCID: 3613949.

17. Kumar VA, Sidell MA, Jones JP, Vonesh EF. Survival of propensity matched incident peritoneal and hemodialysis patients in a United States health care system. Kidney Int. 2014 Nov;86(5):1016-22. PubMed PMID: 24988066.

18. van de Luijtgaarden MW, Noordzij M, Stel VS, Ravani P, Jarraya F, Collart F, et al. Effects of comorbid and demographic factors on dialysis modality choice and related patient survival in Europe. Nephrol Dial Transplant. 2011 Sep;26(9):2940-7. PubMed PMID: 21325351.

19. de Jager DJ, Grootendorst DC, Jager KJ, van Dijk PC, Tomas LM, Ansell D, et al. Cardiovascular and noncardiovascular mortality among patients starting dialysis. JAMA. 2009 Oct 28;302(16):1782-9. PubMed PMID: 19861670.

20. Evans M, Fryzek JP, Elinder CG, Cohen SS, McLaughlin JK, Nyren O, et al. The natural history of chronic renal failure: results from an unselected, population-based, inception cohort in Sweden. Am J Kidney Dis. 2005 Nov;46(5):863-70. PubMed PMID: 16253726.

21. Go AS, Chertow GM, Fan D, McCulloch CE, Hsu CY. Chronic kidney disease and the risks of death, cardiovascular events, and hospitalization. N Engl J Med. 2004 Sep 23;351(13):1296-305. PubMed PMID: 15385656.

22. Ortiz A, Covic A, Fliser D, Fouque D, Goldsmith D, Kanbay M, et al. Epidemiology, contributors to, and clinical trials of mortality risk in chronic kidney failure. Lancet. 2014 May 24;383(9931):1831-43. PubMed PMID: 24856028.

23. Foley RN, Parfrey PS, Sarnak MJ. Clinical epidemiology of cardiovascular disease in chronic renal disease. Am J Kidney Dis. 1998 Nov;32(5 Suppl 3):S112-9. PubMed PMID: 9820470. Epub 1998/11/20.

24. Drueke T, Le Pailleur C, Zingraff J, Jungers P. Uremic cardiomyopathy and pericarditis. Adv Nephrol Necker Hosp. 1980;9:33-70. PubMed PMID: 6447440. Epub 1980/01/01.

25. Stenvinkel P, Carrero JJ, Axelsson J, Lindholm B, Heimburger O, Massy Z. Emerging biomarkers for evaluating cardiovascular risk in the chronic kidney disease patient: how do new pieces fit into the uremic puzzle? Clin J Am Soc Nephrol. 2008 Mar;3(2):505-21. PubMed PMID: 18184879. Pubmed Central PMCID: PMC6631093. Epub 2008/01/11.

26. London GM, Pannier B, Guerin AP, Blacher J, Marchais SJ, Darne B, et al. Alterations of left ventricular hypertrophy in and survival of patients receiving hemodialysis: follow-up of an interventional study. J Am Soc Nephrol. 2001 Dec;12(12):2759-67. PubMed PMID: 11729246.

27. Middleton RJ, Parfrey PS, Foley RN. Left ventricular hypertrophy in the renal patient. J Am Soc Nephrol. 2001 May;12(5):1079-84. PubMed PMID: 11316868. 
28. Paoletti E, Bellino D, Cassottana P, Rolla D, Cannella G. Left ventricular hypertrophy in nondiabetic predialysis CKD. Am J Kidney Dis. 2005 Aug;46(2):320-7. PubMed PMID: 16112052.

29. Zoccali C, Benedetto FA, Mallamaci F, Tripepi G, Giacone G, Cataliotti A, et al. Prognostic value of echocardiographic indicators of left ventricular systolic function in asymptomatic dialysis patients. J Am Soc Nephrol. 2004 Apr;15(4):1029-37. PubMed PMID: 15034106.

30. Foley RN, Parfrey PS, Harnett JD, Kent GM, Martin CJ, Murray DC, et al. Clinical and echocardiographic disease in patients starting end-stage renal disease therapy. Kidney Int. 1995 Jan;47(1):186-92. PubMed PMID: 7731145. Epub 1995/01/01. 31. Moe S, Drueke T, Cunningham J, Goodman W, Martin K, Olgaard K, et al. Definition, evaluation, and classification of renal osteodystrophy: a position statement from Kidney Disease: Improving Global Outcomes (KDIGO). Kidney Int. 2006 Jun;69(11):1945-53. PubMed PMID: 16641930. Epub 2006/04/28.

32. Canziani ME, Tomiyama C, Higa A, Draibe SA, Carvalho AB. Fibroblast growth factor 23 in chronic kidney disease: bridging the gap between bone mineral metabolism and left ventricular hypertrophy. Blood Purif. 2011;31(1-3):26-32. PubMed PMID: 21135546.

33. Gutierrez OM, Januzzi JL, Isakova T, Laliberte K, Smith K, Collerone G, et al. Fibroblast growth factor 23 and left ventricular hypertrophy in chronic kidney disease. Circulation. 2009 May 19;119(19):2545-52. PubMed PMID: 19414634. Pubmed Central PMCID: 2740903.

34. Mirza MA, Larsson A, Melhus H, Lind L, Larsson TE. Serum intact FGF23 associate with left ventricular mass, hypertrophy and geometry in an elderly population. Atherosclerosis. 2009 Dec;207(2):546-51. PubMed PMID: 19524924.

35. Kardami E, Jiang ZS, Jimenez SK, Hirst CJ, Sheikh F, Zahradka P, et al. Fibroblast growth factor 2 isoforms and cardiac hypertrophy. Cardiovasc Res. 2004 Aug 15;63(3):458-66. PubMed PMID: 15276471.

36. Faul C, Amaral AP, Oskouei B, Hu MC, Sloan A, Isakova T, et al. FGF23 induces left ventricular hypertrophy. J Clin Invest. 2011 Nov;121(11):4393-408. PubMed PMID: 21985788. Pubmed Central PMCID: 3204831.

37. John GB, Cheng CY, Kuro-o M. Role of Klotho in aging, phosphate metabolism, and CKD. Am J Kidney Dis. 2011 Jul;58(1):127-34. PubMed PMID: 21496980. Pubmed Central PMCID: PMC3191324. Epub 2011/04/19.

38. Razzaque MS, Lanske B. The emerging role of the fibroblast growth factor-23klotho axis in renal regulation of phosphate homeostasis. J Endocrinol. 2007 Jul;194(1):110. PubMed PMID: 17592015. Pubmed Central PMCID: 2900827.

39. Olauson H, Larsson TE. FGF23 and Klotho in chronic kidney disease. Curr Opin Nephrol Hypertens. 2013 Jul;22(4):397-404. PubMed PMID: 23666415.

40. Pattynama PM, De Roos A, Van der Wall EE, Van Voorthuisen AE. Evaluation of cardiac function with magnetic resonance imaging. Am Heart J. 1994 Sep;128(3):595607. PubMed PMID: 8074024. Epub 1994/09/01.

41. Constantine G, Shan K, Flamm SD, Sivananthan MU. Role of MRI in clinical cardiology. Lancet. 2004 Jun 26;363(9427):2162-71. PubMed PMID: 15220041.

42. Lima JA, Desai MY. Cardiovascular magnetic resonance imaging: current and emerging applications. J Am Coll Cardiol. 2004 Sep 15;44(6):1164-71. PubMed PMID: 15364314.

43. Stewart GA, Foster J, Cowan M, Rooney E, McDonagh T, Dargie HJ, et al. Echocardiography overestimates left ventricular mass in hemodialysis patients relative to 
magnetic resonance imaging. Kidney Int. 1999 Dec;56(6):2248-53. PubMed PMID: 10594802.

44. Jakubovic BD, Wald R, Goldstein MB, Leong-Poi H, Yuen DA, Perl J, et al. Comparative assessment of 2-dimensional echocardiography vs cardiac magnetic resonance imaging in measuring left ventricular mass in patients with and without endstage renal disease. Can J Cardiol. 2013 Mar;29(3):384-90. PubMed PMID: 23103220.

45. Osvaldo Merege Vieira Neto HA. Diálise Peritoneal - Manual Prático - Uso diário ambulatorial e hospitalar. 2016:11-5.

46. Badve SV, Zimmerman DL, Knoll GA, Burns KD, McCormick BB. Peritoneal phosphate clearance is influenced by peritoneal dialysis modality, independent of peritoneal transport characteristics. Clin J Am Soc Nephrol. 2008 Nov;3(6):1711-7. PubMed PMID: 18815242. Pubmed Central PMCID: PMC2572278. Epub 2008/09/26.

47. Debowska M, Gomez R, Pinto J, Waniewski J, Lindholm B. Phosphate clearance in peritoneal dialysis. Sci Rep. 2020 Oct 15;10(1):17504. PubMed PMID: 33060672. Pubmed Central PMCID: PMC7566511. Epub 2020/10/17.

48. Grodstein GP, Blumenkrantz MJ, Kopple JD, Moran JK, Coburn JW. Glucose absorption during continuous ambulatory peritoneal dialysis. Kidney Int. 1981 Apr;19(4):564-7. PubMed PMID: 7241890.

49. Johnson DW, Agar J, Collins J, Disney A, Harris DC, Ibels L, et al. Recommendations for the use of icodextrin in peritoneal dialysis patients. Nephrology (Carlton). 2003 Feb;8(1):1-7. PubMed PMID: 15012742. Epub 2004/03/12.

50. Finkelstein F, Healy H, Abu-Alfa A, Ahmad S, Brown F, Gehr T, et al. Superiority of icodextrin compared with $4.25 \%$ dextrose for peritoneal ultrafiltration. J Am Soc Nephrol. 2005 Feb;16(2):546-54. PubMed PMID: 15625070.

51. Qi H, Xu C, Yan H, Ma J. Comparison of icodextrin and glucose solutions for long dwell exchange in peritoneal dialysis: a meta-analysis of randomized controlled trials. Perit Dial Int. 2011 Mar-Apr;31(2):179-88. PubMed PMID: 21119069.

52. Mistry CD, Gokal R, Peers E. A randomized multicenter clinical trial comparing isosmolar icodextrin with hyperosmolar glucose solutions in CAPD. MIDAS Study Group. Multicenter Investigation of Icodextrin in Ambulatory Peritoneal Dialysis. Kidney Int. 1994 Aug;46(2):496-503. PubMed PMID: 7967363.

53. Mujais S, Nolph K, Gokal R, Blake P, Burkart J, Coles G, et al. Evaluation and management of ultrafiltration problems in peritoneal dialysis. International Society for Peritoneal Dialysis Ad Hoc Committee on Ultrafiltration Management in Peritoneal Dialysis. Perit Dial Int. 2000;20 Suppl 4:S5-21. PubMed PMID: 11098926.

54. Mistry CD, Gokal R. New Osmotic Agents for Peritoneal Dialysis: Where We Are and Where We're Going. Seminars in Dialysis. 1991;4(1):9-12.

55. Blake PG. Icodextrin: fifteen years and counting. Introduction. Perit Dial Int. 2009 Jul-Aug;29(4):367-9. PubMed PMID: 19725196.

56. Moberly JB, Mujais S, Gehr T, Hamburger R, Sprague S, Kucharski A, et al. Pharmacokinetics of icodextrin in peritoneal dialysis patients. Kidney Int Suppl. 2002 Oct(81):S23-33. PubMed PMID: 12230479.

57. Mistry CD, Mallick NP, Gokal R. Ultrafiltration with an isosmotic solution during long peritoneal dialysis exchanges. Lancet. 1987 Jul 25;2(8552):178-82. PubMed PMID: 2885639.

58. Rippe B, Levin L. Computer simulations of ultrafiltration profiles for an icodextrin-based peritoneal fluid in CAPD. Kidney Int. 2000 Jun;57(6):2546-56. PubMed PMID: 10844624. 
59. Tsai CY, Lee SC, Hung CC, Lee JJ, Kuo MC, Hwang SJ, et al. False elevation of blood glucose levels measured by GDH-PQQ-based glucometers occurs during all daily dwells in peritoneal dialysis patients using icodextrin. Perit Dial Int. 2010 MayJun;30(3):329-35. PubMed PMID: 20190030.

60. Delarue J, Maingourd C, Lamisse F, Garrigue MA, Bagros P, Couet C. Glucose oxidation after a peritoneal and an oral glucose load in dialyzed patients. Kidney Int. 1994 Apr;45(4):1147-52. PubMed PMID: 8007585.

61. Wolfson M, Piraino B, Hamburger RJ, Morton AR, Icodextrin Study G. A randomized controlled trial to evaluate the efficacy and safety of icodextrin in peritoneal dialysis. Am J Kidney Dis. 2002 Nov;40(5):1055-65. PubMed PMID: 12407652.

62. Hiramatsu T, Hayasaki T, Hobo A, Furuta S, Kabu K, Tonozuka Y, et al. Icodextrin eliminates phosphate and ameliorates cardiac hypertrophy and valvular calcification in patients with end-stage renal disease and diabetes mellitus undergoing peritoneal dialysis. Adv Perit Dial. 2013;29:9-13. PubMed PMID: 24344483. Epub 2013/12/19.

63. Konings CJ, Kooman JP, Schonck M, Gladziwa U, Wirtz J, van den Wall Bake AW, et al. Effect of icodextrin on volume status, blood pressure and echocardiographic parameters: a randomized study. Kidney Int. 2003 Apr;63(4):1556-63. PubMed PMID: 12631373. Epub 2003/03/13.

64. Paniagua R, Orihuela O, Ventura MD, Avila-Diaz M, Cisneros A, VicenteMartinez M, et al. Echocardiographic, electrocardiographic and blood pressure changes induced by icodextrin solution in diabetic patients on peritoneal dialysis. Kidney Int Suppl. 2008 Apr(108):S125-30. PubMed PMID: 18379535. Epub 2008/05/03.

65. Chen JB, Cheng BC, Liu WH, Liao SC, Fu MM, Moi SH, et al. Longitudinal analysis of cardiac structure and function in incident-automated peritoneal dialysis: comparison between icodextrin solution and glucose-based solution. BMC Nephrol. 2018 May 8;19(1):109. PubMed PMID: 29739354. Pubmed Central PMCID: PMC5941563. Epub 2018/05/10.

66. Takatori Y, Akagi S, Sugiyama H, Inoue J, Kojo S, Morinaga H, et al. Icodextrin increases technique survival rate in peritoneal dialysis patients with diabetic nephropathy by improving body fluid management: a randomized controlled trial. Clin J Am Soc Nephrol. 2011 Jun;6(6):1337-44. PubMed PMID: 21493740. Pubmed Central PMCID: 3109930.

67. Silver SA, Harel Z, Perl J. Practical considerations when prescribing icodextrin: a narrative review. Am J Nephrol. 2014;39(6):515-27. PubMed PMID: 24925229.

68. Oba I, Shinozaki M, Harada K, Mori T, Kanai H. Icodextrin-based continuous ambulatory peritoneal dialysis therapy effectively reduces left ventricular mass index and protects cardiac function in patients with end-stage renal disease. Adv Perit Dial. 2013;29:14-8. PubMed PMID: 24344484.

69. Li PK, Culleton BF, Ariza A, Do JY, Johnson DW, Sanabria M, et al. Randomized, controlled trial of glucose-sparing peritoneal dialysis in diabetic patients. $\mathbf{J}$ Am Soc Nephrol. 2013 Nov;24(11):1889-900. PubMed PMID: 23949801. Pubmed Central PMCID: 3810077.

70. Sara Leonardo SG, Tachibana Adriano, Shiozaki Afonso Akio, Villa Alexandre Volney, Oliveira Amarino Carvalho de et al II Diretriz de Ressonância Magnética e Tomografia Computadorizada Cardiovascular da Sociedade Brasileira de Cardiologia e do Colégio Brasileiro de Radiologia. Arq Bras Cardiol. 2014;103(6 Suppl 3). 
71. Demura S, Sato S, Kitabayashi T. Percentage of total body fat as estimated by three automatic bioelectrical impedance analyzers. J Physiol Anthropol Appl Human Sci. 2004 May;23(3):93-9. PubMed PMID: 15187381. Epub 2004/06/10.

72. Petersen SE, Aung N, Sanghvi MM, Zemrak F, Fung K, Paiva JM, et al. Reference ranges for cardiac structure and function using cardiovascular magnetic resonance (CMR) in Caucasians from the UK Biobank population cohort. J Cardiovasc Magn Reson. 2017 Feb 3;19(1):18. PubMed PMID: 28178995. Pubmed Central PMCID: PMC5304550. Epub 2017/02/10.

73. Garcia-Garcia G, Tachiquin-Bautista N, Luquin-Arellano VH, Ibarra-Hernandez M, Aviles-Gomez R, Briseno-Renteria G, et al. Risk of peritonitis among disadvantaged CAPD patients in Mexico. Contrib Nephrol. 2007;154:145-52. PubMed PMID: 17099310. Epub 2006/11/14.

74. Fernandes N, Bastos MG, Cassi HV, Machado NL, Ribeiro JA, Martins G, et al. The Brazilian Peritoneal Dialysis Multicenter Study (BRAZPD) : characterization of the cohort. Kidney Int Suppl. 2008 Apr(108):S145-51. PubMed PMID: 18379538. Epub 2008/05/03.

75. Wolfson M, Ogrinc F, Mujais S. Review of clinical trial experience with icodextrin. Kidney Int Suppl. 2002 Oct(81):S46-52. PubMed PMID: 12230481. Epub 2002/09/17.

76. Almiani M, Kohn OF. Severe exfoliative skin rash with icodextrin. Kidney Int. 2014 Aug;86(2):449. PubMed PMID: 25079030. Epub 2014/08/01.

77. Mujais S, Story K. Peritoneal dialysis in the US: evaluation of outcomes in contemporary cohorts. Kidney Int Suppl. 2006 Nov(103):S21-6. PubMed PMID: 17080107. Epub 2006/11/03.

78. Balasubramaniyam R, Nirmala VR, Yogesh V, Sethuraman R, Devi SB, Balakrishnan NM, et al. Comparison of peritoneal transport characteristics at the second week and at six months of peritoneal dialysis commencement. Indian J Nephrol. 2013 Sep;23(5):346-50. PubMed PMID: 24049270. Pubmed Central PMCID: PMC3764708. Epub 2013/09/21.

79. Cueto-Manzano AM, Diaz-Alvarenga A, Correa-Rotter R. Analysis of the peritoneal equilibration test in Mexico and factors influencing the peritoneal transport rate. Perit Dial Int. 1999 Jan-Feb;19(1):45-50. PubMed PMID: 10201340. Epub 1999/04/14.

80. Bargman JM, Thorpe KE, Churchill DN. Relative contribution of residual renal function and peritoneal clearance to adequacy of dialysis: a reanalysis of the CANUSA study. J Am Soc Nephrol. 2001 Oct;12(10):2158-62. PubMed PMID: 11562415. Epub 2001/09/20.

81. Cader RA, Ibrahim OA, Paul S, Gafor HA, Mohd R. Left ventricular hypertrophy and chronic fluid overload in peritoneal dialysis patients. Int Urol Nephrol. 2014 Jun;46(6):1209-15. PubMed PMID: 24307428. Epub 2013/12/07.

82. Van Biesen W, Williams JD, Covic AC, Fan S, Claes K, LichodziejewskaNiemierko M, et al. Fluid status in peritoneal dialysis patients: the European Body Composition Monitoring (EuroBCM) study cohort. PLoS One. 2011 Feb 24;6(2):e17148. PubMed PMID: 21390320. Pubmed Central PMCID: PMC3044747. Epub 2011/03/11. 83. Locatelli F, Nissenson AR, Barrett BJ, Walker RG, Wheeler DC, Eckardt KU, et al. Clinical practice guidelines for anemia in chronic kidney disease: problems and solutions. A position statement from Kidney Disease: Improving Global Outcomes (KDIGO). Kidney Int. 2008 Nov;74(10):1237-40. PubMed PMID: 18596731. Epub 2008/07/04. 
84. Leunissen KM. Fluid status in haemodialysed patients. Nephrol Dial Transplant. 1995;10(2):153-5. PubMed PMID: 7753445. Epub 1995/01/01.

85. Luo YJ, Lu XH, Woods F, Wang T. Volume control in peritoneal dialysis patients guided by bioimpedance spectroscopy assessment. Blood Purif. 2011;31(4):296-302. PubMed PMID: 21242684. Epub 2011/01/19.

86. Hur E, Gungor O, Musayev O, Usta M, Toz H, Asci G, et al. Bioimpedance spectroscopy for the detection of hypervolemia in peritoneal dialysis patients. Adv Perit Dial. 2011;27:65-70. PubMed PMID: 22073832. Epub 2011/11/12.

87. Davies SJ, Woodrow G, Donovan K, Plum J, Williams P, Johansson AC, et al. Icodextrin improves the fluid status of peritoneal dialysis patients: results of a doubleblind randomized controlled trial. J Am Soc Nephrol. 2003 Sep;14(9):2338-44. PubMed PMID: 12937311. Epub 2003/08/26.

88. Cho Y, Johnson DW, Badve S, Craig JC, Strippoli GF, Wiggins KJ. Impact of icodextrin on clinical outcomes in peritoneal dialysis: a systematic review of randomized controlled trials. Nephrol Dial Transplant. 2013 Jul;28(7):1899-907. PubMed PMID: 23493329. Epub 2013/03/16.

89. Cheng LT, Tang W, Wang T. Strong association between volume status and nutritional status in peritoneal dialysis patients. Am J Kidney Dis. 2005 May;45(5):891902. PubMed PMID: 15861355. Epub 2005/04/30.

90. Lin W, Chen YC, Wu MS, Hsu HJ, Sun CY, Lin YK, et al. Icodextrin dialysate improves nutritional and inflammatory profiles in peritoneal dialysis patients. Ren Fail. 2009;31(2):98-105. PubMed PMID: 19212905. Epub 2009/02/13.

91. Wang AY. The "heart" of peritoneal dialysis. Perit Dial Int. 2007 Jun;27 Suppl 2:S228-32. PubMed PMID: 17556310. Epub 2007/11/22.

92. Mishra RK, Li Y, Ricardo AC, Yang W, Keane M, Cuevas M, et al. Association of $\mathrm{N}$-terminal pro-B-type natriuretic peptide with left ventricular structure and function in chronic kidney disease (from the Chronic Renal Insufficiency Cohort [CRIC]). Am J Cardiol. 2013 Feb 1;111(3):432-8. PubMed PMID: 23178053. Pubmed Central PMCID: PMC5261861. Epub 2012/11/28.

93. Wang AY, Lam CW, Yu CM, Wang M, Chan IH, Zhang Y, et al. N-terminal probrain natriuretic peptide: an independent risk predictor of cardiovascular congestion, mortality, and adverse cardiovascular outcomes in chronic peritoneal dialysis patients. $\mathbf{J}$ Am Soc Nephrol. 2007 Jan;18(1):321-30. PubMed PMID: 17167121. Epub 2006/12/15. 
ANEXO 1 - Termo de Consentimento livre e esclarecido

\section{HOS PITAL DAS CLÍNICAS DA FACULDADE DE MEDICINA DA UNIVERS IDADE DE SÃO PAULO HCFMUSP}

\section{TERMO DE CONSENTIMENTO LIVRE E ESCLARECIDO}

\section{DADOS DA PESQUISA}

Título da pes quis a: Impacto do uso de icodextrina na hipertrofia miocárdica em pacientes com doença renal crônica em diálise peritoneal

Pesquisador principal: Rosilene Motta Elias

Departamento Nefrologia/Instituto - ICHC

Convite à participação:

Convidamos o(a) $\operatorname{Sr}(a)$

para participar desta pesquisa que tem como objetivo verificar se 0 liquido que pode ser usado como opcao as bolsas de glicose que se chama Icodextrina, ajuda a tirar mais água e controlar melhor a pressão e assim melhorar os exames do coracão dos pacientes que fazem diálise peritoneal.

Procedimentos que serão realizados e métodos que serão empregados - A pesquisa envolve a utilização de uma bolsa para realizar dialise peritoneal com acoes diferenciadas das de uso habitual. A bolsa sera utilizada na ultima infusao, sera o liquido que permanecera por maior tempo na cavidade. Apos o termino das outras bolsas de dialise, o paciente permanecera com a barriga cheia desse liquido durante o dia todo. A noite antes de se ligar na maquina, ira drenar toda a solucao. Iremos realizer exames de sangue e um do coracao antes de iniciar esse novo tratamento e seis meses apos. Iremos analisar ainda alteracoes na forma e tamanho do coracao. Além disso, será realizado exame de Bioimpedância segmentar para avaliação da quantidade de líquidos no seu corpo, 
antes e após o uso dessa nova bolsa. Apos aceitar participar dessa pesquisa, logo que aceito sua inclusao, sera realizado um sorteio para decidir aleatoriamente se usara ou nao esse novo liquido. Sendo assim, alguns receberao esse novo tratamento, e outros continuarao com o antigo.

Explicitação de possíveis desconfortos e riscos decorrentes da participação na pesquisa - podera ocorrer reacao alergica, dor abdominal e desconforto na barriga quando usar esse novo tratamento.

Benefícios esperados para o participante - melhorar o coracao, abaixar a pressao, tirar mais agua, diminuir e controlar melhor 0 fosforo.

Esclarecimento sobre a forma de acompanhamento e assistência a que terão direito os participantes da pesquisa - não mudará em nada as consultas mensais e a assistencia. O paciente que concordar em realizer a pesquisa tera que realizar um exame do coracao chamado Ressonancia cardiaca, que sera realizado no Instituto do Coracao, situado na Av. Dr. Enéas de Carvalho Aguiar, 44 - Pinheiros, São Paulo $\mathrm{SP}$, 05403-900, com dia agendado para isso.

Garantias de plena liberdade ao participante de recusar-se a participar ou retirar o seu consentimento em qualquer fase da pesquisa sem penalização alguma, de sigilo e privacidade

Garantia de que o participante receberá uma via do termo de consentimento - $O$ termo de consentimento possui duas vias, uma deve ser devolvida e outra fica com o paciente, ambas devem ser rubricadas

Explicitação das garantias de ressarcimento por despesas decorrentes da pesquisa e explicitação da garantia de indenização por eventuais danos decorrentes da pesquisa - 0 unico gasto que 0 paciente tera durante a pesquisa sera com transporte para realizar o exame do coracao antes e depois da pesquisa. 
Em qualquer etapa do estudo, você terá acesso aos profissionais responsáveis pela pesquisa para esclarecimento de dúvidas. $O$ principal investigador é a Dra Rosilene Motta Elias e o pesquisador associado é a Dra Lilian Cordeiro que poderão ser encontrados no endereço Rua Enéas de Cravalho Aguiar 155, Cerqueira Cesar Telefone 2661-7167. Se você tiver alguma consideração ou dúvida sobre a ética da pesquisa, entre em contato com o Comitê de Ética em Pesquisa (CEP) - Rua Ovídio Pires de Campos, 225 - 50 andar - tel: (11) 2661-7585, (11) 2661-1548, (11) 2661-1549; e-mail: cappesq.adm@hc.fm.usp.br

Fui suficientemente informado a respeito do estudo (sim/não) “

Eu discuti as informações acima com o Pesquisador Responsável (...................................) ou pessoa (s) por ele delegada (s) (.............................................) sobre a minha decisão em participar nesse estudo. Ficaram claros para mim os objetivos,os procedimentos, os potenciais desconfortos e riscos e as garantias. Concordo voluntariamente em participar deste estudo, assino este termo de consentimento e recebo um via rubricada pelo pesquisador.

Assinatura do participante /representante legal

Data

Assinatura do responsável pelo estudo

Data

DADOS DE IDENTIFICAÇÃO (OU ETIQUETA INS TITUCIONAL DE IDENTIFICAÇÃO) DO PARTICIPANTE DA PESQUIS A OU RESPONSÁVEL LEGAL 
1.NOME:

DOCUMENTO DE IDENTIDADE :

(5) (5) (5) (5) (5) (5)

SEXO : $\because[\quad$ DATA NASCIMENTO: ......................

ENDEREÇO

No

APTO:

BAIRRO:

CIDADE

CEP:......

TELEFONE: DDD (

2.RESPONSÁVEL LEGAL.

(5) (5) (5) (5) (5) (5) (5) (5) (5) (5) (5) (5) (5) (5) (5) (5) (5) (5) (5) (5) (5) (5) (5) (5) (5) (5) (5) (5) (5) (5) (5) (5) (5) (5) (5)

NATUREZA (grau de parentesco, tutor, curador etc.)

DOCUMENTO DE IDENTIDADE:

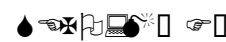

DATA NASCIMENTO.:

ENDEREÇO:

No APTO: BAIRRO:

CIDADE: CEP:

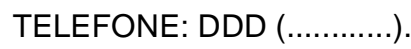




\section{HOSPITAL DAS CLÍNICAS DA FACULDADE DE MEDICINA DA USP - HCFMUSP}

\section{PARECER CONSUBSTANCIADO DO CEP}

\section{DADOS DO PROJETO DE PESQUISA}

Título da Pesquisa: Impacto do uso de icodextrina na hipertrofia miocárdica em pacientes com doença renal crônica em diálise peritoneal

Pesquisador: Rosilene Motta Elias

Área Temática:

Versão: 1

CAAE: 57602516.6.1001.0068

Instituição Proponente: HOSPITAL DAS CLINICAS DA FACULDADE DE MEDICINA DA U S P

Patrocinador Principal: HOSPITAL DAS CLINICAS DA FACULDADE DE MEDICINA DA U S P FUNDACAO DE AMPARO A PESQUISA DO ESTADO DE SAO PAULO

\section{DADOS DO PARECER}

Número do Parecer: 1.739 .787

\section{Apresentação do Projeto:}

A Doença Renal Crônica (DRC) é uma doença de prevalência mundial crescente e que possui como maior causa de mortalidade a cardiovascular. A hipertrofia ventricular (HVE) é um dos principais fatores de risco para morte cardiovascular e é frequentemente encontrada nesse grupo de pacientes. Para minimizar HVE é necessário controlar a pressão arterial, o volume extracelular, o diabetes mellitus, a dislipidemia e especialmente nos pacientes com DRC, controlar os distúrbios do metabolismo mineral e ósseo (DMODRC). A hipervolemia é uma das principais variáveis ligadas diretamente à HVE e em Diálise Peritoneal (DP) muitas vezes torna-se um fator limitante do método. Para melhor controle da hipervolemia, temos como opção terapêutica a icodextrina, solução peritoneal de alto poder osmótico amplamente utilizada no mundo todo para otimização de ultrafiltração. Alguns estudos na literatura obtiveram resultados entusiasmantes após o uso dessa solução. Em um deles, em até quatro meses de uso foi observada redução da HVE documentada por ecocardiograma. Maior depuração de fósforo também já foi relacionada à ação da icodextrina na redução da HVE. O objetivo desse estudo é analisar o papel de marcadores do metabolismo mineral e ósseo e da extração de fósforo na redução de massa de ventrículo esquerdo, com o uso da icodextrina em diálise peritoneal. Além disso, pretendemos confirmar resultados prévios de redução de massa de ventrículo usando técnica considerada gold standard, a

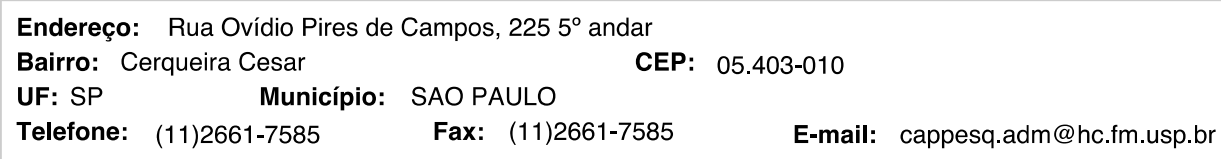




\section{HOSPITAL DAS CLÍNICAS DA re FACULDADE DE MEDICINA DA USP - HCFMUSP}

Continuação do Parecer: 1.739 .787

ressonância nuclear de coração.

\section{Objetivo da Pesquisa:}

5.1 Objetivo Geral

- Avaliar a diminuição da massa de ventrículo esquerdo em pacientes em diálise peritoneal comparando uso de icodextrina com uso de solução padrão de glicose.

5.2 Objetivos Específicos

- Correlacionar a diminuição da massa de ventrículo esquerdo com marcadores de DMO-DRC.

- Confirmar a diminuição da massa de ventrículo esquerdo através de ressonância cardíaca.

\section{Avaliação dos Riscos e Benefícios:}

Riscos: Não há risco iminente ao paciente, pois se trata de procedimentos não-invasivos, sem uso de contraste. O risco mínimo limita-se ao eventual desconforto nos diversos métodos de investigação. São relatados alguns efeitos colaterais após o uso de Icodextrina, como reações cutâneas, reações de hipersensibilidade, dosagens glicêmicas falsamente elevadas e em longo prazo, doenças de depósito.Benefícios:Os pacientes poderão se beneficiar atraves do uso em seu esquema de diálise a icodextrina, solução peritoneal de um polímero da glicose, que devido seu alto poder osmótico é indicada para pacientes com difícil controle de volemia pela sua maior eficiência e poder de ultrafiltração, controlando melhor a hipertensão, reduzindo dispneia e edema de membros inferiores.

\section{Comentários e Considerações sobre a Pesquisa:}

O projeto encontra-se bem delineado e atende aos preceitos éticos.

\section{Considerações sobre os Termos de apresentação obrigatória:}

Adequado

\section{Conclusões ou Pendências e Lista de Inadequações:}

$O$ projeto atende às recomendações éticas.

\section{Considerações Finais a critério do CEP:}

Em conformidade com a Resolução CNS n 466/12 - cabe ao pesquisador: a) desenvolver o projeto conforme delineado; b) elaborar e apresentar relatórios parciais e final; c)apresentar dados solicitados pelo CEP, a qualquer momento; d) manter em arquivo sob sua guarda, por 5 anos da pesquisa, contendo fichas individuais e todos os demais documentos recomendados pelo CEP; e) encaminhar os resultados para publicação, com os devidos créditos aos pesquisadores associados e ao pessoal técnico participante do projeto; f) justificar perante ao CEP interrupção do projeto ou a não publicação dos resultados.

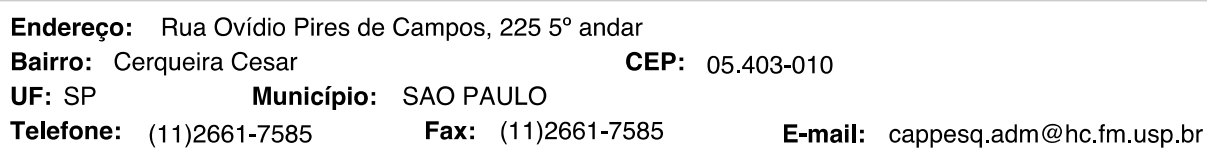




\section{HOSPITAL DAS CLÍNICAS DA FACULDADE DE MEDICINA DA USP - HCFMUSP}

Continuação do Parecer: 1.739.787

Este parecer foi elaborado baseado nos documentos abaixo relacionados:

\begin{tabular}{|l|l|c|l|c|}
\hline \multicolumn{1}{|c|}{ Tipo Documento } & \multicolumn{1}{|c|}{ Arquivo } & Postagem & Autor & Situação \\
\hline $\begin{array}{l}\text { Informações Básicas } \\
\text { do Projeto }\end{array}$ & $\begin{array}{l}\text { PB_INFORMAÇÕES_BÁSICAS_DO_P } \\
\text { ROJETO_730971.pdf }\end{array}$ & $\begin{array}{c}06 / 07 / 2016 \\
12: 05: 15\end{array}$ & & Aceito \\
\hline Outros & AnexolI_Icodextrina.pdf & $\begin{array}{c}06 / 07 / 2016 \\
12: 04: 57\end{array}$ & Rosilene Motta Elias & Aceito \\
\hline Folha de Rosto & folhaderostolCO.pdf & $\begin{array}{c}06 / 07 / 2016 \\
12: 04: 04\end{array}$ & Rosilene Motta Elias & Aceito \\
\hline $\begin{array}{l}\text { Projeto Detalhado / } \\
\text { Brochura } \\
\text { Investigador }\end{array}$ & ProjetolCO.doc & $02 / 06 / 2016$ & LILIAN CORDEIRO & Aceito \\
\hline $\begin{array}{l}\text { TCLE / Termos de } \\
\text { Assentimento / } \\
\text { Justificativa de } \\
\text { Ausência }\end{array}$ & TCLElco.docx & $02 / 06 / 2016: 13$ & & \\
\hline
\end{tabular}

Situação do Parecer:

Aprovado

Necessita Apreciação da CONEP:

Não

SAO PAULO, 22 de Setembro de 2016

Assinado por:

ALFREDO JOSE MANSUR

(Coordenador)

Endereço: Rua Ovídio Pires de Campos, $2255^{\circ}$ andar

Bairro: Cerqueira Cesar

CEP: $05.403-010$

UF: SP Município: SAO PAULO

Telefone: (11)2661-7585 Fax: (11)2661-7585 E-mail: cappesq.adm@hc.fm.usp.br 
Volume:

Rubrica:

\section{FUNDAÇÃO DE AMPARO À PESQUISA DO ESTADO DE SÃO PAULO TERMO DE OUTORGA E ACEITAÇÃO DE AUXÍLIOS} PROCESSO 2016/18798-7

\begin{tabular}{|c|c|}
\hline $\begin{array}{l}\text { Pelo presente instrumento, } \\
\mathrm{XI}, \mathrm{n}^{\circ} 1.500 \text {, Alto da Lapa } \\
\text { denominada OUTORGANT } \\
\text { "b", da Lei Estadual } \mathrm{n}^{\circ} 5 \\
\text { Auxílio para a realização } \\
\text { INSTITUIÇÃO SEDE, de } \\
\text { Anexos, que passam a ser }\end{array}$ & $\begin{array}{l}\text { ndação de Amparo à Pesquisa do Estado de São Paulo, com sede na Rua Pio } \\
\text { Paulo, Capital, inscrita no CNPJ/MF sob n } 43.828 .151 / 0001-45 \text {, doravante } \\
\text { r meio de seu Conselho Técnico-Administrativo, nos termos do Artigo 14, letra } \\
\text { de } 18 \text { de outubro de } 1960 \text {, concede ao OUTORGADO, a seguir qualificado, } \\
\text { ojeto de Pesquisa a seguir especificado, nas instalações e com o apoio da } \\
\text { lo com as especificações, cláusulas e condições descritas a seguir e nos } \\
\text { integrante deste Termo. }\end{array}$ \\
\hline 1.OUTORGADO: & Rosilene Motta Elias Coelho \\
\hline & CPF: 017.398.117-80 \\
\hline & RG: 348073306-SSP/SP \\
\hline 2.Correspondência: & $\begin{array}{l}\text { Rua Xavier Curado, } 351 \text { - apto 204, Ipiranga, São Paulo/SP, CEP 04210-100 } \\
\text { rosilenemotta@hotmail.com }\end{array}$ \\
\hline 3.Instituição Sede: & Faculdade de Medicina/FM \\
\hline & Universidade de São Paulo/USP \\
\hline 4.Projeto de Pesquisa: & $\begin{array}{l}\text { Impacto do uso de icodextrina na hipertrofia miocárdica em pacientes com } \\
\text { doença renal crônica em diálise peritoneal }\end{array}$ \\
\hline 5.Linha de Fomento: & $\begin{array}{l}\text { Programas Regulares / Auxílios a Pesquisa / Projeto de Pesquisa / Projeto de } \\
\text { Pesquisa - Regular }\end{array}$ \\
\hline 6.Área/Subárea: & Medicina \\
\hline & Clinica Médica \\
\hline 7.Coordenação: & Saúde I \\
\hline 8.Período da Vigência: & 01/07/2017 a 30/06/2019 \\
\hline 9.Relatórios Científicos: & $30 / 06 / 2018,30 / 07 / 2019$ \\
\hline 10.Prestações de Contas: & $30 / 06 / 2018,30 / 07 / 2019$ \\
\hline
\end{tabular}

